\title{
Detailed source term estimation of the atmospheric release for the Fukushima Daiichi Nuclear Power Station accident by coupling simulations of an atmospheric dispersion model with an improved deposition scheme and oceanic dispersion model
}

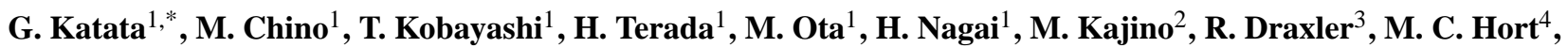 \\ A. Malo ${ }^{5}$, T. Torii ${ }^{6}$, and Y. Sanada ${ }^{7}$ \\ ${ }^{1}$ Japan Atomic Energy Agency (JAEA), Tokai, Naka, Ibaraki, 319-1195, Japan \\ ${ }^{2}$ Meteorological Research Institute, Japan Meteorological Agency (JMA), Tsukuba, Ibaraki, 305-0052, Japan \\ ${ }^{3}$ Air Resources Laboratory, National Oceanic and Atmospheric Administration (NOAA), \\ University Research Court, College Park, Maryland, 20740, USA \\ ${ }^{4}$ Met Office, Exeter, Devon, EX1 3PB, UK \\ ${ }^{5}$ Canadian Meteorological Centre (CMC), Dorval, Quebec, H9P 1J3, Canada \\ ${ }^{6}$ JAEA, Chiyoda, Tokyo, 100-8577, Japan \\ ${ }^{7}$ JAEA, Fukushima, Fukushima, 960-1296, Japan \\ *now at: Atmospheric Environmental Research, Institute of Meteorology and \\ Climate Research, Karlsruhe Institute of Technology (KIT-IMK/IFU), Germany
}

Correspondence to: G. Katata (katata.genki@ jaea.go.jp)

Received: 25 April 2014 - Published in Atmos. Chem. Phys. Discuss.: 5 June 2014

Revised: 12 December 2014 - Accepted: 15 December 2014 - Published: 30 January 2015

\begin{abstract}
Temporal variations in the amount of radionuclides released into the atmosphere during the Fukushima Daiichi Nuclear Power Station (FNPS1) accident and their atmospheric and marine dispersion are essential to evaluate the environmental impacts and resultant radiological doses to the public. In this paper, we estimate the detailed atmospheric releases during the accident using a reverse estimation method which calculates the release rates of radionuclides by comparing measurements of air concentration of a radionuclide or its dose rate in the environment with the ones calculated by atmospheric and oceanic transport, dispersion and deposition models. The atmospheric and oceanic models used are WSPEEDI-II (Worldwide version of System for Prediction of Environmental Emergency Dose Information) and SEA-GEARN-FDM (Finite difference oceanic dispersion model), both developed by the authors. A sophisticated deposition scheme, which deals with dry and fog-water depositions, cloud condensation nuclei $(\mathrm{CCN})$ activation, and subsequent wet scavenging due to mixed-phase cloud microphysics (in-cloud scavenging) for radioactive iodine gas
\end{abstract}

( $\mathrm{I}_{2}$ and $\left.\mathrm{CH}_{3} \mathrm{I}\right)$ and other particles (CsI, Cs, and Te), was incorporated into WSPEEDI-II to improve the surface deposition calculations. The results revealed that the major releases of radionuclides due to the FNPS1 accident occurred in the following periods during March 2011: the afternoon of 12 March due to the wet venting and hydrogen explosion at Unit 1 , midnight of 14 March when the SRV (safety relief valve) was opened three times at Unit 2, the morning and night of 15 March, and the morning of 16 March. According to the simulation results, the highest radioactive contamination areas around FNPS1 were created from 15 to 16 March by complicated interactions among rainfall, plume movements, and the temporal variation of release rates. The simulation by WSPEEDI-II using the new source term reproduced the local and regional patterns of cumulative surface deposition of total ${ }^{131} \mathrm{I}$ and ${ }^{137} \mathrm{Cs}$ and air dose rate obtained by airborne surveys. The new source term was also tested using three atmospheric dispersion models (Modèle Lagrangien de Dispersion de Particules d' ordre zéro: MLDP0, Hybrid Single Particle Lagrangian Integrated Trajectory Model: HYSPLIT, and 
Met Office's Numerical Atmospheric-dispersion Modelling Environment: NAME) for regional and global calculations, and the calculated results showed good agreement with observed air concentration and surface deposition of ${ }^{137} \mathrm{Cs}$ in eastern Japan.

\section{Introduction}

A significant amount of radioactive material was accidentally emitted into the atmosphere from the Fukushima Daiichi Nuclear Power Station (hereafter referred to as FNPS1) due to the catastrophic earthquake and tsunami on 11 March 2011. This caused radiological contamination not only around FNPS1 but over a wide region of Japan (NRA, 2012a). To assess the magnitude of the accident and radiological doses, an accurate estimation of the source term of the radionuclides discharged into the atmosphere is required.

After the accident, the source term of total ${ }^{131} \mathrm{I}$, which includes all the chemical forms of ${ }^{131} \mathrm{I}$ (hereinafter ${ }^{131} \mathrm{I}$ ) and ${ }^{137} \mathrm{Cs}$ was estimated by the researchers from the Japan Atomic Energy Agency (JAEA) using a reverse estimation method (UNSCEAR, 2014). This method calculates the release rates of radionuclides $\left(\mathrm{Bq} \mathrm{h}^{-1}\right)$ by coupling the atmospheric dispersion simulation made with a unit release rate $\left(1 \mathrm{~Bq} \mathrm{~h}^{-1}\right)$ with environmental monitoring data. The ratio of the monitoring data to the dispersion calculation provides an estimate of the source term. Chino et al. (2011) carried out the first estimation of the source term of ${ }^{131} \mathrm{I}$ and ${ }^{137} \mathrm{Cs}$ from 12 March to 5 April 2011. Katata et al. (2012a) estimated a more detailed source term for 15 March 2011 when the highest radiological polluted area was created. Katata et al. (2012b) revised the source term of Chino et al. (2011) for the early phases (12 to 14 March 2011) of the accident. Terada et al. (2012) assembled the above source terms and slightly refined the release rate after 16 March and extended it to 1 May 2011 (hereinafter the last source term in the Introduction). They also showed the regional and local atmospheric dispersion patterns of the radionuclides for March 2011.

The last source term has been validated using atmospheric dispersion simulation results compared with the environmental data which were not used for the source term estimation (e.g., daily fallout and surface deposition) and by comparison with other source terms created using different approaches and data sets. Terada et al. (2012) showed that WSPEEDIII (Worldwide version of System for Prediction of Environmental Emergency Dose Information) could reproduce most of the observed daily fallout in eastern Japan from 20 to 31 March within a factor of 10 using the last source term. Later on, Morino et al. (2013) carried out atmospheric dispersion simulations using several source terms and found that when the last source term was used, the surface deposition pattern of ${ }^{137} \mathrm{Cs}$ in eastern Japan was reproduced with higher accu- racy than when using any of the other source terms. Draxler et al. (2015) showed that five different atmospheric dispersion and meteorological models overall reproduced regional patterns in observed ${ }^{137} \mathrm{Cs}$ deposition and air concentrations of ${ }^{131} \mathrm{I}$ and ${ }^{137} \mathrm{Cs}$ when using the last source term. Meanwhile, Hirao et al. (2013) also estimated the source term using an inverse estimation method (UNSCEAR, 2014) by coupling their atmospheric dispersion model with air concentration and daily fallout data in eastern Japan. Their results agreed with the last source term for many of the large emission events despite using different sets of monitoring data, further supporting the reliability of the last source term. Saunier et al. (2013) and Winiarek et al. (2014) also estimated the source term for the major releases of 14 and 15 March 2011 by inverse estimation methods using air dose rate and daily fallout data, and the airborne survey of ${ }^{137} \mathrm{Cs}$ surface deposition in eastern Japan. Their results were comparable to the last source term for those periods.

While the last source term has been supported by the many studies summarized above, three major improvements are required to determine a more precise source term. First, the deposition scheme of WSPEEDI-II needs to be modified to improve the atmospheric dispersion simulation that affects the accuracy of the source term estimation. The previous scheme employed constant values for the dry deposition velocities and a simple exponential function of precipitation intensity for the wet scavenging coefficients, which are also widely used in the deposition schemes of many other atmospheric dispersion models (Table 1). However, this scheme is insufficient to simulate complicated processes of dry deposition on various surface characteristics and wet scavenging due to mixed-phase cloud microphysics (in-cloud scavenging). For example, Morino et al. (2013) showed the prediction accuracy of the surface deposition pattern of ${ }^{137} \mathrm{Cs}$ in eastern Japan strongly depended on the wet scavenging coefficient. Fog-water deposition is also completely missing in all of the current atmospheric dispersion models (Table 1). Thus, we introduce a new scheme consisting of comprehensive parameterizations for dry, wet, and fog-water depositions of gaseous and particulate radionuclides based on existing modeling approaches into WSPEEDI-II (hereafter the modified WSPEEDI-II).

Second, the last source term was computed using environmental monitoring data collected over the land areas of eastern Japan. However, when plumes flowed directly toward Pacific Ocean, the release rates were simply interpolated between the values estimated during onshore flow. The first results of the source term estimation using both atmospheric and oceanic dispersion models by Kobayashi et al. (2013) revealed that the model calculation with the last source term underestimated the seawater surface concentration of ${ }^{134} \mathrm{Cs}$ in the Pacific Ocean. However, their atmospheric dispersion simulation using the source term modified by oceanic data overestimated deposition amounts over land because their correction was applied for both offshore 
象

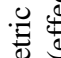

政

車

हो)

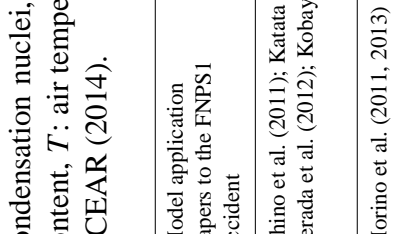
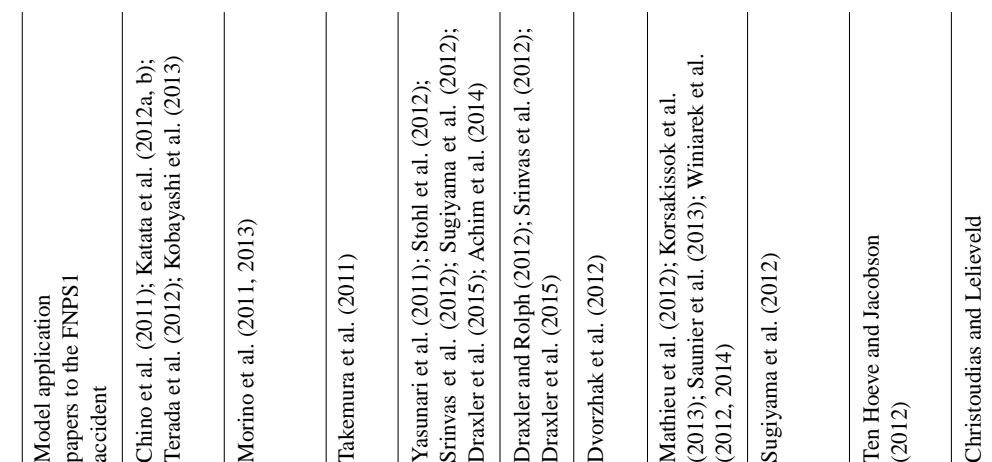

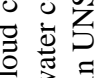

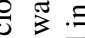

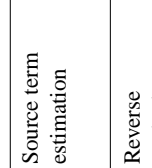

言产

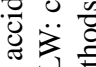

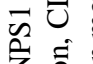

की

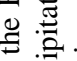

每

尊

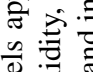

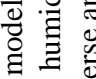

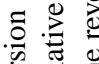

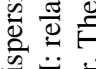

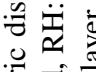

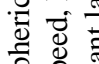

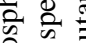

害言

$\Rightarrow \stackrel{\circ}{\circ}$

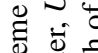

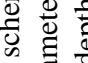

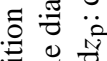

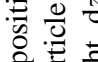

so

这变

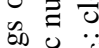

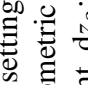

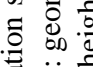

날

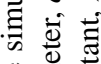

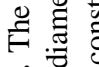

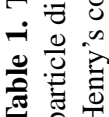
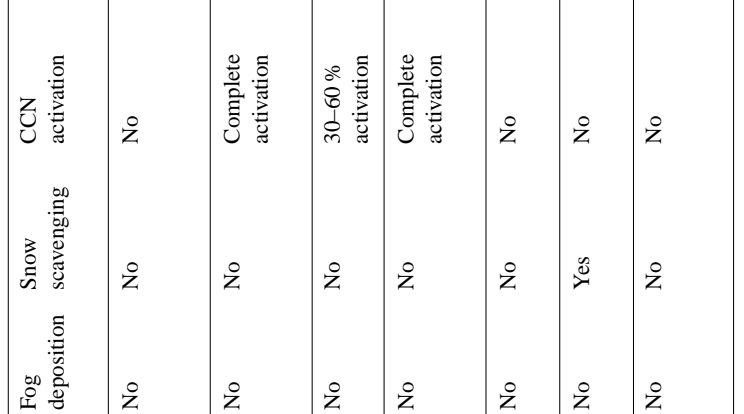

มี

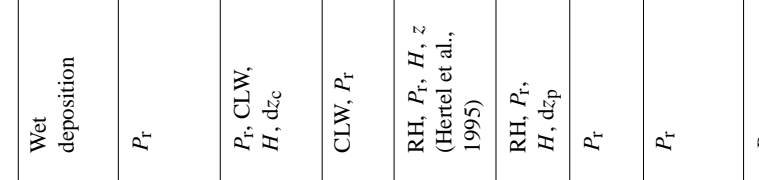

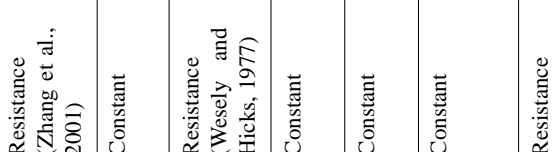

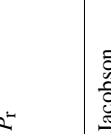

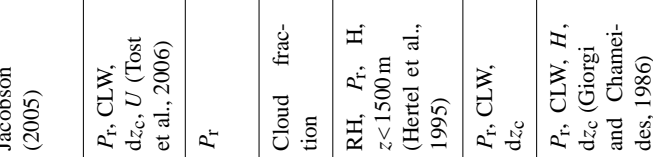

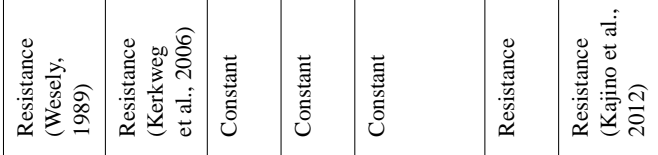

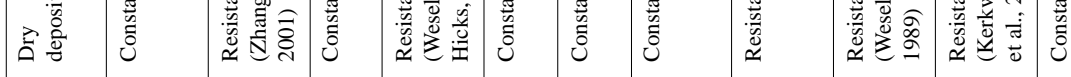

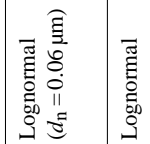

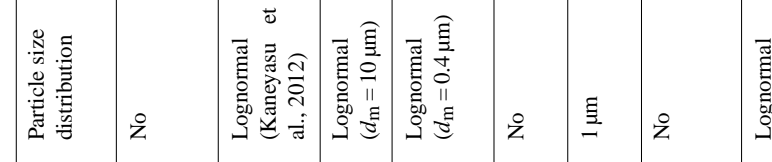

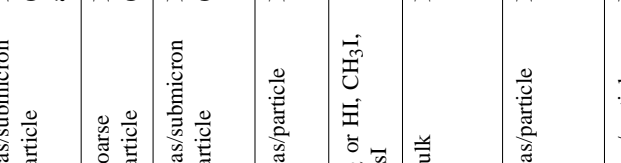

竞

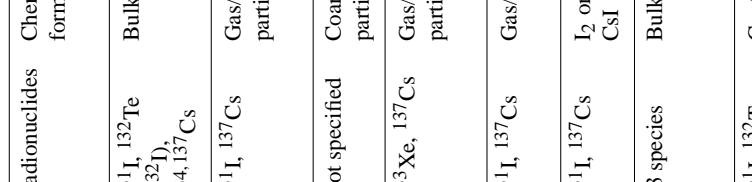

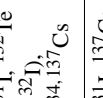

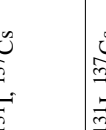


and onshore flow cases. The overestimation of the deposition amount over the land areas of Japan has also been reported by Morino et al. (2013) when using the source term estimated by global simulations with the air concentration data sampled at the Comprehensive Nuclear-Test-Ban Treaty Organization (CTBTO) stations (Stohl et al., 2012). The surface deposition of ${ }^{137} \mathrm{Cs}$ was also clearly overestimated in regional calculations. Thus, only the release rates of the plumes which directly flowed toward the ocean should be re-computed using the coupled simulation of the atmospheric and oceanic dispersion models. For other cases the source term is estimated using only the environmental data collected over land.

Finally, in the last source term, the release rates in the early phase of the accident have been estimated primarily using the air dose rate data observed far from the FNPS1 due to the lack of routine operating equipment (e.g., stack monitors, radiation and meteorological stations) within $20 \mathrm{~km}$ from the station (Katata et al., 2012a, b). Three years after the accident, additional environmental monitoring data from 12 to 31 March 2011 have become available including the air dose rates measured within $20 \mathrm{~km}$ from FNPS1 (Fukushima Prefecture, 2012), a detailed ${ }^{131}$ I deposition map around the station (Torii et al., 2013), and dust sampling (US DOE, 2011; NRA, 2012b). This enables us to make a more detailed estimation of the atmospheric releases during the accident using the reverse estimation method by combining the modified WSPEEDI-II results with these additional monitoring data.

Thus, the present study aims to determine the detailed source terms of ${ }^{131} \mathrm{I}$ and ${ }^{137} \mathrm{Cs}$ during the FNPS1 accident with the reverse estimation method (Sect. 2.1), combining the above new data (Sect. 2.2) and simulations using WSPEEDIII with a modified deposition scheme (Appendix A) and an offline coupling of the atmospheric and oceanic dispersion models (Sect. 2.3). The estimation results of the source term are presented in Sect. 3. The estimated source term is validated by comparing the atmospheric transport and deposition simulations by modified WSPEEDI-II with airborne monitoring data of air dose rate and surface deposition of ${ }^{131} \mathrm{I}$ and ${ }^{137} \mathrm{Cs}$ in eastern Japan (Sect. 4.1.1). Moreover, the source term is independently evaluated based on the simulations of different atmospheric dispersion models by demonstrating model-observation comparisons in atmospheric concentration and surface deposition over regional and global scales (Sect. 4.1.2). Finally, the difference between the new source term and those from prior studies is discussed based on the simulation results (Sect. 4.2).

\section{Material and methods}

\subsection{Source term estimation method}

A typical approach to estimate the source term is by coupling environmental measurements of radionuclides with simula- tions of their atmospheric dispersion using a reverse or inverse estimation method (UNSCEAR, 2014).

A reverse estimation method evaluates the release rates of radionuclides by comparing measurements of air concentration of a radionuclide or dose rate in the environment with one calculated by atmospheric transport, dispersion, and deposition models (ATDM) for a unit release of a radionuclide. The release rate is estimated by the ratio of the measurement to calculation result. This simple comparison without consideration of the uncertainty of the ATDM results may cause the large errors, and, consequently, expert judgment is essential to correct the discrepancy between the measurement and calculation.

An inverse estimation method evaluates the release rates in an objective way using an algorithm to minimize the differences between calculated and measured air concentrations or dose rates. This method is mathematically sophisticated and technical errors are explicitly considered. However, to return the highest-quality estimates, a large number of measured values of air concentrations or dose rates in time and space and high-accuracy meteorological fields for the ATDM simulations are required. The accuracy of the meteorological field is essential, particularly if this method is applied to local-scale dispersion simulations with a point source. The uncertainties caused by lack of above requirements can reduce if a priori release rates are provided from other estimations.

This paper aims at estimating the highest-quality source term which will contribute to the accurate assessment of radiological impacts from local to regional scales. For this purpose, measurements of air concentrations or air dose rates in the local area are used if available rather than more distant data. The merit of using local data is that it is easy to find the correlation between a specific release and the increase of air concentration at a measurement point from atmospheric transport simulation by the ATDM because sharp peaks of both measured and calculated values appearing in the local area clearly show the arrival and departure of the plume. For most comparisons, air concentrations of radionuclides are normally used. However, in the case of the FNPS1 accident, time-dependent air concentrations in the local area from 11 to 31 March were measured at the Japan Atomic Energy Agency (hereinafter JAEA-Tokai), located $100 \mathrm{~km}$ south of FNPS1. Other groups provided a small amount of dust sampling data using monitoring cars at various points mainly after 20 March. Furthermore, due to a change of wind direction, there were several days when no plumes were recorded at the measuring points in the local area. For the source term estimation during those days, air dose rates are used as the second choice, which means that the data available for comparison are a mixture of air concentrations and air dose rates in time. Meteorological measurements in the local area around FNPS1during this period, which are necessary to ensure the accuracy of meteorological input to ATDM, are 


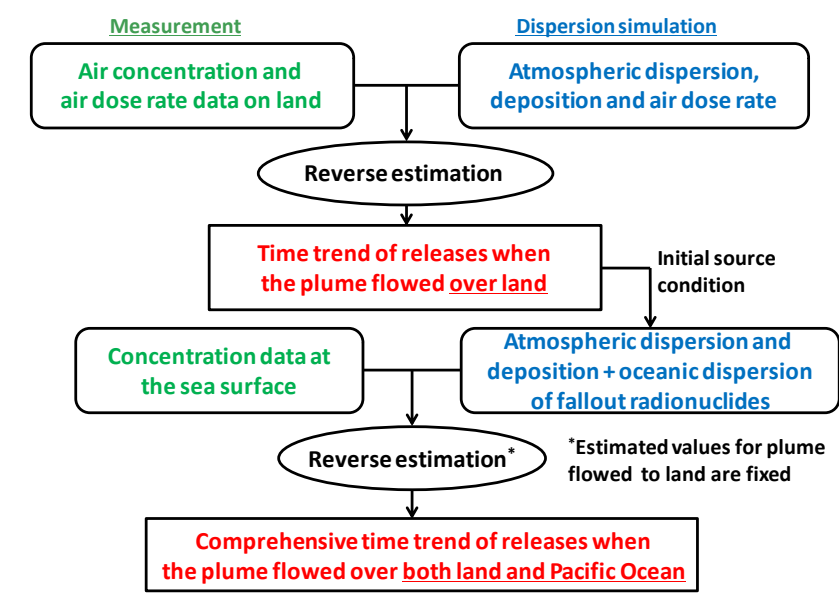

Figure 1. The flowchart of the source term estimation technique based on coupling the atmospheric and oceanic dispersion model simulations.

also limited because the observation systems were inoperative due to the earthquake and tsunami.

Considering the above conditions, we used the reverse estimation method to estimate the source term following our previous studies before we retry the inverse estimation method. It is better to use the same method and show the difference between our old and new estimations resulting from the utilization of additional data and modification of the deposition scheme. These results are expected to become an a priori source term for the inverse estimation method in future studies.

Figure 1 depicts the flowchart of the source term estimation based upon coupling the simulations of the atmospheric and oceanic dispersion models. First, the release rates of the plumes discharged from FNPS1 are estimated by combining the atmospheric dispersion calculation and the data of radionuclide air concentrations and dose rates measured over the land areas of eastern Japan (Sect. 2.1.1). When the plume directly flowed toward the Pacific Ocean, the release rates are initially determined by temporally interpolating two available values just before and after this period. Then, only the interpolated values are revised by coupling a combination of models of atmospheric and oceanic dispersion and the Pacific Ocean sea surface concentrations (Sect. 2.1.2). The role of the atmospheric dispersion model is to provide the oceanic dispersion model with an estimate of the radionuclide deposition to the sea surface.

\subsubsection{Source term estimation by using data over land}

The release rates of individual radionuclides are estimated by the reverse estimation method following our previous work (Chino et al., 2011; Katata et al., 2012a, b), i.e., coupling environmental monitoring data with atmospheric dispersion simulations, assuming a unit release rate $\left(1 \mathrm{~Bq} \mathrm{~h}^{-1}\right)$. Release rates are obtained as the ratio of measured air concentrations to calculated air concentrations of nuclide $i$ at the sampling points, as follows:

$Q_{i, t}=M_{i, t} / C_{i, t}$,

where $Q_{i, t}$ is the release rate $\left(\mathrm{Bq} \mathrm{h}^{-1}\right)$ of nuclide $i$ when discharged into the atmosphere during the time segment $t$ with a constant release rate, $M_{i, t}$ is the measured air concentration $\left(\mathrm{Bq} \mathrm{m}^{-3}\right)$ of $i$ in the plume released during the time segment $t$, and $C_{i, t}$ is the dilution factor $\left(\mathrm{h} \mathrm{m}^{-3}\right)$ of $i$, which is equal to the calculated air concentration of $i$ in the plume released during the time segment $t$ at the measurement point calculated under the assumption of a unit release rate. This method, using air concentration data, is more reliable than the methods using air dose rates because it does not require an additional assumption on the composition of the radionuclides contributing to the dose rates.

Depending on the number of available data, we estimated release rates using Eq. (1) as follows: the number of dust sampling data in Fukushima Prefecture was limited and, furthermore, the concentration data relevant to a specific plume was usually one or at most two or three (see Sect. 2.2.1) data points. Exceptionally, the data at JAEA-Tokai provided temporal variation of air concentrations throughout the period. First, when only one data point is available for the specific plume, we simply use Eq. (1). Second, if concentration values available for the source term estimation were simultaneously observed at more than two sites, release rates were determined by averaging the source term estimated at all sites. If the time-dependent air concentrations measured at one location (JAEA-Tokai) were available for comparison, the peak values from both the measurement and calculation were used in Eq. (1).

Since the uncertainty of model simulation is the primary cause of the discrepancy in the spatiotemporal distribution of the plume between measurements and simulations, the above procedures cannot be applied systematically, and the correction of this discrepancy by "expert judgment" is necessary to reduce the impact of model uncertainty on the source term estimation. The process is to check all available measurements to see if the plume is reproduced appropriately or not for comparing calculations with the measurements, and to determine if the discrepancy is caused mainly by errors in the calculated wind direction. If the plume flow direction is clearly different from the measured wind direction, the calculated plume is rotated to match the measured wind direction and Eq. (1) is applied. The use of peak values corrects any discrepancy in the timing of the arrival of the peak air concentrations between measurements and simulations (at JAEA-Tokai). We assume that the peak values of measurements and simulations are comparable even though the timing or temporal pattern of the arrival of the peak is different because the central plume axis passes across the sampling point differently between measurements and simulations. 
When air concentration data are not available, the release rates are estimated by comparing the observed spatial patterns and/or temporal changes of air dose rates. To use air dose rates, the fractional composition of major radionuclides must be assumed. However, for measured concentrations of noble gases, a primary component of the composition was not available for the local area. Thus, we do not use the peak values of air dose rates during the passage of plume containing noble gases, but use the slopes of the air dose rate after the passage of the peak which is due to the radionuclides on the ground surface (i.e., ground-shine) for the source term estimation. The procedure to determine the composition is described in Sect. 2.3.3. This method is applied to estimate the release rate in the afternoon of 12 March when the venting and hydrogen explosion occurred at Unit 1, and on the morning of 15 March to the noon of 16 March. First, the temporal changes of air dose rates from ground-shine at the measurement points are estimated by the modified WSPEEDI-II for a unit release. Then, the release rate $\left(\mathrm{Bqh}^{-1}\right)$ is computed from the ratio of the measured to calculated ground-shine. Here, we find the appropriate observed point which can be used for the source term estimation by looking for when and where the specific plume increases air dose rate in the simulation of the WSPEEDI-II. For the estimation of the source term during 15-16 March, we need to determine the "net" increase of ground-shine due to the deposition of the objective plume because the monitored air dose rates due to groundshine are influenced by multiple deposition events (i.e., deposition from the past plumes). The net increase is then estimated by subtracting the effect of the past plumes from the ground-shine after the passage of the objective plume.

\subsubsection{Source term estimation by using data over the ocean}

This estimation is applied to only the periods when the plume flowed toward the ocean, while our previous work (Kobayashi et al., 2013) estimated the release rates throughout the simulation period using the oceanic monitoring data. The judgment of whether the plume during each segment directly flowed toward the ocean is done by evaluating the simulation of the modified WSPEEDI-II, observed wind direction, and monitoring data on the land. Two sets of offline coupling simulations of modified WSPEEDI-II and SEAGEARN-FDM are carried out: one simply uses the source term estimated by the method in Sect. 2.1.1 (hereinafter "New-land" source term) throughout the calculation period, and the other uses the release rates for each time segment separating the New-land source term into an arbitrary number of segments. In both cases, the input data of daily cumulative deposition of ${ }^{134} \mathrm{Cs}$ on the sea surface to SEA-GEARN-FDM are supplied from the WSPEEDI calculations using the Newland source term.

In the first simulation, the comprehensive correction index of the New-land source term at the sampling point $j\left(R_{j}\right)$ can be calculated as follows:

$R_{j}=N_{j} / D_{j}$,

where $N_{j}$ and $D_{j}$ are the measurements and SEA-GEARNFDM calculations of sea surface concentration of ${ }^{134} \mathrm{Cs}$ $\left(\mathrm{BqL}^{-1}\right)$ at the sampling point $j$ over the Pacific Ocean, respectively. Instead of ${ }^{137} \mathrm{Cs}$, we used ${ }^{134} \mathrm{Cs}$ as a standard radionuclide because imprints of former atmospheric nuclear tests were detected in the seawater sample of ${ }^{137} \mathrm{Cs}$. Note that, from a preliminary comparison between measurement points of sea surface concentration of ${ }^{134} \mathrm{Cs}$ and the oceanic dispersion area simulated using the source term of direct releases of ${ }^{134} \mathrm{Cs}$ from FNPS1 into the ocean, we chose only the observational points for ${ }^{134} \mathrm{Cs}$ that are not affected by the direct release for the source term estimation.

In the second simulation, the sea surface concentration $O_{j, t}\left(\mathrm{~Bq} \mathrm{~L}^{-1}\right)$ of ${ }^{134} \mathrm{Cs}$ at the sampling point of $j$ that originated from the discharge of time segment $t$ can be calculated using SEA-GEARN-FDM in a manner similar to the first simulation. If the total number of time segments is represented as $n t$, the contribution ratio of $t$ at the sampling point of $j, P_{j, t}$ can be defined as the ratio of calculated sea surface concentration for the time segment of $t$ to that for the whole simulation period, expressed as follows:

$P_{j, t}=\frac{O_{j, t}}{\sum_{t=1}^{n t} O_{j, t}}=\frac{O_{j, t}}{D_{j}}$.

Here, a large value of $P_{j, t}$ indicates a large contribution of the release for the time segment $t$ to the concentration at the sampling point $j$ accumulated for whole simulation period, i.e., $D_{j}$ in Eq. (2). The correction index $S_{t}$ of the New-land source term for $t$ is expressed by weighting the contribution ratio $P_{j, t}$ at sampling point of $j$ :

$S_{t}=10^{\sum_{j=1}^{n p}\left(P_{j, t} \cdot \log _{10} R_{j}\right) / \sum_{j=1}^{n p} P_{j, t}}$,

where $n p$ is the total number of sampling points (46 in this study). By using Eq. (4), the new release rate of ${ }^{134} \mathrm{Cs}$ for the segment $t, U_{i, t}\left(\mathrm{~Bq} \mathrm{~h}^{-1}\right)$, is finally obtained by multiplying the release rate of ${ }^{134} \mathrm{Cs}$ for the same time segment in the New-land source term, $Q_{i, t}$, with the correction index, $S_{t}$ :

$U_{i, t}=Q_{i, t} S_{t}$

For other radionuclides, release rates are calculated by multiplying $U_{i, t}$ of Eq. (5) with the time interpolated composition ratio of each nuclide to ${ }^{134} \mathrm{Cs}$ for the New-land source term.

\subsection{Observational data}

\subsubsection{Observational data for source term estimation over land}

The data sets of dust sampling and air dose rates (groundshine) used for the source estimation over land (Sect. 2.1.1) 


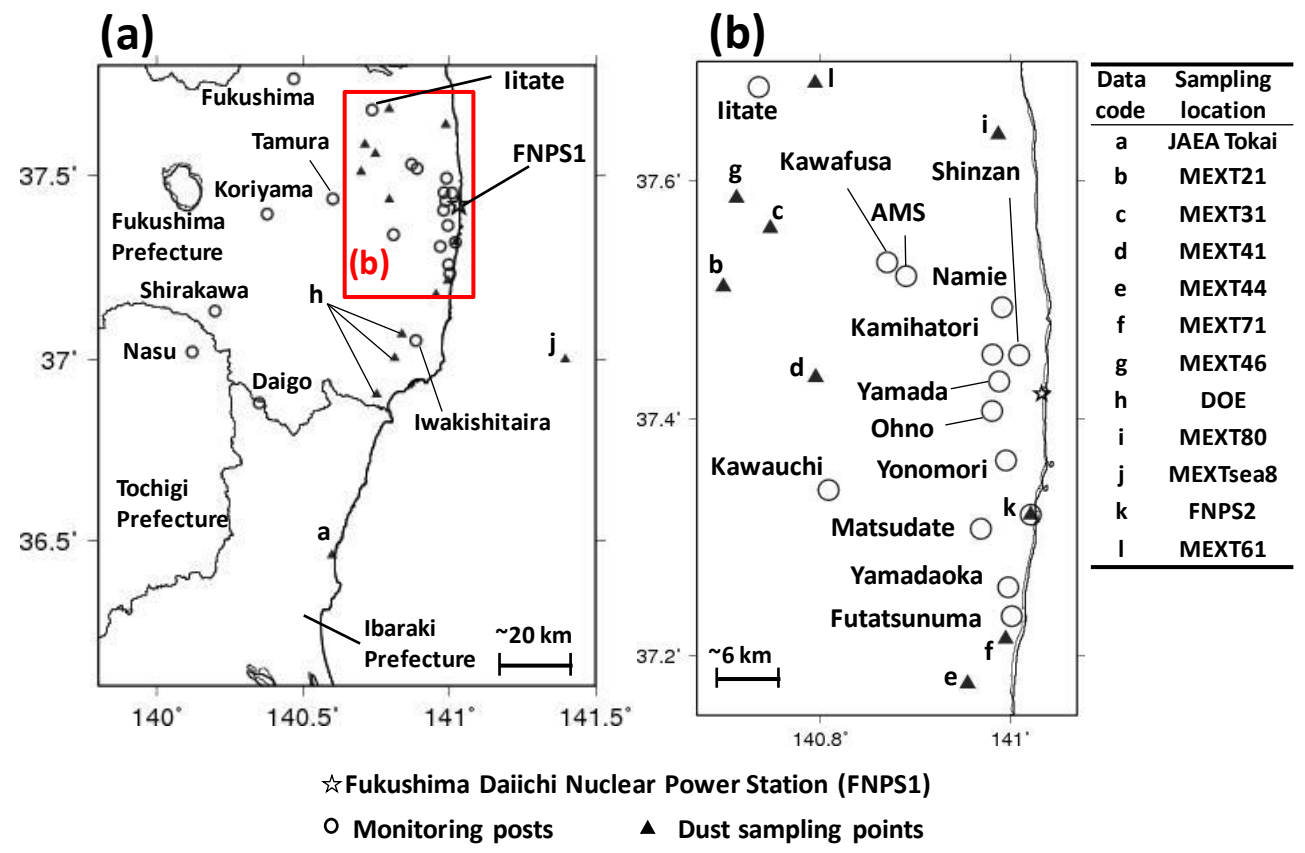

Figure 2. The sampling locations of the environmental monitoring data over the land used for the source term estimation.

are summarized in Tables 2 and 3, respectively. The location maps of sampling points are illustrated in Fig. 2. For the period of 12 March and 15-16 March 2011, the release rates are estimated primarily using ground-shine data observed by portable monitors (Fukushima Prefecture, 2011a, b; Ibaraki Prefecture, 2011; Tochigi Prefecture, 2011; TEPCO, 2011a) and at automatic monitoring posts (Fukushima Prefecture, 2012) located $22-81 \mathrm{~km}$ and 4-21 km downwind from FNPS1, respectively. For other periods, we use the dust sampling data of ${ }^{131} \mathrm{I}$ and ${ }^{137} \mathrm{Cs}$ in Fukushima Prefecture (TEPCO, 2011a; NISA 2011; NRA, 2011, 2012b; US DOE, 2012) and at JAEA-Tokai in Ibaraki Prefecture (Ohkura et al., 2012) (Fig. 2). Here, the dust sampling in Fukushima Prefecture was carried out by limited number of monitoring cars and consequently, the data are not continuous in time, and there are only a few data points each day. At JAEA-Tokai, which is the closest monitoring station of FNPS1, high-resolution temporal variations of air concentrations including both gaseous and particulate forms of ${ }^{131}$ I were observed continuously. Compared with our previous studies (Katata et al., 2012b; Terada et al., 2012), the data of air dose rate within $20 \mathrm{~km}$ from FNPS1 (Fukushima Prefecture, 2012) and dust sampling (US DOE, 2011; NRA, $2012 b$ ) are used for the first time in this study.

\subsubsection{Observational data for source term estimation over the ocean}

For the source term estimation method over the ocean (Sect. 2.1.2), we used two data sets of seawater concentration of ${ }^{134}$ Cs sampled from 14 April to 3 May 2011 in the north-western North Pacific region (450-2000 km from FNPS1, Honda et al., 2012) and from 2 April to 17 May 2011 over a much larger North Pacific region (300-8400 km from FNPS1, Aoyama et al., 2012), respectively. Figure $3 \mathrm{a}$ and $\mathrm{b}$ depict the location of all sampling points over the Pacific Ocean.

\subsubsection{Observational data for verification of source term}

For verification of the source term, the cumulative surface deposition of ${ }^{137} \mathrm{Cs}$ over eastern Japan measured by the aerial radiological survey of 31 May 2012 (NRA, 2012a) is used. The observed surface deposition map of ${ }^{131}$ I near the plant on 1 April 2011 reconstructed by Torii et al. (2013) is also compared with the calculated one. For the evaluation of the release rates during the early stages of the accident, we use the aerial survey of total air dose rate on 17-19 March 2011 (US DOE/NNSA, 2011). Furthermore, in the atmospheric dispersion analysis, we mainly focus on temporal variations in air concentration sampled at the CTBTO stations (CTBTO, 2011) and four stations in the United States: Sacramento, California; Melbourne, Florida; Sand Point, Alaska; and Oahu, Hawaii (Fig. 3a), where the plume was detected in the early stages of the accident.

\subsection{Models and simulation settings}

\subsubsection{Models}

The emergency response system's atmospheric dispersion model (WSPEEDI-II) and an oceanic dispersion model (SEA-GEARN-FDM) are used to estimate the source term. 
Table 2. Dust sampling data used for the source term estimation. The locations of monitoring data are illustrated in Fig. 2. The concentration calculations for source term estimation were carried out under the assumption of unit release rate $\left(1 \mathrm{Bqh}^{-1}\right)$.

\begin{tabular}{|c|c|c|c|c|c|c|c|}
\hline $\begin{array}{l}\text { Data } \\
\text { no. }\end{array}$ & $\begin{array}{l}\text { Location code } \\
\text { in Fig. } 2\end{array}$ & $\begin{array}{l}\text { Sampling } \\
\text { location }\end{array}$ & $\begin{array}{l}\text { Sampling date and time } \\
\text { (Japan standard time) }\end{array}$ & $\begin{array}{l}\text { Total }{ }^{131} \mathrm{I} \\
\text { observed }\end{array}$ & $\begin{array}{l}\text { Concentration }\left(\mathrm{Bq} \mathrm{m}^{-3}\right) \\
\text { calculated }\end{array}$ & $\begin{array}{l}{ }^{137} \mathrm{Cs} \\
\text { observed }\end{array}$ & $\begin{array}{l}\text { Concentration }\left(\mathrm{Bq} \mathrm{m}^{-3}\right) \\
\text { calculated }\end{array}$ \\
\hline 1 & $\mathrm{a}$ & JAEA-Tokai & $15 / 301: 25-15 / 301: 45$ & 240 & $-^{\mathrm{a}}$ & 16 & $-^{\mathrm{a}}$ \\
\hline 2 & & (Ohkura et & $15 / 304: 25-15 / 304: 45$ & 1260 & $-^{\mathrm{a}}$ & 160 & $-^{\mathrm{a}}$ \\
\hline 3 & & al., 2012) & $15 / 306: 55-15 / 308: 15$ & $920-2600$ & $8.0 \times 10^{-13}-2.8 \times 10^{-12}$ & $110-310$ & $6.4 \times 10^{-13}-2.7 \times 10^{-12}$ \\
\hline 4 & & & $20 / 3$ 11:35-20/3 11:55 & 140 & $4.4 \times 10^{-12}$ & 26 & $4.7 \times 10^{-12}$ \\
\hline 5 & & & 21/3 03:45-21/3 07:05 & 1916 & $1.0 \times 10^{-11}$ & 438 & $1.1 \times 10^{-11}$ \\
\hline 6 & $\mathrm{~b}$ & MEXT21 & $20 / 3 \quad 14: 13-20 / 3 \quad 14: 33$ & 4800 & $1.6 \times 10^{-11}$ & 1000 & $1.5 \times 10^{-11}$ \\
\hline 7 & $\mathrm{c}$ & MEXT31 & 20/3 14:15-20/3 14:35 & 1000 & $1.1 \times 10^{-11}$ & 180 & $1.1 \times 10^{-11}$ \\
\hline 8 & $\mathrm{~d}$ & MEXT41 & 20/3 11:37-20/3 11:49 & 970 & $2.2 \times 10^{-11}$ & - & - \\
\hline 9 & $\mathrm{e}$ & MEXT44 & 21/3 10:50-21/3 11:08 & 1420 & $3.4 \times 10^{-11}$ & - & - \\
\hline 10 & $\mathrm{f}$ & MEXT71 & 21/3 13:00-21/3 13:40 & 5600 & $9.4 \times 10^{-11}$ & 36 & $8.8 \times 10^{-11}$ \\
\hline 11 & & & $22 / 314: 55-22 / 316: 30$ & $570-1100$ & $4.8 \times 10^{-12}-1.1 \times 10^{-11}$ & $7.7-11$ & $4.8 \times 10^{-12}-1.1 \times 10^{-11}$ \\
\hline 12 & & & $23 / 3 \quad 13: 15-23 / 315: 59$ & $110-530$ & $7.4 \times 10^{-13}-2.0 \times 10^{-12}$ & $2.1-6.6$ & $7.3 \times 10^{-13}-2.0 \times 10^{-12}$ \\
\hline 13 & & & $24 / 3$ 10:06-24/3 12:26 & $5.9-12$ & $2.2 \times 10^{-13}-2.4 \times 10^{-12}$ & $0.7-11$ & $2.2 \times 10^{-13}-2.4 \times 10^{-12}$ \\
\hline 14 & & & $25 / 3$ 11:51-25/3 16:42 & $10-43$ & $3.4 \times 10^{-13}-1.0 \times 10^{-12}$ & $0.7-2.3$ & $3.5 \times 10^{-13}-1.0 \times 10^{-12}$ \\
\hline 15 & & & $31 / 312: 22-31 / 315: 44$ & $13-24$ & $1.6 \times 10^{-12}-9.2 \times 10^{-12}$ & $1.0-4.5$ & $1.6 \times 10^{-12}-9.3 \times 10^{-12}$ \\
\hline 16 & $\mathrm{~g}$ & MEXT46 & 20/3 14:45-20/3 14:55 & 4100 & $1.3 \times 10^{-11}$ & - & - \\
\hline 17 & & & $25 / 3 \quad 15: 02-25 / 3 \quad 15: 22$ & $290-555$ & $2.1 \times 10^{-13}-1.9 \times 10^{-11}$ & $7.7-14$ & $2.0 \times 10^{-13}-8.7 \times 10^{-12}$ \\
\hline 18 & & & $30 / 3$ 14:11-30/3 14:32 & 89 & $1.0 \times 10^{-12 \mathrm{a}}$ & 91 & $1.0 \times 10^{-12 \mathrm{a}}$ \\
\hline 19 & $\mathrm{~h}$ & DOE & $22 / 3$ 06:00-22/3 07:00 & $360-2960$ & $1.4 \times 10^{-12}-1.3 \times 10^{-11}$ & $2-19$ & $9.4 \times 10^{-13}-8.3 \times 10^{-12}$ \\
\hline 20 & $\mathrm{i}$ & MEXT80 & $24 / 3$ 14:55-24/3 15:15 & 193 & $7.3 \times 10^{-12}$ & 2.9 & $7.0 \times 10^{-12}$ \\
\hline 21 & & & $29 / 311: 17-29 / 315: 00$ & $29-75$ & $5.4 \times 10^{-12}-1.1 \times 10^{-11}$ & $23-46$ & $5.3 \times 10^{-12}-1.1 \times 10^{-11}$ \\
\hline 22 & $\mathrm{j}$ & MEXTsea8 & $27 / 311: 45$ & 20 & $9.8 \times 10^{-13}$ & 0.88 & $1.0 \times 10^{-12}$ \\
\hline 23 & $\mathrm{k}$ & FNPS2 & $30 / 3$ 09:27-30/3 09:35 & 1490 & $1.7 \times 10^{-10}$ & 820 & $1.6 \times 10^{-10}$ \\
\hline 24 & 1 & MEXT61 & $30 / 3 \quad 14: 15-30 / 3 \quad 14: 35$ & 28 & $1.1 \times 10^{-12}$ & 20 & $1.3 \times 10^{-12}$ \\
\hline 25 & & & $1 / 412: 00-1 / 412: 20$ & 1.78 & $1.1 \times 10^{-11}$ & 1.69 & $1.1 \times 10^{-11}$ \\
\hline
\end{tabular}

${ }^{\text {a }}$ Expert judgement (Sect. 2.1.1).

Table 3. Air dose rate monitoring data used for the source term estimation. The locations of monitoring site are illustrated in Fig. 2. The air dose rate calculations for source term estimation were carried out under the assumption of unit release rate $\left(1 \mathrm{Bqh}^{-1}\right)$.

\begin{tabular}{|c|c|c|c|c|}
\hline Data no. & Name of monitoring location & $\begin{array}{l}\text { Monitoring date and time } \\
\text { (Japan standard time) }\end{array}$ & $\begin{array}{c}\text { Ground-shine }\left(\mu \mathrm{Gy} \mathrm{h}^{-1}\right) \\
\text { observed }\end{array}$ & calculated \\
\hline 1 & Kamihatori MP & $14 / 300: 00$ & 37 & $1.3 \times 10^{-14}$ \\
\hline 2 & Shinzan MP & $14 / 300: 00$ & 250 & $1.7 \times 10^{-14}$ \\
\hline 3 & Nasu MP & 17/3 00:00 & 0.6 & $2.5 \times 10^{-15}$ \\
\hline 4 & Koriyama MP & $17 / 300: 00$ & 2.8 & $3.3 \times 10^{-15}$ \\
\hline \multirow[t]{3}{*}{5} & Kawauchi MP & 17/3 00:00 & 1.6 & $1.3 \times 10^{-15}$ \\
\hline & Ohno MP & 17/3 00:00 & $3.4^{\mathrm{a}}$ & $5.2 \times 10^{-15}$ \\
\hline & Yamada MP & 17/3 00:00 & $10.1^{\mathrm{a}}$ & $8.0 \times 10^{-15}$ \\
\hline 6 & Iitate MP & $17 / 300: 00$ & $6.9^{\mathrm{a}}$ & $1.9 \times 10^{-14}$ \\
\hline 7 & AMS near Kawafusa (extrapolated to 17 March) & $17 / 300: 00$ & $200-300$ & $1.0 \times 10^{-13}$ \\
\hline 8 & Yamada MP & 17/3 00:00 & $390^{\mathrm{a}}$ & $8.7 \times 10^{-14}$ \\
\hline 9 & Ohno MP & 17/3 00:00 & $62^{\mathrm{a}}$ & $3.1 \times 10^{-15}$ \\
\hline \multirow[t]{2}{*}{10} & Futatsunuma MP & $17 / 300: 00$ & $1.9^{\mathrm{a}}$ & $6.0 \times 10^{-16}$ \\
\hline & Yamadaoka MP & 17/3 00:00 & $0.8^{\mathrm{a}}$ & $6.7 \times 10^{-16}$ \\
\hline 11 & FNPS2 MP & 17/3 00:00 & $9.3^{\mathrm{a}}$ & $5.9 \times 10^{-15}$ \\
\hline \multirow[t]{3}{*}{12} & FNPS2 MP & $17 / 300: 00$ & $2.9^{\mathrm{a}}$ & $4.6 \times 10^{-16}$ \\
\hline & Futatsunuma MP & $17 / 300: 00$ & $1.8^{\mathrm{a}}$ & $1.2 \times 10^{-15}$ \\
\hline & Yamadaoka MP & 17/3 00:00 & $1.3^{\mathrm{a}}$ & $1.5 \times 10^{-15}$ \\
\hline
\end{tabular}

\footnotetext{
${ }^{a}$ Uncertainty of observed ground-shine estimates due to the plume passing through the monitoring place several times.
} 


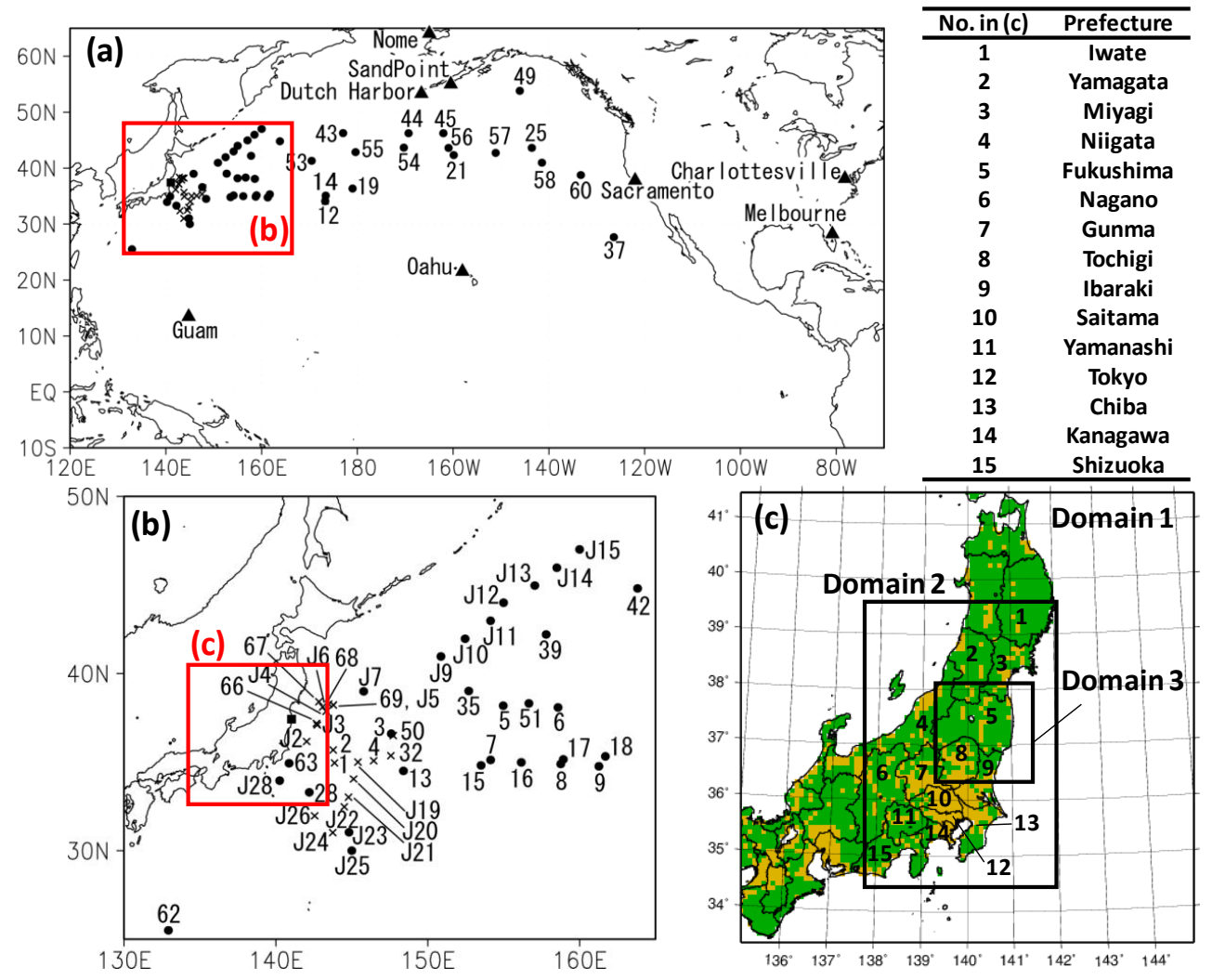

Figure 3. The simulation domains for $(\mathbf{a}, \mathbf{b})$ the oceanic dispersion and (c) the atmospheric dispersion simulations. The sampling locations of the sea surface concentration data for the source term estimation are plotted in (a) and (b) (black circles), while the sampling points affected by the direct release of radionuclides from the FNPS1 to the ocean were not considered in the reverse estimation (crosses), as indicated by Kobayashi et al. (2013). The prefectures (number) and forest cover (green shaded areas) over eastern Japan are shown in (c).

WSPEEDI-II combines two models: a non-hydrostatic atmospheric dynamic model (MM5, Grell et al., 1994) and a Lagrangian particle dispersion model (GEARN, Terada and Chino, 2008). MM5 predicts three-dimensional fields of wind, precipitation, diffusion coefficients, etc. based upon the atmospheric dynamic equations at an appropriate spatial and temporal resolution by using nested domains. GEARN calculates the advection and diffusion of radioactive plumes, radioactive decay, dry, and wet deposition onto the ground surface, and air dose rate from radionuclides in the air (cloudshine) and ground-shine. GEARN can predict the atmospheric dispersion on both local and regional domains simultaneously by considering in- and out-flow between the domains. The areas of two GEARN domains are the same as the MM5 nested domains. The performance of this system was evaluated by its application to the field tracer experiment over Europe, European Tracer EXperiment (ETEX) (Furuno et al., 2004), the Chernobyl accident (Terada et al., 2004; Terada and Chino, 2005, 2008), and the FNPS1 accident (Katata et al., 2012a, b; Terada et al., 2012). A detailed description of the models is provided in Terada et al. (2004) and Terada and Chino (2005).
In the present study, the deposition scheme of WSPEEDIII is modified to improve the atmospheric dispersion simulation and hence the resulting accuracy of the source term estimation. The scheme consists of parameterizations for dry deposition, wet deposition (in-cloud and below-cloud scavenging; cloud condensation nuclei $(\mathrm{CCN})$ activation and scavenging in mixed-phase clouds), and fog-water deposition of gaseous and particulate radionuclides based on existing modeling approaches. Details of the scheme are described in Appendix A.

SEA-GEARN-FDM is a finite difference model used to simulate radionuclide transport in the ocean (Kawamura et al., 2014). The model calculates the temporal variation of sea surface concentration of ${ }^{134} \mathrm{Cs}$ (half-life $=2.1$ years). Horizontal turbulent mixing is modeled using the Smagorinsky formula (Smagorinsky, 1963). For vertical mixing fluxes, an empirical value of eddy diffusivity in the mixing layer $\left(4.0 \times 10^{-3} \mathrm{~m}^{2} \mathrm{~s}^{-1}\right)$ is adopted at all model grid points throughout the simulation period. SEA-GEARNFDM uses the 10-day mean ocean current fields from the ocean-atmosphere global model K7 (Sugiura et al., 2008). The K7 model is a fully coupled global general circulation model (GCM) developed by the Data Research Center for 
Marine-Earth Sciences, Japan Agency for Marine-Earth Science and Technology (JAMSTEC/DrC). The coupled GCM is composed of the Atmospheric GCM for the Earth Simulator (AFES; Ohfuchi et al., 2004) and the Ocean-Sea Ice GCM for the Earth Simulator (OIFES; Masuda et al., 2006). The AFES and OIFES have horizontal grid resolutions of T42 (approximately $2.8^{\circ} \times 2.8^{\circ}$ ) and $1^{\circ} \times 1^{\circ}$ with 24 and 45 vertical layers in $\sigma$ coordinates, respectively. The fourdimensional variation method is used to execute the reanalysis of data in $\mathrm{K} 7$.

\subsubsection{Simulation settings}

The study area covers regional and northern-hemispheric areas around FNPS1 (Fig. 3). The simulation conditions of modified WSPEEDI-II are summarized in Table 4. Two sets of meteorological input data, a grid point value (GPV) of the Global Spectral Model for the Japan region (GSM) and the Meso-Scale Model (MSM) provided by the Japan Meteorological Agency (JMA) are used for initial and boundary conditions of MM5. MSM, which covers Japan with a finer resolution, is adopted for the reverse estimation over land, and GSM over the globe is used for the estimation over the ocean. A four-dimensional data assimilation method is also employed by using the GPV data, observed wind data at FNPS1 and FNPS2 (TEPCO, 2011b, c), and surface weather stations to improve the prediction accuracy of the meteorological fields around FNPS1. While most model settings were similar to Katata et al. (2012b), the revised approach uses the more sophisticated Reisner graupel microphysics parameterization (Reisner et al., 1998) of MM5 to simulate the precipitation and ice physics. When compared to the observed rainfall amount in Fukushima Prefecture (Fig. S1), the new calculations are overall the same as or sometimes better than Katata et al. (2012b) and Terada et al. (2012). During 15-17 March 2011, the model also reproduces the upperair observations of wind and air temperature above $400 \mathrm{~m}$ at Ibaraki Prefecture (Fig. S2). The simulation by the modified WSPEEDI-II (hereinafter the WSPEEDI-II simulation in Sects. 2 and 3) for the source term estimation over the ocean is conducted using the GPV of the GSM by JMA. Time steps of MM5 and GEARN are set to $120 \mathrm{~s}$ and $60 \mathrm{~s}$, respectively.

The time step in SEA-GEARN-FDM calculations is set to $60 \mathrm{~min}$. The calculation period of SEA-GEARN was from 12 March to 30 June. The horizontal spatial resolution of the model was set to $1^{\circ} \times 1^{\circ}$ with 45 vertical layers. The deposition amounts calculated by the WSPEEDI simulation were given to the surface layer of SEA-GEARN-FDM every $24 \mathrm{~h}$.

\subsubsection{Source assumption}

During the accident, radioactive nuclides were discharged into the atmosphere by various processes, venting, hydrogen explosion, and continuous leakage from the reactor build- ings. A more complete analysis of the features of releases related to the events in the reactor is still under investigation. Note that the time zone used in the following sections is Japan standard time (JST $=\mathrm{UTC}+9 \mathrm{~h}$ ).

Under such situations, the fractional composition of major radionuclides, the chemical form of radionuclides, the release period, i.e., the starting and ending points of each release and release height, are assumed as follows.

The fractional composition of major radionuclides contributing to ground-shine, e.g., ${ }^{131} \mathrm{I},{ }^{132} \mathrm{Te}\left({ }^{132} \mathrm{I}\right),{ }^{133} \mathrm{I},{ }^{134} \mathrm{Cs}$, and ${ }^{137} \mathrm{Cs}$, is determined based on various measurement data sets over eastern Japan: METI (METI, 2011a), FNPS1, FNPS2 (TEPCO, 2011a), MEXT (NRA, 2011b), MEXTsea (NRA, 2011b), DOE (US DOE, 2011), JAEA-Tokai (Ohkura et al., 2012; Furuta et al., 2011), KEK (KEK, 2011), RIKEN (Haba et al., 2012), JCAC (Amano et al., 2012), and the Tokyo Metropolitan Government (2011). These radionuclides are selected based on their relative contribution to the total composition and their dose conversion factor. Figure 4 depicts the radioactive ratios for all dust sampling data. In Fig. $4 \mathrm{a}$ and $\mathrm{b}$, the decay curves for the radioactive ratio of total inventory of Units 1 to 3 (Table 5) of ${ }^{133} \mathrm{I} /$ Total ${ }^{131} \mathrm{I}$ and ${ }^{132} \mathrm{Te} /{ }^{137} \mathrm{Cs}$ are also plotted. When unit release rate is applied for ${ }^{131} \mathrm{I}$, the ratio of other radionuclides to ${ }^{131} \mathrm{I}$ is determined as follows. The temporal change of the ratio of ${ }^{133} \mathrm{I} /{ }^{131} \mathrm{I}$ is determined by the decay curve as shown in Fig. 4a. The ${ }^{137} \mathrm{Cs} /{ }^{131} \mathrm{I}$ ratio can be determined from the data for most of the simulation periods (Fig. $4 \mathrm{c}$ ). The ${ }^{137} \mathrm{Cs} /{ }^{131} \mathrm{I}$ ratio at the released time should be different from that at the measurement time because of radioactive decay during the transport of the plume and the difference of deposition processes of both nuclides in the environment. However, the transport time period between the FNPS1 and the monitoring points used to determine the ${ }^{137} \mathrm{Cs} /{ }^{131} \mathrm{I}$ ratio (Fig. 4c) are within about $10 \mathrm{~h}$ and sufficiently small compared with decay constants of both nuclides (Table 5). Thus, we only consider the latter effect to adjust the ratio obtained at the measurement points to that at the release point.

Although the reason why the temporal variation of ratio of ${ }^{132} \mathrm{Te} /{ }^{137} \mathrm{Cs}$ is almost correlated with the decay curve is not clear, the ratio exponentially decreased fromthe value of approximately 20 on 12 March as shown in Fig. 4b. Thus, we also use the decay curve to estimate the ${ }^{132} \mathrm{Te} /{ }^{137} \mathrm{Cs}$ ratio. ${ }^{132} \mathrm{I}$ (half-life $=2.3 \mathrm{~h}$ ) is treated as ${ }^{132} \mathrm{Te}$ progeny nuclide and assumed to be radioactive equilibrium with ${ }^{132} \mathrm{Te}$ (halflife $=3.2$ days).

Consequently, the ratio of ${ }^{131} \mathrm{I}:{ }^{132} \mathrm{Te}$ $\left({ }^{132} \mathrm{I}\right):{ }^{133} \mathrm{I}:{ }^{134} \mathrm{Cs}:{ }^{137} \mathrm{Cs}$ when we determine the source term by using air dose rates from ground-shine is set to $1: 1.5: 1.1: 0.1: 0.1$ in the afternoon of 12 March. From the morning of 15 March until noon of 16 March, $1: 0.8$ $0.9: 0.1-0.2: 0.1: 0.1$ is set from $04: 00$ to $20: 00$ of 15 March, $1: 0.2: 0.09-0.1: 0.014: 0.014$ from $20: 00$ of 15 March to $06: 00$ of 16 March, and $1: 0.6-0.7: 0.08: 0.1: 0.1$ from 06:00 to 11:00 of 16 March. 
Table 4. The settings for the WSPEEDI-II atmospheric dispersion model used in the coupling of the atmospheric and oceanic dispersion simulations.

\begin{tabular}{|c|c|c|c|c|}
\hline & \multicolumn{3}{|c|}{ Reverse estimation over land } & \multirow{2}{*}{$\begin{array}{c}\text { Reserve estimation over the ocean } \\
\text { Domain } 1\end{array}$} \\
\hline & Domain 1 & Domain 2 & Domain 3 & \\
\hline Study areas & \multicolumn{3}{|c|}{ Eastern Japan } & North Pacific \\
\hline Applied GEARN calculations & No & Yes & Yes & Yes \\
\hline Simulation period for GEARN & \multicolumn{3}{|c|}{ 05:00 on 12 March-0:00 on 1 April 2011} & $\begin{array}{l}\text { 05:00 on } 12 \text { March-09:00 on } \\
31 \text { May } 2011\end{array}$ \\
\hline $\begin{array}{l}\text { Horizontal grid cell } \\
\text { Spatial resolutions }\end{array}$ & $\begin{array}{c}100 \times 100 \\
9 \mathrm{~km}\end{array}$ & $\begin{array}{c}190 \times 130 \\
3 \mathrm{~km}\end{array}$ & $\begin{array}{c}190 \times 190 \\
1 \mathrm{~km}\end{array}$ & $\begin{array}{l}250 \times 150 \\
80 \mathrm{~km}\end{array}$ \\
\hline $\begin{array}{l}\text { Boundary and initial } \\
\text { conditions of MM5 }\end{array}$ & \multicolumn{3}{|c|}{$\begin{array}{c}\text { Meso-Scale Model (MSM) } \\
\text { by Japan Meteorological Agency (JMA) }\end{array}$} & $\begin{array}{l}\text { Global Spectral Model (GSM) for the global } \\
\text { region by JMA }\end{array}$ \\
\hline 3-D/surface analysis nudging & \multicolumn{3}{|c|}{$\begin{array}{l}\text { Utilized with wind data at FNPP1 (surface), } \\
\text { and surface weather stations }\end{array}$} & Utilized for 3-D \\
\hline Observation nudging & \multicolumn{3}{|c|}{$\begin{array}{l}\text { Utilized with wind data at FNPP1 } \\
\text { (surface) and FNPP2 }(120 \mathrm{~m})\end{array}$} & No \\
\hline Release rates and heights & \multicolumn{4}{|c|}{ Given in Table 6} \\
\hline $\begin{array}{l}\text { Other parameters } \\
\text { for MM5 }\end{array}$ & \multicolumn{4}{|c|}{$\begin{array}{l}\text { Same as Katata et al. (2012a, b) and Kobayashi et al. (2013) } \\
\text { except for Reisner microphysics scheme }\end{array}$} \\
\hline
\end{tabular}

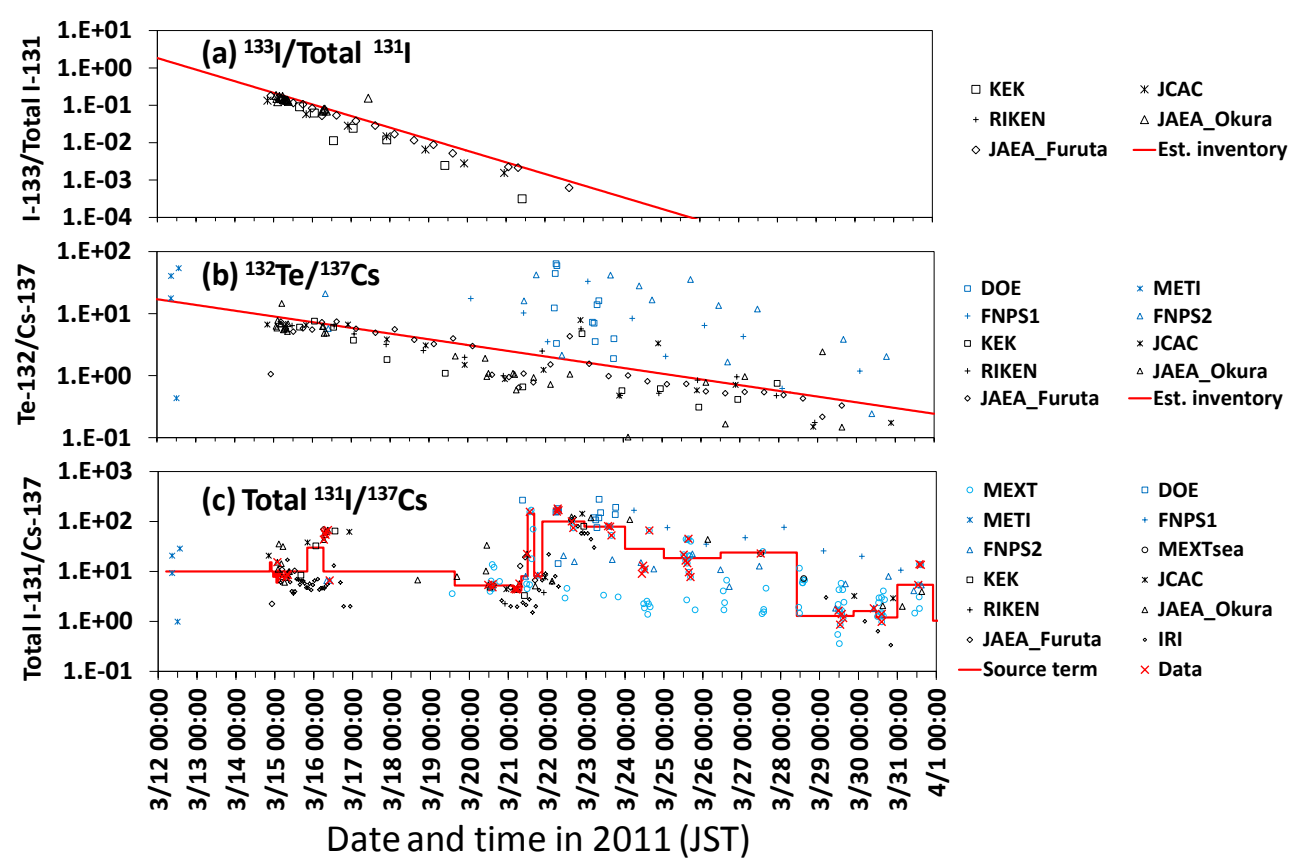

Figure 4. The time series in (a) the ratios of ${ }^{133} \mathrm{I}$ to total ${ }^{131} \mathrm{I}$, (b) ${ }^{132} \mathrm{Te}$ to ${ }^{137} \mathrm{Cs}$, and (c) total ${ }^{131} \mathrm{I}$ to ${ }^{137} \mathrm{Cs}$ in the atmosphere for the data sampled at each station [blue symbols: METI, FNPS1, FNPS2, MEXT, MEXTsea, and DOE] and at off-site monitoring sites in eastern Japan (black symbols: JAEA-Tokai, KEK, RIKEN, JCAC, and Tokyo Metropolitan Government (IRI)) from 12 to 31 March 2011. The red solid lines in (a) and (b) are the curves derived from the inventories and radioactive decay with the value of ${ }^{132} \mathrm{Te} /{ }^{137} \mathrm{Cs}=20$ at the shutdown time. The red solid line in (c) represents the ratio of total ${ }^{131} \mathrm{I}$ to ${ }^{137} \mathrm{Cs}$ for the source term estimated in this study, which is assumed or determined from the data shown as the red symbols in (c). 

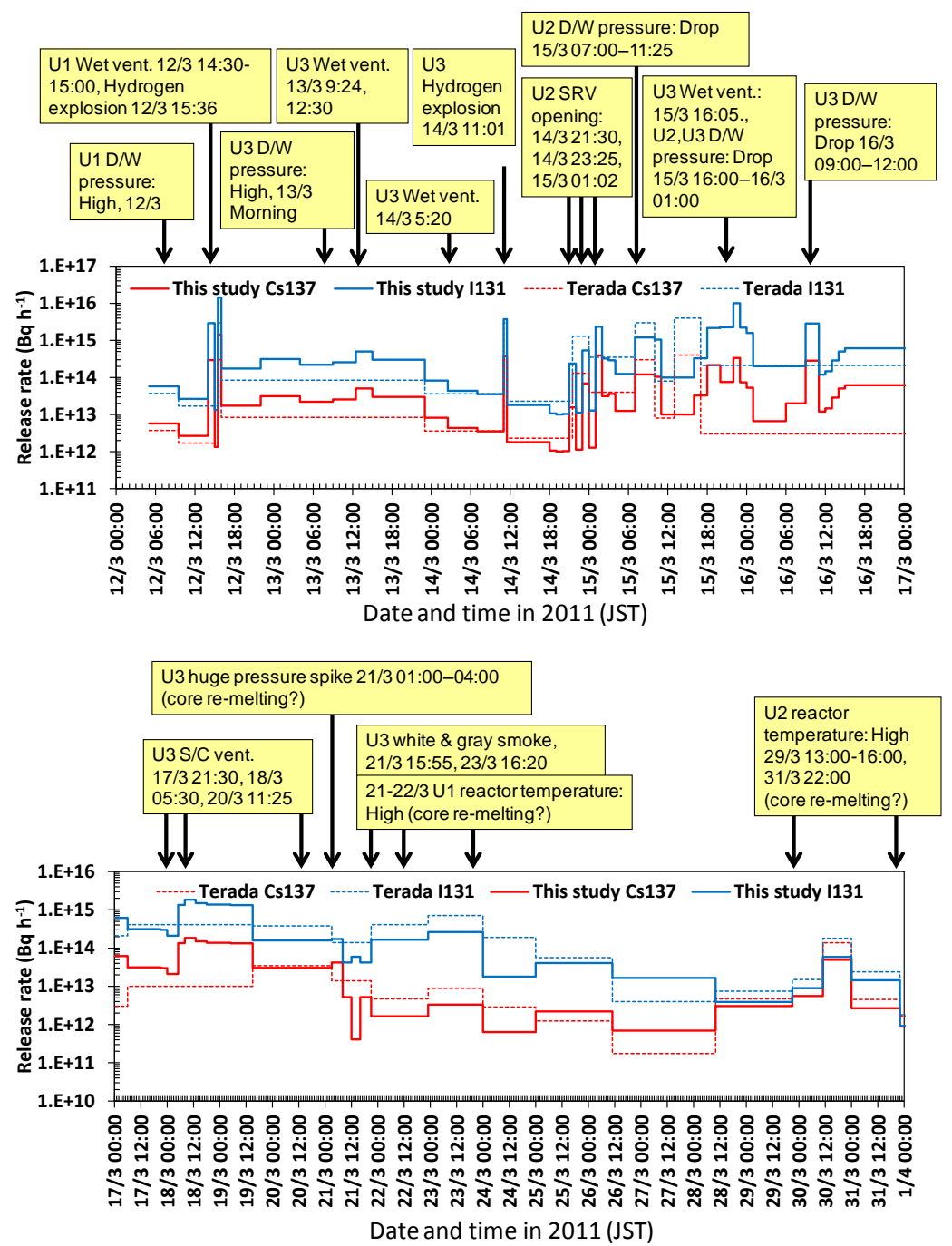

Figure 5. Temporal changes in release rate of total ${ }^{131} \mathrm{I}$ and ${ }^{137} \mathrm{Cs}$ from 12 March to 1 April 2011 reconstructed in this study (solid lines) and Terada et al. (2012) (dashed lines). The recognized events in the reactors (Prime Minister of Japan and His Cabinet, 2011; TEPCO, 2011a; 2012) are shown above the figure.

Concerning the chemical form, the ratio of gaseous to particulate ${ }^{131} \mathrm{I}$ is also determined from air concentration data collected at JAEA-Tokai (Ohkura et al., 2012), although this ratio varies widely depending on the observation points (Tsuruta et al., 2012). As mentioned above, we correct the ${ }^{137} \mathrm{Cs} /{ }^{131}$ I ratio at JAEA-Tokai to that at the release point considering the history of the air mass from the simulation model, which can treat the differences of deposition processes of gaseous and particulate matter. Because there are no observed data on the ratio of elemental iodine $\left(\mathrm{I}_{2}\right)$ and organic iodine $\left(\mathrm{CH}_{3} \mathrm{I}\right)$, the ratio of gaseous $\mathrm{CH}_{3} \mathrm{I}$ to $\mathrm{I}_{2}$ is assumed to be constant of 0.6 throughout the simulation period according to the method of RASCAL 4.0 (US NRC, 2012). There are uncertainties in the determination of the ratio of $\mathrm{I}_{2}, \mathrm{CH}_{3} \mathrm{I}$, and particulate iodine mentioned above. Because the deposition mechanisms for these three types of iodine are different in the environment, the estimation of the iodine source term is affected by this uncertainty. ${ }^{132} \mathrm{Te}$ should be a particulate in the atmosphere, similar to ${ }^{134} \mathrm{Cs}$ and ${ }^{137} \mathrm{Cs}$, according to the observational data of Ohkura et al. (2012) (Fig. 4b).

The starting and ending points of each release are determined by the following method. During the period from the early morning of 12 March to the evening of 14 March, the release periods for the venting from Units 1 and 3 reported by TEPCO (TEPCO, 2011a) are determined by the periods of the decreases of the drywell (DW) pressure and those for hydrogen explosions tentatively $30 \mathrm{~min}$. As mentioned in Sect. 3.2, these release periods are partially verified by comparing the calculation results of WSPEEDI-II with monitoring data. In other periods, the continuous leakage from Units 1 and/or 3 due to the increases of pressure in the contain- 
Table 5. Characteristics and total inventories of radionuclides for Units 1-3 at FNPS1 (Nishihara et al., 2012).

\begin{tabular}{llccc}
\hline Radionuclide & State in atmosphere & Half-life & Boiling point $\left({ }^{\circ} \mathrm{C}\right)$ & Total inventory $(\mathrm{PBq})$ \\
\hline${ }^{131} \mathrm{I}$ & Gas/aerosol & 8.0 days & 180 & $6.02 \times 10^{6}$ \\
${ }^{132} \mathrm{I}$ & Gas/aerosol & 2.3 hours & 180 & $8.85 \times 10^{6}$ \\
${ }^{132} \mathrm{Te}$ & Aerosol & 3.2 days & 1400 & $8.68 \times 10^{6}$ \\
${ }^{133} \mathrm{I}$ & Gas/aerosol & 21.0 hours & 180 & $1.26 \times 10^{7}$ \\
${ }^{137} \mathrm{Cs}$ & Aerosol & 30.0 years & 670 & $6.98 \times 10^{5}$ \\
${ }^{134} \mathrm{Cs}$ & Aerosol & 2.1 years & 670 & $7.18 \times 10^{5}$ \\
\hline
\end{tabular}

ment vessels are assumed because even for the period when the special events were not reported, air dose rates near the boundary of FNPS1 increased when the measurement point was located downwind. Concerning the release height, the venting is assumed to be from the stack at a height of $120 \mathrm{~m}$ above the ground level; hydrogen explosion, a volume source whose size is determined from film; and other leakages from the building from a height of $20 \mathrm{~m}$.

During the period from 21:00 of 14 March to 04:00 of 15 March, the safety relief valve (SRV) was opened three times to decrease the pressure of the reactor pressure vessel (RPV) at Unit 2 and, according to these operations, the environmental monitoring data clearly showed increases of air concentration and air dose rates downwind. Thus, we assume the three releases are at the periods which are the same as those corresponding to decreases in the RPV pressure. The release is assumed to occur from the stack via the RPV.

From 04:00 of 15 March to 11:00 of 16 March, although it was expected from environmental monitoring data that a number of large releases occurred, the reason is still not clear. Thus, the source term is estimated in detail by the comparison of calculation results for a unit release every hour to every several hours with relevant increases of air dose rates. Concerning the release height, the release from the Unit 2 building is assumed until 16:00 of 15 March. After 16:00 of 15 March to 06:00 of 16 March, the mixture of releases from the Unit 2 building and Unit 3 stack is assumed because the venting at Unit 3 started at 16:01 of 15 March. Since the ratio of release amounts from Units 2 and 3 is not clear, the vertical line source from 20 to $120 \mathrm{~m}$ height is applied.

After 17 March, wet venting operations at Unit 3 on 21:30 of 17 March, 05:30 of 18 March, and 11:25 on 20 March was reported (TEPCO, 2011a). However, except for these venting operations, the events which caused the atmospheric releases are not clear. For this period, Tanabe (2012) discussed the possibility of a core fuel material re-melt at Units 3 and 1 on 21 March and 22-23 March, respectively, due to a water shortage to cool the molten cores. The white and gray smoke observed at Unit 3 at 15:55 on 21 March and at 16:20 on 23 March indicated possible fires (Prime Minister of Japan and His Cabinet, 2011; TEPCO, 2011a). These events probably caused the release from the building. Thus, we assume the continuous releases except for the period of venting op- erations. The duration of the continuous release is roughly estimated by assuming that the certain specific rate tween two released times of sampled air used for the source estimation. Because the sampling time irregularly changed day by day, the duration for continuous release of specific release rate is consequently different as shown in Fig. 5. Thus, this difference in release periods has no physical meaning after 17 March.

\section{Source term estimation and local-scale dispersion analysis}

The estimated source term is shown in Table 6 and the temporal variation of the release rates are depicted in Fig. 5. The release rates shown in Table 6 and Fig. 5 are not decay normalized values to the shutdown time but are valid at the release time. The events in the reactors (TEPCO, 2011a, 2012; Tanabe, 2012) are also shown in Fig. 5, but it is not clear from the reverse estimation that the events shown in Fig. 5 mainly caused the atmospheric releases, particularly after 15 March. The estimated values show total release rates from Units 1 to 3.

The major differences of the estimated source term in this study from our previous work (Terada et al., 2012) are described below.

\subsection{Afternoon of 12 March}

In the afternoon of 12 March, the wet venting started at 14:00 and the extreme decrease of the pressure of the primary containment vessel of Unit 1 (PCV-U1) from 14:00 to $15: 00$ indicated atmospheric discharges of radionuclides. The source term estimation for this venting is possible using data from an automatic monitoring post at Kamihatori $(5 \mathrm{~km}$ northwest from FNPS1). The hourly averaged air dose rates increased to $1590 \mu \mathrm{Gy} \mathrm{h}^{-1}$ from $14: 00$ to $15: 00$, and then rapidly decreased (Fig. 6a). The WSPEEDI simulation shows that this high air dose rate was due to the large releases during the wet venting of Unit 1. The estimated release rates were $2.9 \times 10^{15}$ and $2.9 \times 10^{14} \mathrm{~Bq} \mathrm{~h}^{-1}$ for ${ }^{131} \mathrm{I}$ and ${ }^{137} \mathrm{Cs}$, respectively. In Fig. 6a, the red line is the result of the WSPEEDI simulation using the estimated source term. The timing of a peak appearance by the plume arrival and the values of the 
Table 6. Release period, release duration, release rate of total ${ }^{131} \mathrm{I}$, radioactivity ratio of ${ }^{137} \mathrm{Cs} /$ total ${ }^{131} \mathrm{I}$, the ratio of gaseous ${ }^{131} \mathrm{I}$ to total ${ }^{131} \mathrm{I}$, and release height for the period between 05:00 on 12 March and 00:00 on 1 May 2011. Notations of "L" and "O" in the first column represent estimations using land and ocean environmental monitoring data, respectively. In the last column, MP: monitoring post, C: concentration, and AMS: Aerial Measuring System of the US Department of Energy/National Nuclear Security Administration (US DOE/NNSA, 2011).

\begin{tabular}{|c|c|c|c|c|c|c|c|}
\hline No. & $\begin{array}{c}\text { Release period } \\
\text { (Japan standard time) }\end{array}$ & $\begin{array}{c}\text { Release } \\
\text { duration }(\mathrm{h})\end{array}$ & $\begin{array}{l}\text { Release rate of } \\
\text { total }{ }^{131} \mathrm{I}\left(\mathrm{Bq} \mathrm{h}^{-1}\right)\end{array}$ & $\begin{array}{l}{ }^{137} \mathrm{Cs} / \\
\text { total }{ }^{131} \mathrm{I}\end{array}$ & $\begin{array}{l}\text { Gaseous }{ }^{131} \mathrm{I} / \\
\text { total }{ }^{131} \mathrm{I}\end{array}$ & $\begin{array}{l}\text { Release height/ } \\
\text { volume }(\mathrm{m})\end{array}$ & $\begin{array}{l}\text { Monitoring data } \\
\text { for estimation }\end{array}$ \\
\hline 10 & $12 / 305: 00-12 / 309: 30$ & 4.5 & $5.8 \times 10^{13}$ & 0.100 & 0.500 & 20 & Seawater C \\
\hline 20 & $12 / 3$ 09:30-12/3 14:00 & 4.5 & $2.7 \times 10^{13}$ & 0.100 & 0.500 & 20 & Seawater C \\
\hline $3 \mathrm{~L}$ & $12 / 3$ 14:00-12/3 15:00 & 1.0 & $2.9 \times 10^{15}$ & 0.100 & 0.500 & 120 & Kamihatori MP (1 in Table 3 ) \\
\hline 40 & $12 / 3 \quad 15: 00-12 / 315: 30$ & 0.5 & $1.3 \times 10^{13}$ & 0.100 & 0.500 & 20 & Seawater $\mathrm{C}$ \\
\hline $5 \mathrm{~L}$ & $12 / 315: 30-12 / 3 \quad 16: 00$ & 0.5 & $1.4 \times 10^{16}$ & 0.100 & 0.500 & $\begin{array}{c}100 \times 100 \times \\
100^{\mathrm{a}}\end{array}$ & $\begin{array}{l}\text { Shinzan MP } \\
(2 \text { in Table } 3)\end{array}$ \\
\hline 60 & $12 / 3 \quad 16: 00-12 / 322: 00$ & 6.0 & $1.7 \times 10^{14}$ & 0.100 & 0.500 & 120 & Seawater $\mathrm{C}$. \\
\hline 70 & $12 / 322: 00-13 / 304: 00$ & 6.0 & $3.1 \times 10^{14}$ & 0.100 & 0.500 & 120 & Seawater C \\
\hline 80 & 13/3 04:00-13/3 09:00 & 5.0 & $2.2 \times 10^{14}$ & 0.100 & 0.500 & 120 & Seawater C \\
\hline 90 & $13 / 3$ 09:00-13/3 12:30 & 3.5 & $2.6 \times 10^{14}$ & 0.100 & 0.500 & 120 & Seawater C \\
\hline 100 & $13 / 312: 30-13 / 315: 00$ & 2.5 & $5.0 \times 10^{14}$ & 0.100 & 0.500 & 120 & Seawater C \\
\hline 110 & $13 / 315: 00-13 / 323: 00$ & 8.0 & $3.0 \times 10^{14}$ & 0.100 & 0.500 & 120 & Seawater C \\
\hline 120 & $13 / 323: 00-14 / 302: 30$ & 3.5 & $8.2 \times 10^{13}$ & 0.100 & 0.500 & 120 & Seawater C \\
\hline 130 & $14 / 3$ 02:30-14/3 07:00 & 4.5 & $4.4 \times 10^{13}$ & 0.100 & 0.500 & 120 & Seawater C \\
\hline 140 & $14 / 3$ 07:00-14/3 11:00 & 4.0 & $3.5 \times 10^{13}$ & 0.100 & 0.500 & 120 & Seawater C \\
\hline 150 & $14 / 311: 00-14 / 311: 30$ & 0.5 & $3.7 \times 10^{15}$ & 0.100 & 0.500 & $100 \times 100 \times 300^{\mathrm{a}}$ & Seawater C \\
\hline 160 & $14 / 311: 30-14 / 318: 00$ & 6.5 & $1.8 \times 10^{13}$ & 0.100 & 0.500 & 20 & Seawater C \\
\hline 170 & $14 / 3$ 18:00-14/3 19:00 & 1.0 & $1.1 \times 10^{13}$ & 0.100 & 0.500 & 20 & Seawater C \\
\hline 180 & $14 / 3$ 19:00-14/3 20:00 & 1.0 & $1.0 \times 10^{13}$ & 0.100 & 0.500 & 20 & Seawater C \\
\hline 190 & $14 / 320: 00-14 / 321: 00$ & 1.0 & $1.0 \times 10^{13}$ & 0.100 & 0.500 & 20 & Seawater C \\
\hline $20 \mathrm{~L}$ & $14 / 321: 00-14 / 322: 00$ & 1.0 & $2.4 \times 10^{14}$ & 0.066 & 0.500 & 20 & JAEA-Tokai C ( 1 in Table 2$)$ \\
\hline 210 & $14 / 322: 00-14 / 323: 00$ & 1.0 & $1.1 \times 10^{13}$ & 0.100 & 0.500 & 20 & Seawater $\mathrm{C}$ \\
\hline $22 \mathrm{~L}$ & $14 / 323: 00-15 / 300: 00$ & 1.0 & $5.4 \times 10^{14}$ & 0.128 & 0.500 & 20 & JAEA-Tokai C ( 2 in Table 2 ) \\
\hline 230 & 15/3 00:00-15/3 01:00 & 1.0 & $1.3 \times 10^{13}$ & 0.100 & 0.500 & 20 & Seawater $\mathrm{C}$ \\
\hline $24 \mathrm{~L}$ & 15/3 01:00-15/3 02:00 & 1.0 & $2.3 \times 10^{15}$ & 0.167 & 0.500 & 20 & JAEA-Tokai C (3 in Table 2 ) \\
\hline $25 \mathrm{~L}$ & $15 / 302: 00-15 / 303: 00$ & 1.0 & $3.3 \times 10^{14}$ & 0.095 & 0.500 & 20 & JAEA-Tokai C ( 3 in Table 2 ) \\
\hline $26 \mathrm{~L}$ & 15/3 03:00-15/3 04:00 & 1.0 & $2.9 \times 10^{14}$ & 0.125 & 0.500 & 20 & JAEA-Tokai C (3 in Table 2) \\
\hline $27 \mathrm{~L}$ & $15 / 304: 00-15 / 307: 00$ & 3.0 & $1.3 \times 10^{14}$ & 0.100 & 0.500 & 20 & Nasu MP (3 in Table 3 ) \\
\hline $28 \mathrm{~L}$ & 15/3 07:00-15/3 10:00 & 3.0 & $1.2 \times 10^{15}$ & 0.100 & 0.500 & 20 & Koriyama MP (4 in Table 3 ) \\
\hline $29 \mathrm{~L}$ & $15 / 310: 00-15 / 311: 00$ & 1.0 & $1.0 \times 10^{15}$ & 0.100 & 0.500 & 20 & Kawauchi, Ohno, \& Yamada MPs (5 in Table 3 ) \\
\hline $30 \mathrm{~L}$ & 15/3 11:00-15/3 16:00 & 5.0 & $1.0 \times 10^{14}$ & 0.100 & 0.500 & 20 & AMS air dose rate map \\
\hline $31 \mathrm{~L}$ & $15 / 316: 00-15 / 318: 00$ & 2.0 & $3.3 \times 10^{14}$ & 0.100 & 0.500 & $20-120^{\mathrm{b}}$ & Iitate MP (6 in Table 3$)$ \\
\hline $32 \mathrm{~L}$ & $15 / 318: 00-15 / 320: 00$ & 2.0 & $2.2 \times 10^{15}$ & 0.100 & 0.500 & $20-120^{\mathrm{b}}$ & AMS near Kawafusa ( 7 in Table 3 ) \\
\hline $33 \mathrm{~L}$ & $15 / 320: 00-15 / 322: 00$ & 2.0 & $2.3 \times 10^{15}$ & 0.033 & 0.700 & $20-120^{\mathrm{b}}$ & Yamada MP (8 in Table 3$)$ \\
\hline $34 \mathrm{~L}$ & $15 / 322: 00-15 / 323: 00$ & 1.0 & $1.0 \times 10^{16}$ & 0.033 & 0.700 & $20-120^{\mathrm{b}}$ & Ohno MP (9 in Table 3$)$ \\
\hline $35 \mathrm{~L}$ & 15/3 23:00-16/3 00:00 & 1.0 & $2.2 \times 10^{15}$ & 0.033 & 0.700 & $20-120^{\mathrm{b}}$ & Futatsunuma \& Yamadaoka MPs (10 in Table 3 ) \\
\hline $36 \mathrm{~L}$ & 16/3 00:00-16/3 01:00 & 1.0 & $1.6 \times 10^{15}$ & 0.033 & 0.700 & $20-120^{\mathrm{b}}$ & FNPS2 MP (11 in Table 3$)$ \\
\hline 370 & $16 / 3$ 01:00-16/3 06:00 & 5.0 & $2.0 \times 10^{14}$ & 0.033 & 0.700 & $20-120^{\mathrm{b}}$ & Seawater C \\
\hline 380 & $16 / 306: 00-16 / 309: 00$ & 3.0 & $2.0 \times 10^{14}$ & 0.100 & 0.500 & 20 & Seawater C \\
\hline $39 \mathrm{~L}$ & $16 / 3$ 09:00-16/3 11:00 & 2.0 & $2.8 \times 10^{15}$ & 0.100 & 0.500 & 20 & $\begin{array}{l}\text { FNPS2, Futatsunuma } \\
\& \text { Yamadaoka MPs (12 in Table } 3 \text { ) }\end{array}$ \\
\hline 400 & $16 / 311: 00-16 / 312: 00$ & 1.0 & $1.2 \times 10^{14}$ & 0.100 & 0.500 & 20 & Seawater C \\
\hline 410 & $16 / 312: 00-16 / 313: 00$ & 1.0 & $1.5 \times 10^{14}$ & 0.100 & 0.500 & 20 & Seawater C \\
\hline 420 & $16 / 313: 00-16 / 314: 00$ & 1.0 & $2.9 \times 10^{14}$ & 0.100 & 0.500 & 20 & Seawater C \\
\hline 430 & $16 / 314: 00-16 / 315: 00$ & 1.0 & $5.0 \times 10^{14}$ & 0.100 & 0.500 & 20 & Seawater $\mathrm{C}$ \\
\hline 440 & $16 / 315: 00-17 / 306: 00$ & 15.0 & $6.2 \times 10^{14}$ & 0.100 & 0.500 & 20 & Seawater C \\
\hline 450 & $17 / 306: 00-17 / 321: 00$ & 15.0 & $3.1 \times 10^{14}$ & 0.100 & 0.500 & 20 & Seawater $\mathrm{C}$ \\
\hline 460 & $17 / 321: 00-18 / 300: 00$ & 3.0 & $3.0 \times 10^{14}$ & 0.100 & 0.500 & 20 & Seawater C \\
\hline 470 & $18 / 300: 00-18 / 305: 00$ & 5.0 & $2.1 \times 10^{14}$ & 0.100 & 0.500 & 20 & Seawater C \\
\hline 480 & $18 / 305: 00-18 / 308: 00$ & 3.0 & $1.3 \times 10^{15}$ & 0.100 & 0.500 & 20 & Seawater C \\
\hline 490 & $18 / 3$ 08:00-18/3 13:00 & 5.0 & $1.8 \times 10^{15}$ & 0.100 & 0.500 & 20 & Seawater C \\
\hline 500 & $18 / 3$ 13:00-18/3 18:00 & 5.0 & $1.5 \times 10^{15}$ & 0.100 & 0.500 & 20 & Seawater C \\
\hline 510 & $18 / 3$ 18:00-19/3 05:00 & 11.0 & $1.4 \times 10^{15}$ & 0.100 & 0.500 & 20 & Seawater C \\
\hline $52 \mathrm{O}$ & $19 / 3$ 05:00-19/3 15:00 & 10.0 & $1.3 \times 10^{15}$ & 0.100 & 0.500 & 20 & Seawater C \\
\hline $53 \mathrm{~L}$ & 19/3 15:00-21/3 03:00 & 36.0 & $1.6 \times 10^{14}$ & 0.192 & 0.500 & 20 & $\begin{array}{l}\text { MEXT21, } 31,41,46 \\
\text { \& JAEA-Tokai C }(4,6,7,8 \text { \& } 16 \text { in Table } 2)\end{array}$ \\
\hline $54 \mathrm{~L}$ & 21/3 03:00-21/3 08:00 & 5.0 & $1.7 \times 10^{14}$ & 0.242 & 0.486 & 20 & JAEA-Tokai C (5 in Table 2$)$ \\
\hline $55 \mathrm{~L}$ & 21/3 08:00-21/3 12:00 & 4.0 & $4.2 \times 10^{13}$ & $0.125^{\mathrm{c}}$ & 0.658 & 20 & MEXT44 C (9 in Table 2) \\
\hline
\end{tabular}


(a) Kamihatori

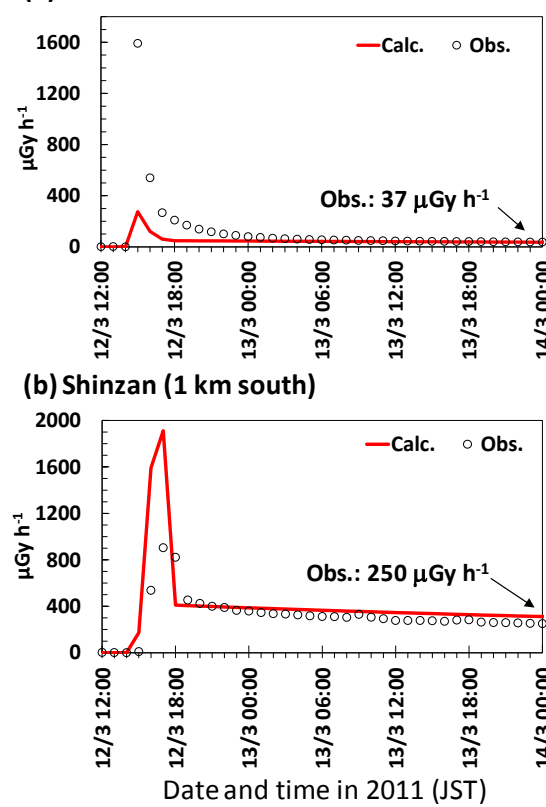

(c)

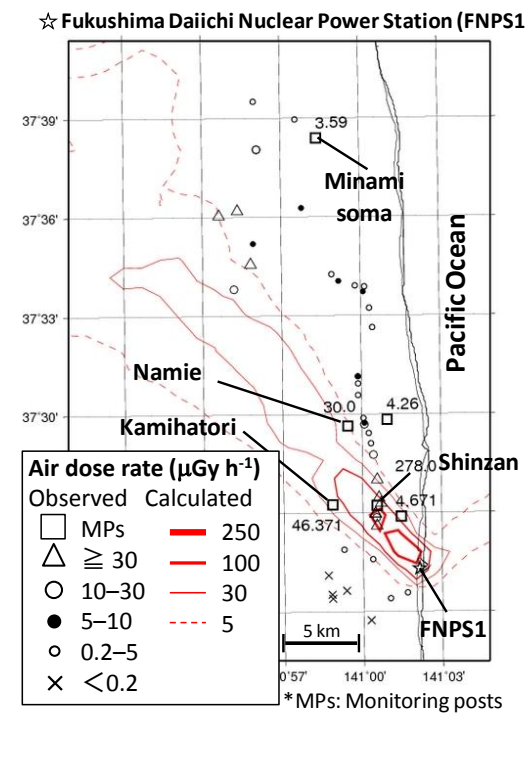

Figure 6. Time series of calculated (solid lines) and observed air dose rates (open circles) at the automated monitoring posts (a) Kamihatori and (b) Shinzan (1 km south of the actual monitoring post of Shinzan), and (c) comparison of the calculated air dose rates at 12:00 on 13 March 2011 in the north-northwest area of the FNPS1 versus measurements from 06:00 to 15:00. In (b), the calculated air dose rate at $1 \mathrm{~km}$ south of Shinzan was compared with the observed one because the principal axis of the calculated plume seemed to be several kilometers further west from that of the observed one.

Table 6. Continued.

\begin{tabular}{|c|c|c|c|c|c|c|c|}
\hline No. & $\begin{array}{l}\text { Release period } \\
\text { (Japan standard time) }\end{array}$ & $\begin{array}{c}\text { Release } \\
\text { duration (h) }\end{array}$ & $\begin{array}{l}\text { Release rate of } \\
\text { total }{ }^{131} \mathrm{I}\left(\mathrm{Bq} \mathrm{h}^{-1}\right)\end{array}$ & $\begin{array}{l}{ }^{137} \mathrm{Cs} / \\
\text { total }{ }^{131} \mathrm{I}\end{array}$ & $\begin{array}{l}\text { Gaseous }{ }^{131} \mathrm{I} / \\
\text { total }{ }^{131} \mathrm{I}\end{array}$ & $\begin{array}{l}\text { Release height/ } \\
\text { volume (m) }\end{array}$ & $\begin{array}{l}\text { Monitoring data } \\
\text { for estimation }\end{array}$ \\
\hline $56 \mathrm{~L}$ & 21/3 12:00-21/3 16:00 & 4.0 & $5.9 \times 10^{13}$ & 0.007 & 0.594 & 20 & MEXT71 C (10 in Table 2) \\
\hline $57 \mathrm{~L}$ & $21 / 316: 00-21 / 321: 00$ & 5.0 & $4.2 \times 10^{13}$ & $0.125^{c}$ & 0.658 & 20 & Assumed same as $55 \mathrm{~L}$ (9 in Table 2 ) \\
\hline $58 \mathrm{~L}$ & $21 / 321: 00-22 / 323: 00$ & 26.0 & $1.6 \times 10^{14}$ & 0.010 & 0.671 & 20 & DOE \& MEXT $71 \mathrm{C}(11 \& 19$ in Table 2$)$ \\
\hline $59 \mathrm{~L}$ & $22 / 323: 00-24 / 300: 00$ & 25.0 & $2.6 \times 10^{14}$ & 0.013 & 0.495 & 20 & MEXT71 C (12 in Table 2) \\
\hline $60 \mathrm{~L}$ & $24 / 300: 00-25 / 300: 00$ & 24.0 & $1.8 \times 10^{13}$ & 0.035 & 0.605 & 20 & MEXT71 \& $80 \mathrm{C}(13 \& 20$ in Table 2$)$ \\
\hline $61 \mathrm{~L}$ & 25/3 00:00-26/3 11:00 & 35.0 & $4.1 \times 10^{13}$ & 0.054 & 0.681 & 20 & MEXT46 \& $71 \mathrm{C}(14 \& 17$ in Table 2$)$ \\
\hline $62 \mathrm{O}$ & $26 / 3$ 11:00-28/3 10:00 & 47.0 & $1.7 \times 10^{13}$ & 0.042 & 0.901 & 20 & Seawater \& MEXTsea8 C (22 in Table 2) \\
\hline $63 \mathrm{O}$ & 28/3 10:00-29/3 21:00 & 35.0 & $3.9 \times 10^{12}$ & 0.781 & 0.927 & 20 & Seawater \& MEXT80 C (21 in Table 2) \\
\hline $64 \mathrm{~L}$ & $29 / 321: 00-30 / 311: 00$ & 14.0 & $9.0 \times 10^{12}$ & 0.621 & 0.544 & 20 & FNPS2 C (23 in Table 2$)$ \\
\hline $65 \mathrm{~L}$ & $30 / 311: 00-31 / 300: 00$ & 13.0 & $5.9 \times 10^{13}$ & 0.833 & 0.688 & 20 & MEXT46 \& $61 \mathrm{C}(18 \& 24$ in Table 2$)$ \\
\hline 660 & $31 / 300: 00-31 / 322: 00$ & 22.0 & $1.4 \times 10^{13}$ & 0.186 & 0.707 & 20 & Seawater \& MEXT71 C (15 in Table 2$)$ \\
\hline 670 & $31 / 322: 00-2 / 4$ 09:00 & 35.0 & $9.2 \times 10^{11}$ & 0.970 & 0.933 & 20 & Seawater \& MEXT61 C (25 in Table 2) \\
\hline $68 \mathrm{~L}$ & 2/4 09:00-4/4 09:00 & 48.0 & $1.0 \times 10^{13}$ & 0.323 & 0.894 & 20 & Seawater $\mathrm{C}$ \\
\hline $69 \mathrm{~L}$ & 4/4 09:00-7/4 17:00 & 80.0 & $3.9 \times 10^{12}$ & 0.204 & 0.894 & 20 & Seawater C \\
\hline $70 \mathrm{~L}$ & $7 / 4$ 17:00-13/4 23:00 & 150.0 & $7.0 \times 10^{11}$ & 0.500 & 0.948 & 20 & Terada et al. (2012) \\
\hline $71 \mathrm{~L}$ & 13/4 23:00-1/5 00:00 & 409.0 & $7.0 \times 10^{11}$ & 0.257 & 0.948 & 20 & Terada et al. (2012) \\
\hline
\end{tabular}

a Volume sources were assumed to be the hydrogen explosions at Units 1 and 3 (Katata et al., 2012b). The three values indicate the source volume dimension in the directions $x, y$, and $z$. The source center height are 50 and $150 \mathrm{~m}$ above the ground level for nos. $5 \mathrm{~L}$ and $15 \mathrm{O}$, respectively.

$\mathrm{b}$ The situations of both leakage from the primary containment vessel (PCV) and venting at the top of stack with 20 and $120 \mathrm{~m}$ height were assumed

${ }^{\mathrm{c}}$ Interpolated from the ratios of $55 \mathrm{~L}$ and $57 \mathrm{~L}$ due to lack of the data of ${ }^{137} \mathrm{Cs}$.

ground-shine shown as a slow decrease in air dose rates after the peak agreed well with the observation. This shows that the source term estimated from the ground-shine is appropriate. The temporal variation of air dose rates every $10 \mathrm{~min}$ at Kamihatori (Fukushima Prefecture, 2012) shows that high dose rates continued for approximately $1 \mathrm{~h}$. This means the release period of $1 \mathrm{~h}$ determined from the decrease of DW pressure is appropriate.

The hydrogen explosion of Unit 1 at 15:36 also discharged a huge amount of radionuclides into the atmosphere. According to the WSPEEDI simulation, the radioactive plume flowed toward the north-northwest, which drastically increased the air dose rates at automatic monitoring posts of 
Shinzan (3.9 km north-northwest) and Namie (8.6 km northnorthwest), and Kiyohashi ( $8.2 \mathrm{~km}$ north) and Minamisoma $(24.9 \mathrm{~km}$ north-northwest) in Fukushima Prefecture from 17:00 and 20:00, respectively. In our previous work (Katata et al., 2012b), the source term for this hydrogen explosion was estimated by using air dose rates measured by portable monitors on 13 March. However, the measurement was done by a $\mathrm{NaI}(\mathrm{Tl})$ scintillation counter limited to measuring only up to $30 \mu \mathrm{Gy} \mathrm{h}^{-1}$ and, as a result, only the edge of the deposition area could be measured. Thus, in this study, we used the additional data using the ionization chamber at Shinzan, located along the contamination band after the hydrogen explosion. The estimated release rates from 15:30 to 16:00 were $1.4 \times 10^{16}$ and $1.4 \times 10^{15} \mathrm{~Bq} \mathrm{~h}^{-1}$ for ${ }^{131} \mathrm{I}$ and ${ }^{137} \mathrm{Cs}$, respectively. In Fig. 6b, the red line of the WSPEEDI simulation also agreed with the observed peak appearance and groundshine. These increases of air dose rates due to the hydrogen explosion were also observed by airborne survey within $5 \mathrm{~km}$ from FNPS1 (Fig. 7), which showed the narrow contamination band to the north-northwest direction of FNPS1 in both air dose rate and ${ }^{137} \mathrm{Cs}$ deposition. Since large increases of air dose rates were not recorded in the areas in the north-northwest to north directions of FNPS1 after 13 March, this contamination band over the monitoring post of Shinzan must have been due to the dry deposition of radionuclides discharged during the hydrogen explosion. Figure 6c compares the distribution of air dose rates in the daytime of March 13 between the WSPEEDI simulation and observations by the portable monitors as mentioned above. While the calculated result is slightly shifted to the west due to the delay of the wind shift comparing with observed wind shift, both results show a similar distribution pattern of the groundshine. The contamination band was narrow despite the fact that wind direction data at FNPS1 (TEPCO, 2011b) rapidly changed in a clockwise direction during that period. This indicates that the major release due to hydrogen explosion was instantaneous.

\subsection{March to the evening of 14 March}

Venting operations were conducted to decrease the pressure of PCV-U3 at 09:24 and 12:30 on 13 March. The WSPEEDI simulation shows that the plume almost flowed toward the ocean in this period. According to the simulation, although the plume sometimes flowed over the coastline of Fukushima Prefecture or stagnated around FNPS1 due to calm conditions, only a very small number of monitoring posts near the coast caught the movement of the plume (Fukushima Prefecture, 2012). The estimation result shows that the large releases due to wet venting continued until 23:00 on 13 March on the order of $10^{14}$ and $10^{13} \mathrm{~Bq} \mathrm{~h}^{-1}$ for ${ }^{131} \mathrm{I}$ and ${ }^{137} \mathrm{Cs}$, respectively.

Despite several venting operations at Unit 3 on 13 and 14 March, a hydrogen explosion occurred at Unit 3 at 11:01 on 14 March (Fig. 5). In previous work, the source term for this

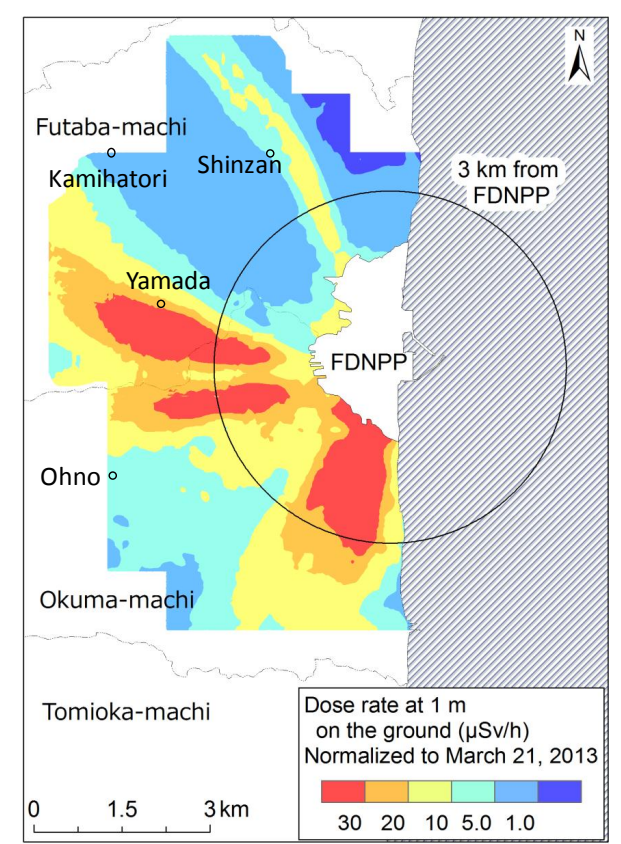

Figure 7. Spatial distributions of the air dose rate within the $5 \mathrm{~km}$ area around FNPS1 observed by airborne survey from 28 January to 20 March 2013 (Sanada and Torii, 2015).

hydrogen explosion was just assumed as same as that of the explosion at Unit 1 on 12 March because the wind blew toward the Pacific Ocean and no measurement data were available. In this study, we could estimate it using the sea-water concentration data over the ocean. According to our estimation, the release rates of ${ }^{131} \mathrm{I}$ and ${ }^{137} \mathrm{Cs}$ were $3.7 \times 10^{15}$ and $3.7 \times 10^{14} \mathrm{~Bq} \mathrm{~h}^{-1}$ for about 30 min, respectively, which are slightly smaller than those of the hydrogen explosion at Unit 1 (Sect. 3.1). Here, the release period is still assumed as same as the explosion at Unit 1.

\subsection{Night of 14 March to the early morning of 15 March}

Figure $8 \mathrm{a}$ and $\mathrm{b}$ depict the time evolutions of the pressure of the reactor pressure vessel (RPV) at Unit 2, air dose rates, and air concentrations measured at the south area of FNPS1. During this period, dry venting was tried at Unit 2, but it is not clear if the venting succeeded. The safety relief valve (SRV) was also opened at 21:00 and 23:00 on 14 March and at 01:00 on 15 March to decrease the pressure of RPV and, as a result, the pressure decreased after these operations (Fig. 8a). If a meltdown had already occurred in Unit 2, the vapor containing radionuclides would flow to the PCV and raise the possibility of atmospheric releases with the operation of SRV. In this period, the WSPEEDI simulation shows that the plume flowed toward the south to south-southwest and the observed air dose rates at FNPS2 (11.4 km south) and Kitaibaraki ( $80 \mathrm{~km}$ south), and air concentrations of ${ }^{131} \mathrm{I}$ 


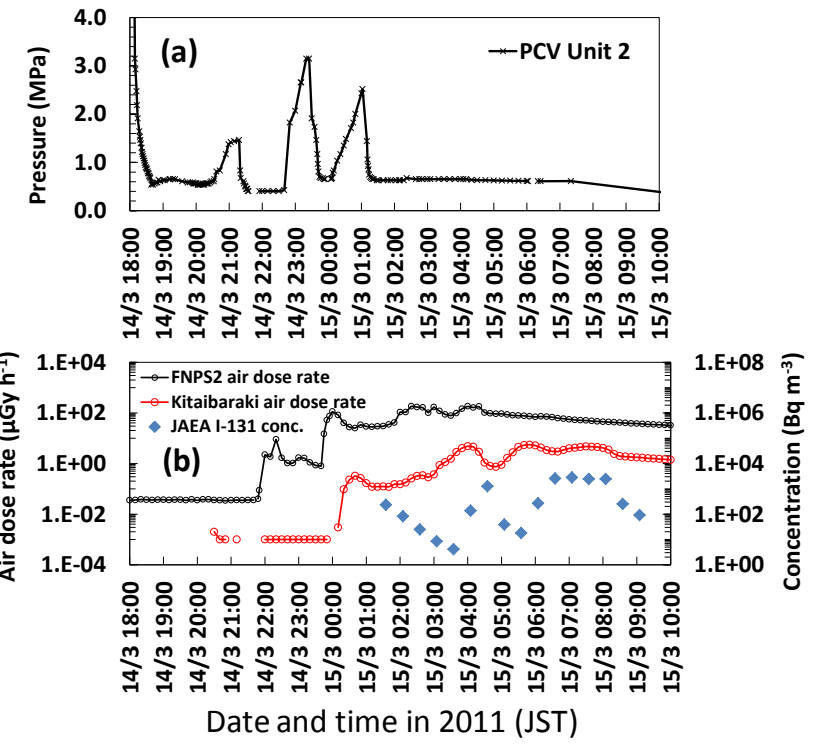

Figure 8. Temporal changes in measurements of (a) the pressure of the reactor pressure vessel (RPV) at Unit 2 of FNPS1, and (b) the air dose rates and total ${ }^{131}$ I concentration at several monitoring posts and JAEA-Tokai, respectively, from 14 to 15 March. The locations of the monitoring posts are depicted in Fig. 2.

and ${ }^{137}$ Cs measured at JAEA-Tokai (100 km south) showed three increases with time (Fig. 8b). Based upon the downwind distances from FNPS1 and the wind speed data, the time of the peak appearances at these three monitoring points are reasonably explained by the releases when the SRV was opened (Fig. 8a and b). In our source term estimation, the release rates in this period gradually increased with time from $2.4 \times 10^{14}$ to $2.3 \times 10^{15} \mathrm{~Bq} \mathrm{~h}^{-1}$ and from $1.6 \times 10^{13}$ to $3.9 \times 10^{14} \mathrm{~Bq} \mathrm{~h}^{-1}$ for ${ }^{131} \mathrm{I}$ and ${ }^{137} \mathrm{Cs}$, respectively. In previous work, the source term for this period was almost constant in time. In this study, the detailed source term in time is estimated based on the detailed analysis of the relation between the incident in the reactor and temporal variation of environmental data. These results indicate that the three times major releases in our source term estimation occurred due to SRV openings.

\subsection{Morning of 15 March to the early morning of 16 March}

Figure $9 \mathrm{a}$ and $\mathrm{b}$ show the temporal change of the DW pressure at Units 2 and 3 and air dose rates observed at automatic monitoring posts around the plant. Temporal variations of the vertically accumulated air concentration and precipitation bands in the WSPEEDI simulation are shown in Fig. 10.

On the morning of 15 March, the pressure of PCV-U2 decreased between 07:00 and 12:00. This decrease corresponded with the extreme increase of air dose rate (peak approximately $1.5 \times 10^{4} \mu \mathrm{Gy} \mathrm{h}^{-1}$ ) observed at the main gate from 07:00 to 10:00, clearly indicating a huge release into

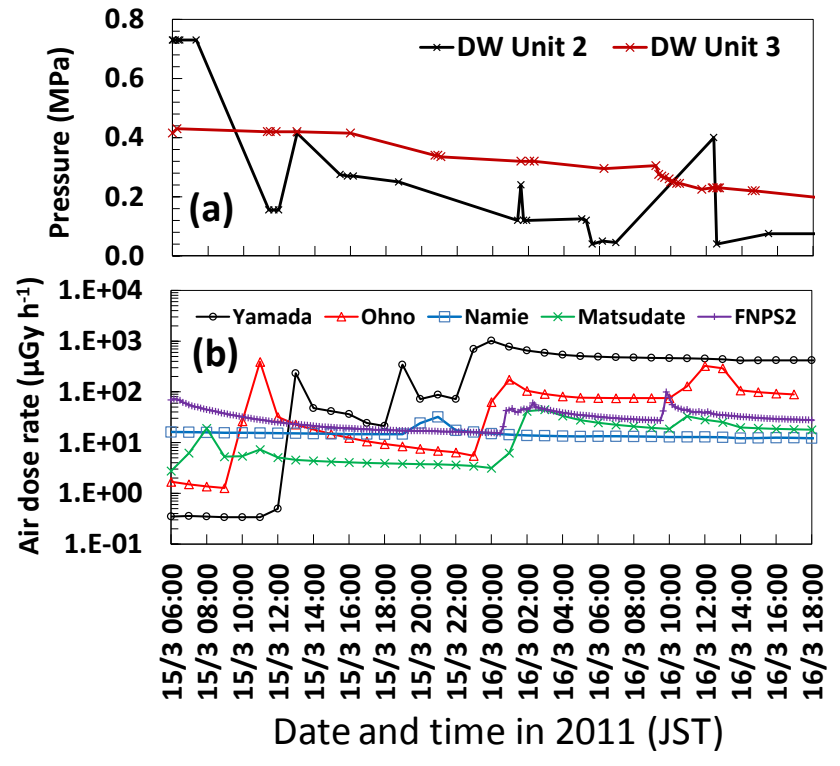

Figure 9. Temporal changes in measurements of (a) the pressures of the drywell (DW) at Units 2 and 3 of FNPS1, and (b) the air dose rates at several monitoring posts from 15 to 16 March 2011. The locations of the monitoring posts are depicted in Fig. 2.

the atmosphere. According to the WSPEEDI simulation, the plume discharged in the morning first flowed toward the south-southwest and then gradually changed direction clockwise. Around the area of FNPS1, the observed air dose rates was still 41 and $19 \mu \mathrm{Gy} \mathrm{h}^{-1}$ at the two monitoring posts of Yonomori (7.3 km south-southwest) and Matsudate (14.2 km south-southwest) at 07:00 on 15 March, respectively. Subsequently the following monitoring points detected higher air dose rates: $390 \mu \mathrm{Gy} \mathrm{h}^{-1}$ at Ohno (4.9 km west-southwest) at 11:00, and $232 \mu \mathrm{Gy} \mathrm{h}^{-1}$ at Yamada (4.1 km west-northwest) at 13:00 (Fig. 9b). The WSPEEDI simulation shows these high air dose rates were due to this huge amount of release in the morning (Fig. 10a). Furthermore, the WSPEEDI simulation shows the plume discharged in the morning encountered a rain band along the Nakadori including Koriyama $(58 \mathrm{~km} \mathrm{~W})$ and Shirakawa (81 km WSW) (Fig. 10a) and the north and northwest areas of FNPS1 including Fukushima $(62.7 \mathrm{~km} \mathrm{NW})$ and Iitate $(38.9 \mathrm{~km} \mathrm{NW})$ in the afternoon (Fig. 10b). The release rate from 07:00 to $11: 00$ is estimated on the order of $10^{15}$ and $10^{14} \mathrm{~Bq} \mathrm{~h}^{-1}$ for ${ }^{131} \mathrm{I}$ and ${ }^{137} \mathrm{Cs}$, respectively. The air dose rate map from groundshine observed by the airborne survey of 17-19 March (US DOE/NNSA, 2011) is shown in Fig. 11a. This figure shows that the high dose rate zone due to dry deposition to the southwest is narrow, suggesting that the period of the large release in the morning did not continue for a long time.

After the major release on the morning of 15 March, the pressure of the DW at Unit 2 decreased continuously from the afternoon to the evening (Fig. 9a). According to the WSPEEDI simulation, a southeasterly wind transported 
(a) 6:00-12:00 on 15 Mar.

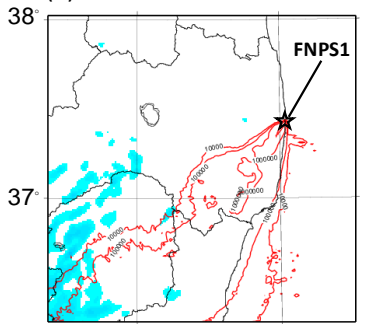

(c) 18:00-24:00 on 15 Mar.

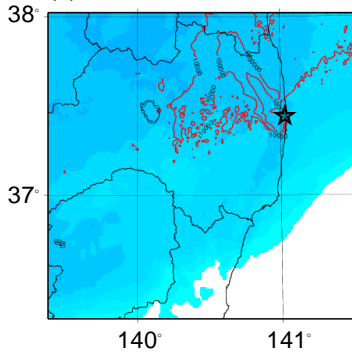

(b) 12:00-18:00 on 15 Mar.

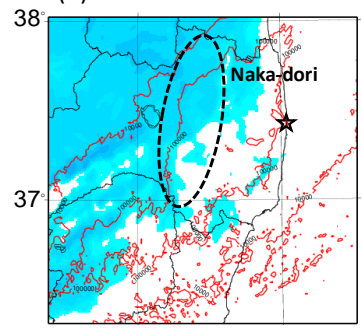

(d) 0:00-6:00 on 16 Mar.

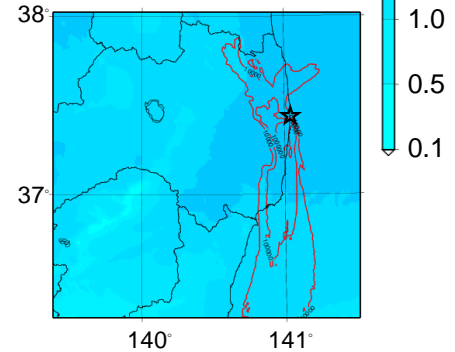

Figure 10. Spatial distributions of the vertical cumulative air concentration of ${ }^{137} \mathrm{Cs}\left(\mathrm{Bq} \mathrm{m}^{-3}\right.$, red contour lines) and precipitation amount (mm, shaded areas) accumulated at ((a) 06:00-12:00 on 15 March, (b) 12:00-18:00 on 15 March, (c) 18:00-24:00 on 15 March, and (d) 0:00-6:00 on 16 March calculated by WSPEEDI-II using the new source term. The dashed ellipse in (b) represents the Nakadori area in Fukushima Prefecture (Sect. 3.4).

radionuclides emitted during this period toward litate and Fukushima directly and resulted in wet deposition to the northwest of the plant, as discussed in Katata et al. (2012a). However, by our estimates, the release rates are not as high during the morning releases (Table 6). This result is different from our previous study (Katata et al., 2012a), in which a large amount of release was estimated during the period from 13:00 to 17:00. Due to an increase of the wet scavenging coefficient in the modified deposition scheme (Fig. A2b), the calculated air dose rates due to wet deposition of the plume released during the morning can almost represent the measured ones at Iitate and Fukushima without the additional deposition from the plume released in the afternoon (Sect. 4.1.1, Fig. 12). Figure 12 shows temporal changes in the air dose rate in Fukushima Prefecture from 15 to 20 March. The measured air dose rates at Fukushima and Iitate areas (Fig. 12c and d) also show that a large increase in the air dose rates did not appear at two points. Afterward, the air dose rates largely increased around 13:00-14:00 on 15 March (Fig. 12). One possible reason that a large increase did not appear at the two monitoring points might be that most of the radionuclides deposited before the air mass arrived there. However, rain bands coming from the northwest during the afternoon of 15 March caused precipitation around Iitate area from 16:00 with a very small intensity of approximately $1 \mathrm{~mm} \mathrm{~h}^{-1}$ (Fig. S1). Moreover, Ohno (4.9 km WSW from the site) had no rainfall until the night (Fig. S1). These facts suggest that the plume discharged in the afternoon should

produce lower amounts of (dry) deposition along the pathway from the FNPS1 to the northwest direction. Therefore, the plume could have reached Iitate and an increase in the air dose rate due to wet deposition could have occurred if a large amount of radionuclides were discharged during the afternoon.

The second huge increase of the release rate was estimated during the period from 18:00 of 15 March to 01:00 of 16 March with the maximum values from 22:00 to 23:00 on 15 March of $1.0 \times 10^{16}$ and $3.4 \times 10^{14} \mathrm{~Bq} \mathrm{~h}^{-1}$ for ${ }^{131} \mathrm{I}$ and ${ }^{137} \mathrm{Cs}$. During the evening of $15 \mathrm{March}$, wet venting was conducted at Unit 3, corresponding to the decline in DW pressure at Unit 3 from 16:05 (Fig. 9a). Afterward, wet venting was carried out at Unit 3 several times, and the decline in DW pressure finally stopped around 06:00 on 16 March. At the same time, the DW pressure dropped steeply at Unit 2 from 18:00 on 15 March to 2:00 on 16 March. These facts imply that the large release rate estimated during the evening originated from Units 2 and 3. The WSPEEDI simulation shows that, after the plume flowed clockwise from the west to northwest direction in the afternoon, it reached Namie $(8.6 \mathrm{~km}$ north-northwest) at 21:00 on 15 March, and then the flow direction switched to counterclockwise. At midnight on 15 March, the wind direction was from the east and the rain band approached FNPS1 from the northwest (Fig. 10c and d), suggested by both the WSPEEDI simulations and the meteorological data at Ohno (Fig. S1). Furthermore, the air dose rates observed at monitoring posts on 16 March drastically increased to $1020 \mu \mathrm{Gy} \mathrm{h}^{-1}$ at Yamada at 00:00, $173 \mu \mathrm{Gy} \mathrm{h}$ at Ono at 01:00, and $44.5 \mu \mathrm{Gy} \mathrm{h}^{-1}$ at Matsudate at 03:00 (Fig. 9b). Thus, the release in the night on 15 March is considered to have created the highest dose rate zone in the western area close to FNPS1 between Yamada and Ohno, as shown by $5 \mathrm{~km}$ airborne survey (Fig. 7). At these locations, decreases of air dose rates after the passage of the plume were small (Fig. 9b), indicating that this high dose rate zone was created by wet deposition. The $5 \mathrm{~km}$ airborne survey showed two clear highly contaminated bands to the west of FNPS1 between Yamada and Ohno. This indicates the shortterm variation in release rates during the period, while the temporal and spatial resolutions of the WSPEEDI simulation are not sufficiently fine to resolve these bands completely.

Our results of the source term estimation and the WSPEEDI simulation from 15 to 16 March reveal that the highest contamination areas around the FNPS1 were not continuous but consisted of two parts; i.e., the northwest contamination area extended a great distance, mainly created by the release on the morning of 15 March, and the west and west-southwest areas near the site contaminated by the highly concentration plume discharged during the night of 15 March (Fig. S3). This conclusion is also supported by the $5 \mathrm{~km}$ airborne survey (Fig. 7) showing the contamination areas near the site distributed not to the northwest direction but the west-northwest and west directions of FNPS1. Although the contamination areas around the FNPS1 are known to have 
(a) Total air dose rate observed from 17-19 March 2011

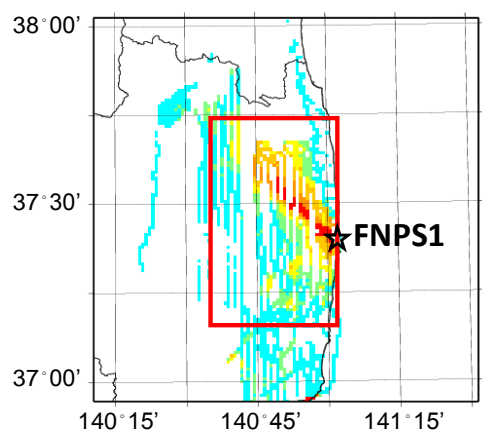

(d) Total air dose rate at 21:00 on 18 March

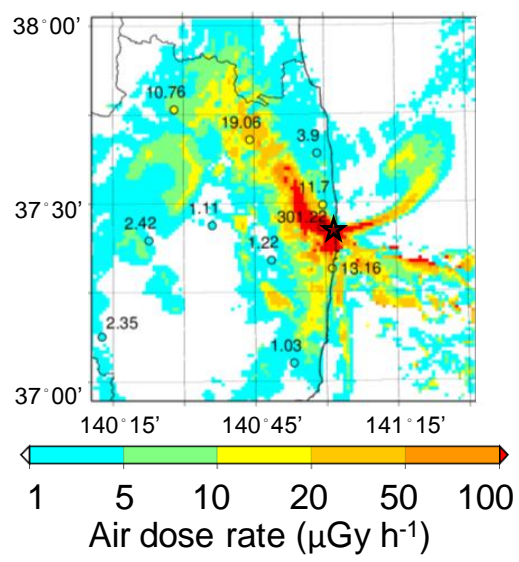

(b) ${ }^{137}$ Cs deposition observed on 31 May 2012

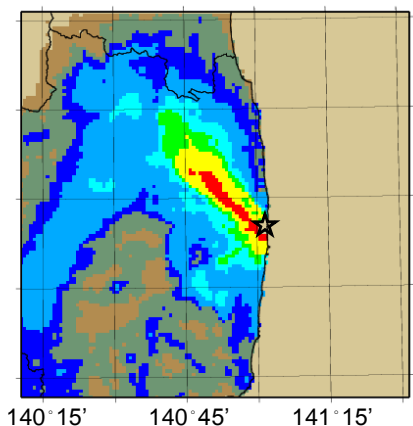

(e) ${ }^{137}$ Cs deposition at 0:00 on 1 April

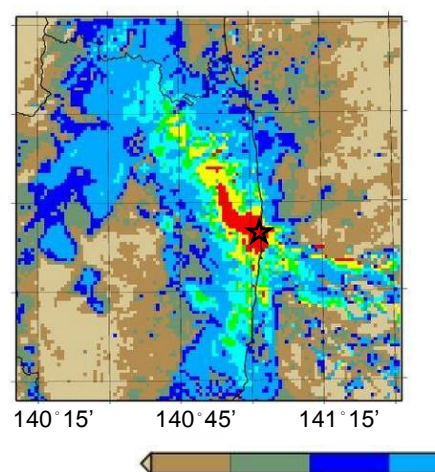

(c) Total ${ }^{131}$ I deposition observed on 1 April 2011

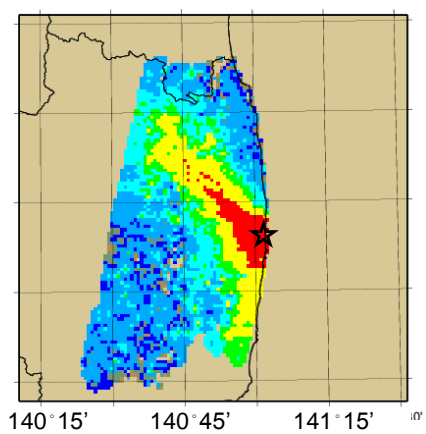

(f) Total ${ }^{131}$ I deposition at 0:00 on 1 April

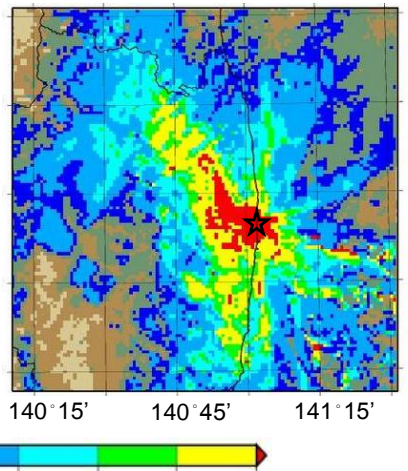

$10 \quad 30 \quad 60 \quad 100 \quad 300 \quad 60010003000$ Deposition ( $\mathrm{kBq} \mathrm{m}^{-2}$ )

Figure 11. Spatial distributions of (a, d) air dose rates (US DOE/NNSA, 2011), (b, e) ${ }^{137}$ Cs deposition (NRA, 2012a), and (c, f) total ${ }^{131}$ I deposition (Torii et al., 2013) comparing (a, c) the measurements and (d, f) calculations using the modified WSPEEDI-II with the new source term for Domain 3. The red-colored square in (a) represents the area compared with calculation results in Fig. 16d. Values and colors of circles in (d) represent observed air dose rates at monitoring posts with a minimum significant digit of 0.01 .

been created on 15-16 March by wet deposition as concluded in Chino et al. (2011), Katata et al. (2012a), and later studies (Mathieu et al., 2012; Srinvas et al., 2012; Korsakissok et al., 2013; Morino et al., 2013; Winiarek et al., 2014), our results indicate that the formation processes were quite complicated and the above two contaminated areas, in different directions from FNPS1, were created at different time periods.

Figure $11 \mathrm{~b}$ and $\mathrm{c}$ show the deposition distributions of ${ }^{131} \mathrm{I}$ and ${ }^{137} \mathrm{Cs}$ in the area within $80 \mathrm{~km}$ from FNPS1 observed by the airborne survey. The figures show that the distribution patterns of both radionuclides are slightly different, e.g., the large deposition area of ${ }^{137} \mathrm{Cs}$ is limited to the narrow band to the northwest and south directions, while that of ${ }^{131} \mathrm{I}$ is distributed toward the west and southwest areas within $10 \mathrm{~km}$ from FNPS1. As discussed above, according to the WSPEEDI simulation, the major deposition in the west and southwest areas was probably created by wet deposition of the highly concentration plume released during the night of 15 March when the rain band overlapped with the plume.
The WSPEEDI simulation also shows that this plume gradually flowed to the south of FNPS1 and reached JAEA-Tokai on the morning of 16 March (Fig. 10d). As described in Sect. 2.3.3, the ratio of ${ }^{131} \mathrm{I} /{ }^{137} \mathrm{Cs}=60$ sampled at JAEATokai on the morning of 16 March was clearly higher than that of ${ }^{131} \mathrm{I} /{ }^{137} \mathrm{Cs}=7.7$ on 15 March (Ohkura et al., 2012). Although this ratio at the release point decreased to 30 on the morning of 16 March in the WSPEEDI simulation due to the difference of deposition processes of iodine and cesium in the environment, it can still be concluded that the highly concentration plume discharged in the night was iodine-rich, resulting in the large deposition of ${ }^{131} \mathrm{I}$ near the plant compared with that of ${ }^{137} \mathrm{Cs}$. One possible reason for the change in the ratio of ${ }^{131} \mathrm{I} /{ }^{137} \mathrm{Cs}$ at JAEA-Tokai from 15 and 16 March is that, according DW pressure data (Fig. 9a), the source was from Unit 2 on the morning of 15 March and Units 2 and 3 on the night of 15 March to the early morning of 16 March. 


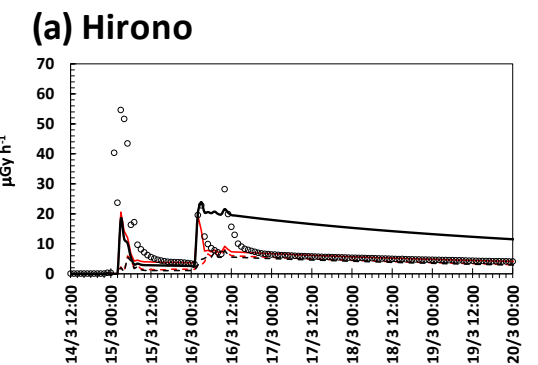

\section{(b) Kawauchi}

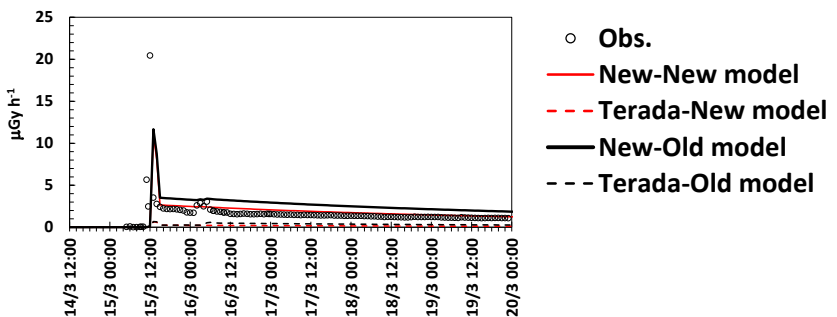

\section{(c) Fukushima}

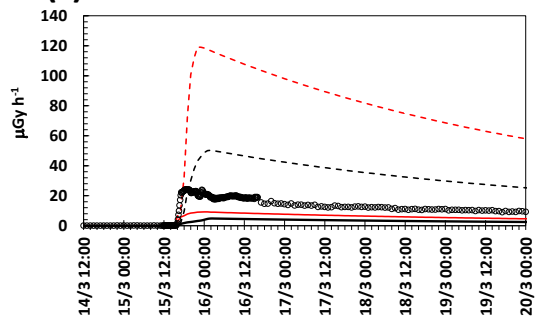

\section{(d) litate}

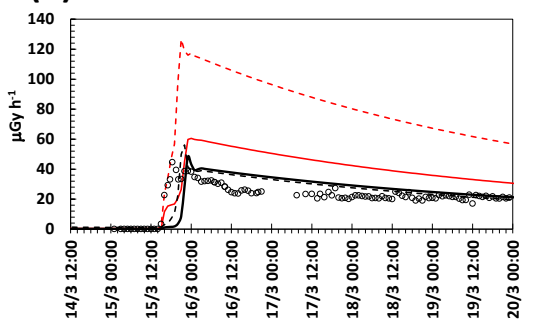

\section{(e) Kawafusa (NW of FNPS1)}
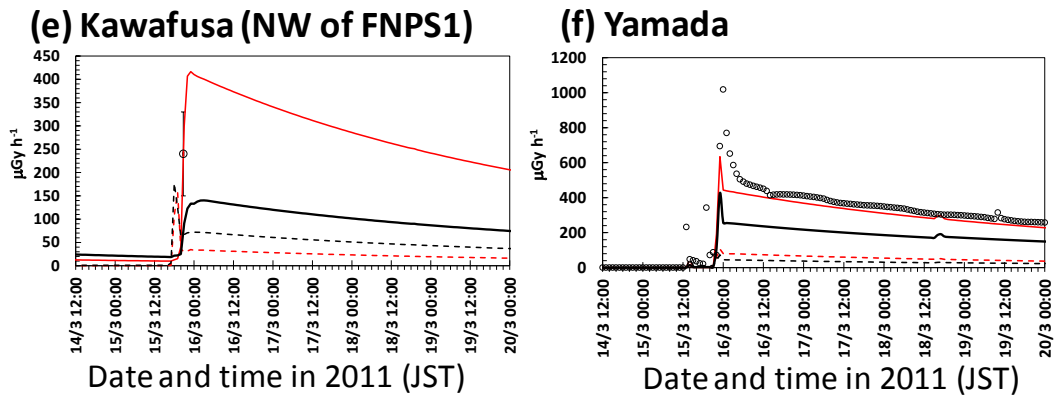

Figure 12. Temporal changes in the air dose rates in Fukushima Prefecture from 15 to 16 March 2011 in the four simulations using original and modified WSPEEDI-II (referred as "Old model" and "New model", respectively) and Terada at al. (2012) and the new source terms (referred as "Terada" and "New", respectively). Locations of the monitoring points are shown in Fig. 2. The error bar with observational data in (e) represents the range of values measured by Geiger-Müller survey meters and ionization chambers at three locations from 20:40 to 20:50 on 15 March (MEXT, 2011).

\subsection{Morning to noon of 16 March}

In this period, the pressure decrease was reported at Unit 3 from 09:00 to 11:00 (Fig. 9a). In addition, the white smoke from the building of Unit 3 was also observed at 08:30 on 16 March (TEPCO, 2012). The WSPEEDI simulation shows that the plume released during the decrease of the DW pressure flowed toward the Pacific Ocean in the morning, and then it returned to the inland around noon. This movement of plume probably caused large increases of air dose rates to 33 and $324 \mu \mathrm{Gy} \mathrm{h}^{-1}$ at Matsudate and Ohno at 11:00 and 12:00 on 16 March, respectively (Fig. 9b). In this study, the data from Ohno was used for the source term estimation. The estimated release rate increased to $2.8 \times 10^{15}$ and $2.8 \times 10^{14} \mathrm{~Bq} \mathrm{~h}^{-1}$ for ${ }^{131} \mathrm{I}$ and ${ }^{137} \mathrm{Cs}$, respectively.

\section{Discussion}

\subsection{Verification of source term}

In this section, we first tested the new source terms for ${ }^{137} \mathrm{Cs}$ and ${ }^{131}$ I with the modified WSPEEDI-II and compared the results over local and regional scales to the airborne survey's surface deposition and air dose rate data. These comparisons were made between four simulation cases with combinations of original or modified WSPEEDI-II and the source term from this study or Terada et al. (2012). Then, the new source term was further tested using different atmospheric dispersion and meteorological models over regional and global scales to evaluate its reliability for general atmospheric dispersion model studies during the FNPS1 accident. 


\subsubsection{Validation using WSPEEDI-II}

\subsubsection{Air dose rate at ground monitoring points}

Figure 12 shows the temporal changes in the air dose rates from four simulations at selected monitoring points in Fukushima Prefecture from 15 to 19 March. By using the new source term, the calculated ground-shine shown as slow slope after the peak due to the large deposition event of 1516 March agreed with observed data within a factor of 2 at most of the monitoring points. At Hirono (21.4 km south) and Kawauchi (22 km west-southwest) (Fig. 12a and b), affected by dry deposition from the night of 14 March to the morning of 15 March, respectively (Sects. 3.3 and 3.4), observed air dose rates were reproduced by using the new source term. A similar improvement of the simulation results when using the new source term can be found in the dry deposition during the afternoon of 12 March (Fig. 6a and b). These results indicate that the use of additional monitoring data near the plant (Fukushima Prefecture, 2012) in the new source term is needed to reproduce the ground-shine due to dry deposition during the FNPS 1 accident.

Increases of ground-shine at Fukushima $(63 \mathrm{~km}$ northwest) and Iitate (39 km northwest) (Fig. 12c and d) were not perfectly reproduced using any combination of models and source terms. Since both sites were affected by wet deposition in the afternoon of 15 March (Sect. 3.4), uncertainties of the source term and wet deposition scheme still remain during the afternoon of 15 March. Nevertheless, the calculated ground-shine at both sites agreed better with observed one when using the new source term. Moreover, the increase of air dose rate around 14:00 on 15 March was accurately reproduced in the modified WSPEEDI-II simulation due to higher scavenging coefficient in the new deposition scheme (Fig. A2b). The greatest ground-shine was observed at Kawafusa $(20 \mathrm{~km}$ northwest) and Yamada $(4.1 \mathrm{~km}$ westnorthwest) from the evening to the midnight of 15 March due to wet deposition. The high doses at both sites were accurately reproduced by the modified WSPEEDI-II simulation with the new source term (Fig. 12f), while the doses were clearly underestimated in all other combinations. Therefore, both revision of the source term and the wet deposition scheme play an important role in this period.

\subsubsection{Regional deposition of ${ }^{137}$ Cs over eastern Japan}

Figure 13 illustrates the regional deposition of ${ }^{137} \mathrm{Cs}$ by combinations of original and modified WSPEEDI-II and the two source terms. The original WSPEEDI-II simulation using the source term of Terada et al. (2012) showed some disagreement in the surface deposition of ${ }^{137} \mathrm{Cs}$ between observations from the airborne survey (Fig. 13e) and the calculations at several areas over eastern Japan (Fig. 13a). When using the new source term, as shown in Fig. 13b, this issue was slightly resolved in the original WSPEEDI simulation; the overestimation of surface deposition from the north part of Fukushima Prefecture to Miyagi Prefecture partially disappeared. The modified WSPEEDI-II using the source term of Terada et al. (2012) is also effective in eliminating the overestimation in this region (Fig. 13c). Furthermore, the modified model reproduced the contaminated areas observed in the airborne survey in Tochigi and Gunma Prefectures and Nakadori in the middle of Fukushima Prefecture. These results indicates that the modification of the wet deposition scheme is more effective in the regional-scale simulation than the new source term. Uncertainties of rainfall (Fig. S1) and wet deposition in the above regions and Kanto area in the modified WSPEEDI-II simulations are discussed in the Supplement, and should be analyzed in more detail in the future. Finally, the best performance for deposition pattern was obtained in the modified WSPEEDI-II simulation with the new source term (Fig. 13d). These results show that the enhancement of the scavenging coefficient in the modified wet deposition scheme (Fig. A2b) plays an important role in the improvement of the regional-scale simulations that are mainly characterized by wet deposition.

\subsubsection{Local depositions of ${ }^{131} \mathrm{I},{ }^{137} \mathrm{Cs}$, and air dose rates over Fukushima Prefecture}

Figure 11d-f show the spatial distributions of the air dose rate and cumulative surface deposition of ${ }^{137} \mathrm{Cs}$ and ${ }^{131} \mathrm{I}$ around FNPS1 calculated by the modified WSPEEDI-II using the new source term. Comparisons of these figures with the observations (Fig. 11a-c) show that the model reproduced the deposition patterns of each radionuclide; i.e., the large deposition area of ${ }^{137} \mathrm{Cs}$ is limited to the northwest direction of FNPS1 compared with that of ${ }^{131}$ I which has a larger southern component. The improvements resulting from both the revisions of WSPEEDI-II and the source term become apparent when comparing four simulation cases of surface deposition (Figs. 14 and 15). The two calculations using the source term of Terada et al. (2012) (Fig. 14a and c) showed a large overestimation of ${ }^{137} \mathrm{Cs}$ deposition near Fukushima (63 km northwest). This overprediction is reduced by calculations using the new source term because of a decrease of release rate in the afternoon of 15 March (Fig. 14c). However, the highest contaminated zone to the northwest of FNPS1 was still significantly underestimated in all three cases (Fig. 14a-c). This underprediction was reduced using the modified WSPEEDI-II and the new source term (Fig. 14d) due to higher scavenging coefficient of ${ }^{137} \mathrm{Cs}$ in the new deposition scheme (Fig. A2b). Thus, both revisions of the deposition scheme and the source term are required for more accurate simulation of the ${ }^{137} \mathrm{Cs}$ deposition.

In the ${ }^{131} \mathrm{I}$ deposition simulations using the original WSPEEDI-II (Fig. 15a, b), the highly contaminated areas spread to the west of FNPS1 more broadly as indicated by the airborne observations (Fig. 11c). These results suggests that the new source term, which increases in the ratio of ${ }^{131} \mathrm{I}$ 
(a) Terada-Old model

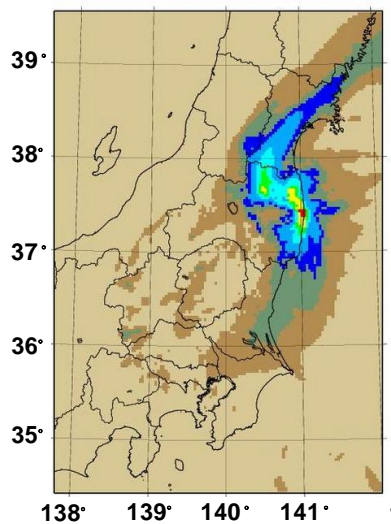

(b) New-Old model

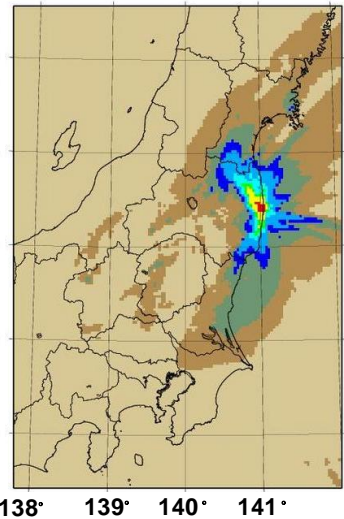

(c) Terada-New model

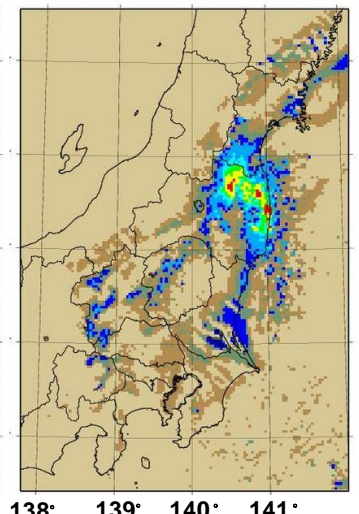

(d) New-New model

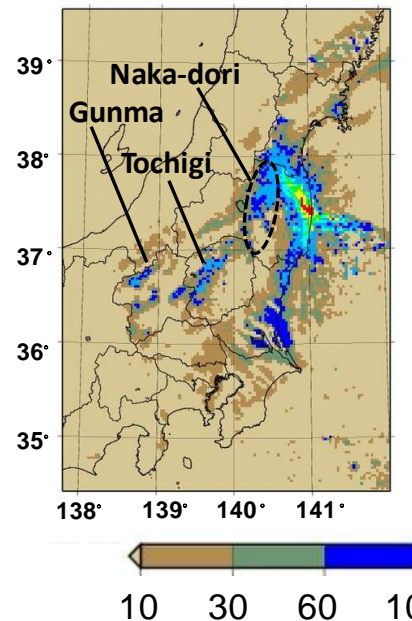

(e) Observation on 31 May 2012

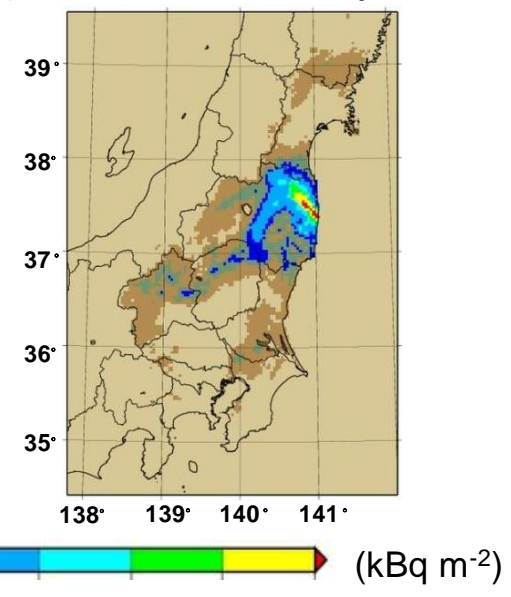

$10 \quad 30 \quad 60 \quad 100 \quad 300 \quad 60010003000$

Figure 13. Spatial distributions of surface deposition of ${ }^{137}$ Cs over eastern Japan (Domain 2) in (a-d) the four simulations using original and modified WSPEEDI-II (referred as "Old model" and "New model", respectively) and Terada at al. (2012) and the new source terms (referred as "Terada" and "New", respectively) and (e) observations (NRA, 2012a) and at 00:00 on 1 April 2011. The dashed ellipse in (d) represents the Nakadori area in Fukushima Prefecture (Sect. 4.1.1).

to ${ }^{137} \mathrm{Cs}$ around midnight on 15 March (Sect. 3.4), reproduced the difference in the observed deposition patterns between both radionuclides in the original WSPEEDI-II simulation. However, both calculation results also show general overestimation of observed ${ }^{131}$ I deposition (Fig. 15a and b). This issue was solved in the modified WSPEEDI-II simulations with the new source term (Fig. 15d) and by using smaller scavenging coefficient for gaseous ${ }^{131} \mathrm{I}$ in the model (Fig. A2b). Therefore, we have a conclusion similar to that of the ${ }^{137}$ Cs deposition simulation results; both revisions of the wet deposition scheme and the source term are important to reproduce the local-scale ${ }^{131}$ I deposition pattern.

In addition to the surface deposition, the spatial patterns in calculated and observed air dose rates due to groundshine just after the formation of the highest contamination areas near FNPS1 (17-18 March) were compared in Fig. 11a and $\mathrm{d}$. The modified WSPEEDI-II simulation using the new source term reproduced the high dose rate zones observed at the monitoring posts and the airborne survey from 17 to 19 March. The good performance for the dose calculations indicate that the modifications to the deposition scheme and source term are reasonable, particularly for ${ }^{132} \mathrm{Te}$ and ${ }^{131} \mathrm{I}$, which are the major contributors to ground-shine in the early phases of the accident.

\subsubsection{Statistical comparisons}

Figure 16 shows the scatterplots of the surface deposition of ${ }^{131} \mathrm{I}$ and ${ }^{137} \mathrm{Cs}$, and air dose rate in the modified WSPEEDIII simulation using the new source term. Overall, the model reproduced the highly contamination areas over regional and local scales within a factor of 10 . The statistical comparisons for four calculation cases are summarized in Table 7, while comparisons of the air concentration of ${ }^{131} \mathrm{I}$ and ${ }^{137} \mathrm{Cs}$ at various monitoring sites in eastern Japan are also summarized in Table S1. In general, the original and modified WSPEEDI- 
(a) Terada-Old model

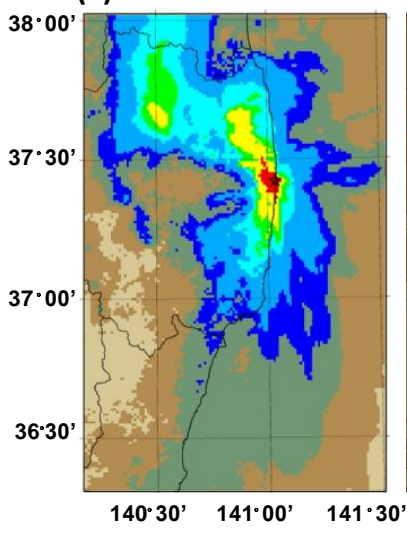

(b) New-Old model

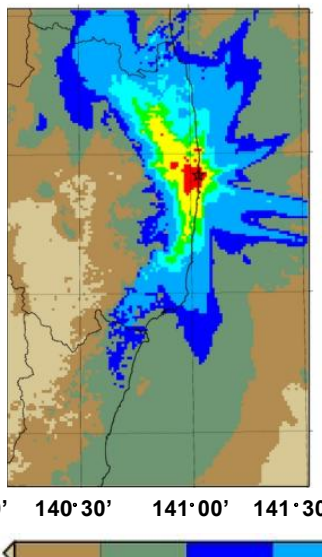

(c) Terada-New model

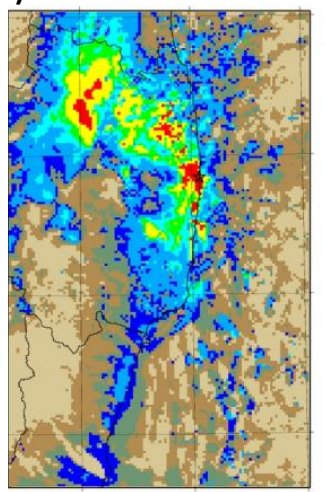

$141^{\circ} 00^{\prime}, 141^{\circ} 30^{\prime}$ (d) New-New model

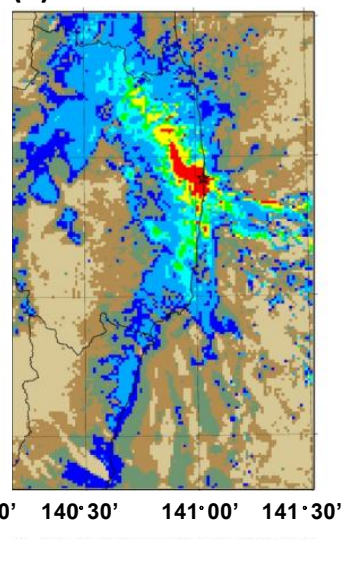

$10 \quad 30 \quad 60 \quad 100 \quad 30060010003000$ Deposition $\left(\mathrm{kBq} \mathrm{m}^{-2}\right)$

Figure 14. Local-scale spatial distributions of surface deposition of ${ }^{137} \mathrm{Cs}$ (Domain 3 ) in the four simulations using original and modified WSPEEDI-II (referred as "Old model" and "New model", respectively) and Terada at al. (2012) and the new source terms (referred as "Terada" and "New", respectively) at 00:00 on 1 April 2011.

(a) Terada-Old model

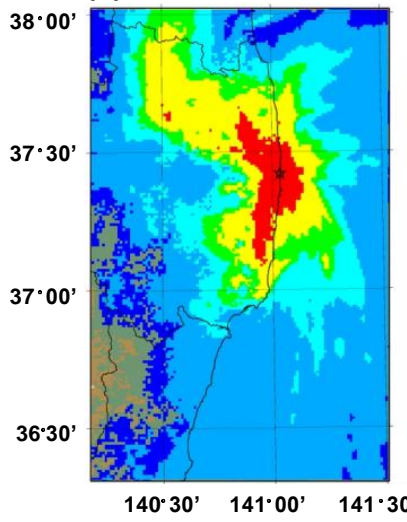

(b) New-Old model

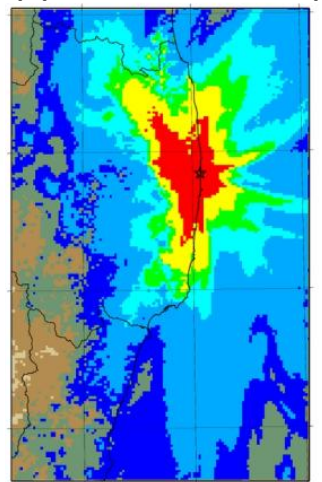

(c) Terada-New model

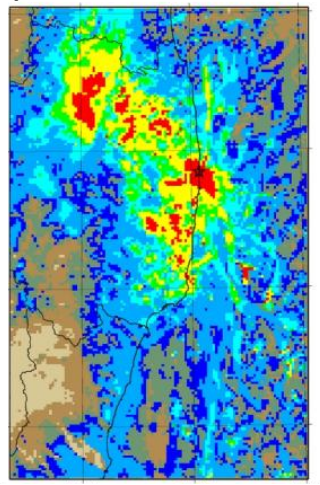

$1400^{\circ} 30^{\prime} 141^{\circ} 00^{\prime} 141 \cdot 30^{\prime} 140^{\circ} 30^{\prime}$

$141^{\circ} 00$

\section{(d) New-New model}

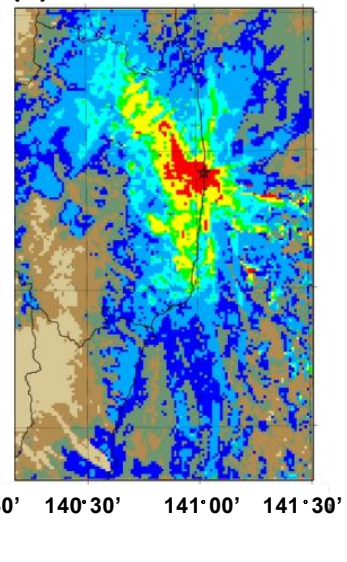

$10 \quad 30 \quad 60 \quad 100 \quad 300 \quad 60010003000$ Deposition $\left(\mathrm{kBq} \mathrm{m}^{-2}\right)$

Figure 15. Local-scale spatial distributions of surface deposition of ${ }^{131}$ I (Domain 3 ) in the four simulations using original and modified WSPEEDI-II (referred as "Old model" and "New model", respectively) and Terada at al. (2012) and the new source terms (referred as "Terada" and "New", respectively) at 00:00 on 1 April 2011.

II simulations using the new source term reproduced each observational data set with a higher correlation coefficient $(C C \geq 0.53)$ than those using the source term of Terada et al. (2012). Statistics of fractional bias (FB) and normalized mean square error (NMSE) for ${ }^{131}$ I deposition were significantly improved in modified WSPEEDI-II calculations that included the effect of gaseous ${ }^{131} \mathrm{I}$ on the scavenging coefficient (Fig. 15d). On the other hand, the scores of CC, FB, and NMSE values in Tables 7 and S1 were sometimes worse when using new source term, although the improvements in the modified WSPEEDI-II simulation with the new source term were apparent in visual comparisons (Figs. 13-15). Introducing physically consistent schemes may not always improve statistical scores because, in some cases, simple parameterizations can readily improve statistical scores by tuning a lower number of parameters compared with more sophisticated ones. To obtain a better performance of the new scheme, additional improvements related to wet deposition may be required, e.g., the accurate meteorological field calculated by spectral cloud microphysics modules or data as- 
Table 7. Statistics of the surface depositions of total ${ }^{131} \mathrm{I}$ and ${ }^{137} \mathrm{Cs}$, and air dose rate between observations and calculations using any combinations of original and modified WSPEEDI-II (referred as "Old model" and "New model", respectively) and Terada at al. (2012) and the new source terms (referred as "Terada" and "New", respectively). Six statistical parameters were selected to represent different evaluation metrics: the correlation coefficient (CC), the fractional bias (FB), the normalized mean square error (NMSE), and the percent within a factor of two, five, and ten (FA2, FA5, FA10). Regional- and local-scale data were compared with calculations of WSPEEDI-II over domain 2 and 3 , respectively.

\begin{tabular}{lcccccc}
\hline Source term \& model & CC & FB & NMSE & FA2 & FA5 & FA10 \\
\hline Regional-scale ${ }^{137}$ Cs surface deposition over East Japan at 00:00 on 1 April 2011 \\
\hline Terada-Old model & 0.56 & -0.177 & 20.0 & 0.43 & 0.80 & 0.94 \\
New-Old model & 0.67 & 0.055 & 18.7 & 0.41 & 0.78 & 0.92 \\
Terada-New model & 0.41 & -0.624 & 55.6 & 0.39 & 0.77 & 0.93 \\
New-New model & 0.63 & -0.248 & 42.3 & 0.42 & 0.78 & 0.92 \\
\hline Local-scale ${ }^{137}$ Cs surface deposition near FNPS1 at $00: 00$ on 1 April 2011 & \\
\hline Terada-Old model & 0.52 & -0.103 & 9.6 & 0.39 & 0.82 & 0.96 \\
New-Old model & 0.65 & 0.111 & 8.4 & 0.36 & 0.75 & 0.92 \\
Terada-New model & 0.29 & -0.614 & 37.7 & 0.38 & 0.75 & 0.91 \\
New-New model & 0.53 & -0.185 & 24.7 & 0.39 & 0.76 & 0.90 \\
\hline Local-scale ${ }^{131}$ I surface deposition near FNPS1 at $00: 00$ on 1 April 2011 & \\
\hline Terada-Old model & 0.52 & -0.944 & 224.1 & 0.42 & 0.84 & 0.95 \\
New-Old model & 0.61 & -0.967 & 140.2 & 0.50 & 0.89 & 0.96 \\
Terada-New model & 0.59 & -0.339 & 12.5 & 0.49 & 0.87 & 0.97 \\
New-New model & 0.67 & -0.223 & 21.4 & 0.52 & 0.87 & 0.95 \\
\hline Local-scale air dose rate at 00:00 on 18 March 2011 & & & \\
\hline Terada-Old model & 0.51 & 0.078 & 18.9 & 0.38 & 0.83 & 0.97 \\
New-Old model & 0.63 & -0.421 & 23.0 & 0.46 & 0.84 & 0.98 \\
Terada-New model & 0.46 & -0.159 & 19.4 & 0.35 & 0.74 & 0.90 \\
New-New model & 0.67 & -0.386 & 32.0 & 0.48 & 0.89 & 0.98 \\
\hline
\end{tabular}

similation techniques for cloud/rain observation data, and the online coupling simulation of meteorological and atmospheric dispersion models. While there are no clear differences in FA2, 5, and 10 among four simulation cases, most data points (76-89\%) of air dose rate and cumulative surface depositions calculated by the modified WSPEEDI-II with new source term were within a factor of 5 . Therefore, it can be concluded that our modified deposition scheme and emission estimates for the major releases during the FNPS1 accident are reasonable.

\subsubsection{Validation using several regional and global atmospheric dispersion models}

To evaluate the new source term independently of the one dispersion model used to develop the source term, numerical simulations from three atmospheric dispersion models (MLDP0, D’Amours et al., 2010; HYSPLIT, Draxler and Rolph, 2012; and NAME, Jones et al., 2007) were compared to observations using our new source term estimates. These model simulations, organized by the World Meteorological Organization (WMO, 2014), were initially conducted prior to our study to assist the Scientific Committee on the Effects of Atomic Radiation (UNSCEAR, 2014) in its dose assessment efforts. The WMO sponsored calculations were all done in $3 \mathrm{~h}$ time segments using a unit source emission rate, which permitted their use with the new source term. The calculations from the above mentioned three models as well as several others are available online (NOAA, 2014) where any source term combination can be interactively evaluated and compared with observations.

The simulation settings of the deposition scheme in each atmospheric dispersion model are summarized in Table 1. Meteorological data from the Meso-Scale Model (MSM) were provided by the Japan Meteorological Agency (JMA) at 3-hourly intervals at a $5 \mathrm{~km}$ horizontal resolution and were used to drive the three dispersion models. A one-domain calculation covering eastern Japan was carried out for each model run from 11 to 31 March 2011. Details of the simulation settings are available in Draxler et al. (2015). Both the MLDP0 and NAME calculations were the original WMO (2014) calculations. However, the HYSPLIT calculation settings were changed from the original calculation to turn off the use of the vertical motion field from MSM. In addition, in 
(a) ${ }^{137} \mathrm{Cs}$ (regional)

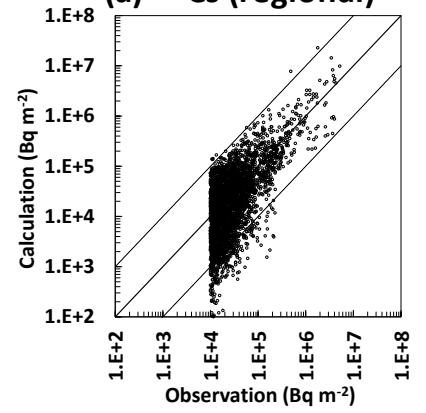

(c) ${ }^{131}$ (local)

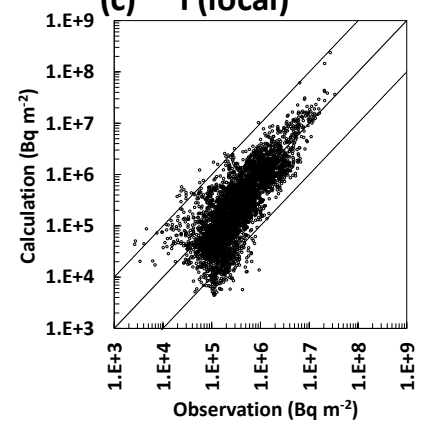

(b) ${ }^{137} \mathrm{Cs}$ (local)

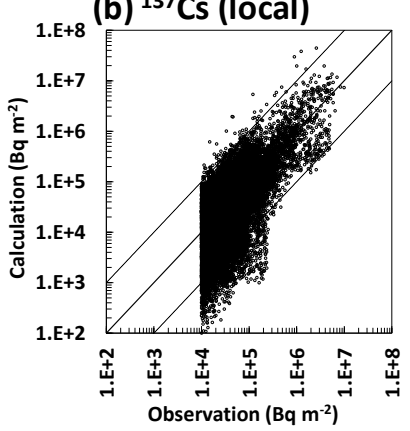

(d) Air dose rate (local)

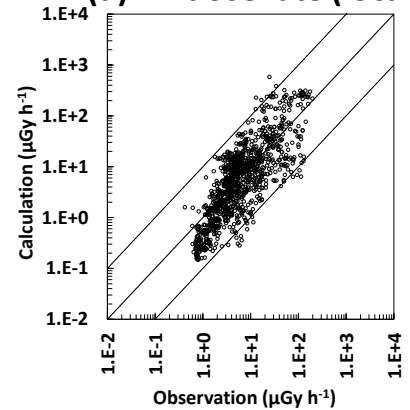

Figure 16. Scatter diagrams of the surface deposition of (ab) ${ }^{137} \mathrm{Cs}$ and (c) total ${ }^{131} \mathrm{I}\left(\mathrm{Bq} \mathrm{m}^{-2}\right)$ on 1 April 2011 and of (d) the total air dose rate $\left(\mu \mathrm{Gy} \mathrm{h}^{-1}\right)$ on 18 March 2011 comparing the measurements (US DOE/NNSA, 2011; NRA, 2012a; Torii et al., 2013) and calculations using the modified WSPEEDI-II with the new source term for (a) Domain 2 and (b-d) Domain 3. The black solid lines show $1: 1$ correspondence, and the bands within a factor of 10. The region for the air dose rate comparison is depicted in Fig. 11a.

the original HYSPLIT simulations, the wet deposition is calculated using both in-cloud and below-cloud scavenging processes. The in-cloud scheme was based upon an empirically derived scavenging ratio based on the ratio of pollutant concentration measurements in rain to air, while the below-cloud process was parameterized through a decay process defined by a time constant. The modified scavenging scheme used here is a simplified version of the previous HYSPLIT scheme and it now uses the same time constant decay process for both in-cloud and below-cloud removals. The numerical formulation for removal processes is similar to that in the NAME model. Both the original and modified NOAA calculations are available online (NOAA, 2014). Two source terms, Terada et al. (2012) and this study, averaged at 3-hourly intervals, were used for the emission scenarios.

Figure 17 shows the temporal changes in the air concentrations of ${ }^{137} \mathrm{Cs}$ at JAEA-Tokai (Fig. 2a) in the simulations using the three WMO models. Modeled results using either of the two source terms generally reproduced the observed time trends of air concentrations and the high values observed on 15, 16, 20-21, and 30 March.

Figure 18 shows the spatial distributions of the cumulative ${ }^{137}$ Cs surface deposition over eastern Japan calculated using three WMO models. The improvement when using the new source term compared with Terada et al. (2012) is obvious in the deposition pattern as well as the WSPEEDI-II calculations shown previously (Sect. 4.1.1). For example, the calculated large deposition areas extending from the north part of Fukushima Prefecture to Miyagi Prefecture, not observed by the airborne survey (NRA, 2012a), significantly decreased when using the new source term because of a decrease of release rates during the afternoon of 15 March. This is also apparent in the scatterplots (Fig. 19), which show overestimation in the range of measured surface deposition between 10 and $1000 \mathrm{kBq} \mathrm{m}^{-2}$ for all model results using the source term of Terada et al. (2012). Furthermore, utilization of the new source term clearly increased the calculated deposition amounts in the areas to the northwest of FNPS1 (Fig. 18), which matched airborne observations (Fig. 11b). As discussed above, we can see the improvement of the WMO model results similar to WSPEEDI-II calculations when using the new source term, indicating that the new source term is also effective in atmospheric dispersion simulations of the FNPS1 accident using other models.

To test the new source term for the plumes flowing over the ocean, the global simulation results from HYSPLIT were compared with measurements at several locations over the Pacific, the Americas, and Europe. It is useful to validate the new source term estimated by monitoring not only data over land but also the seawater concentration of ${ }^{134} \mathrm{Cs}$. The global HYSPLIT simulations had previously been described by Draxler and Rolph (2012). The model configuration used here is identical to the revised WMO regional calculations discussed previously except that the calculations consisted of $6 \mathrm{~h}$ time segments. The calculations used the $0.5^{\circ}$ horizontal resolution meteorological data from NOAA's Global Forecast System (GFS), consisting of a series of 0 to $+6 \mathrm{~h}$ forecasts available on GFS native model sigma levels (56) with meteorological fields available every $3 \mathrm{~h}$. The concentration grid was global at $1^{\circ}$ horizontal resolution with a vertical extent of $500 \mathrm{~m}$. The global measurement data used for the evaluations consisted of the United States National Data Center (US NDC, 2011) and Health Canada's Radiation Monitoring (HCRM, 2011) stations in the CTBTO network, the US Environmental Protection Agency's Radiation Monitoring Network (RADNET, 2011), and selected stations in Europe run by various national authorities (Masson et al., 2011).

Figure 20 shows the time series of ${ }^{137} \mathrm{Cs}$ air concentrations at a few selected locations in North America, Hawaii, Alaska, Ireland, and Canada representing the emissions from FNPS1 that flowed over the Pacific Ocean and arrived during the early phases of the accident. As shown in the figure, there is a good agreement in the first arrival time of the plume, and overall the general time trends were reproduced by HYSPLIT using the new source term. Scatter diagrams of the observed and calculated air concentrations for the global- 


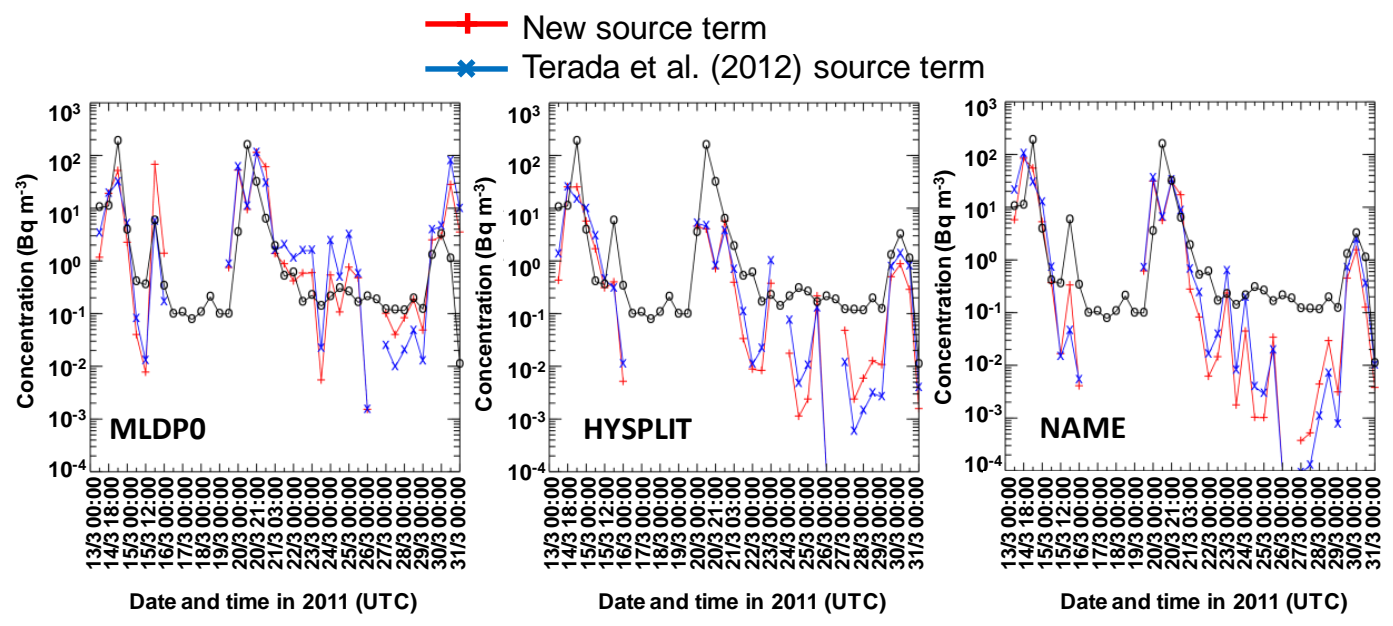

Figure 17. Temporal changes in observed (lines with open circles) and modeled air concentrations (Bq ${ }^{-3}$ ) using three WMO models (MLDP0, HYSPLIT, and NAME) with the source terms of this study (red lines with pluses) and Terada et al. (2012) (blue lines with crosses) for ${ }^{137}$ Cs at JAEA-Tokai in Ibaraki Prefecture from 13 to 31 March 2011.

(a) New source term
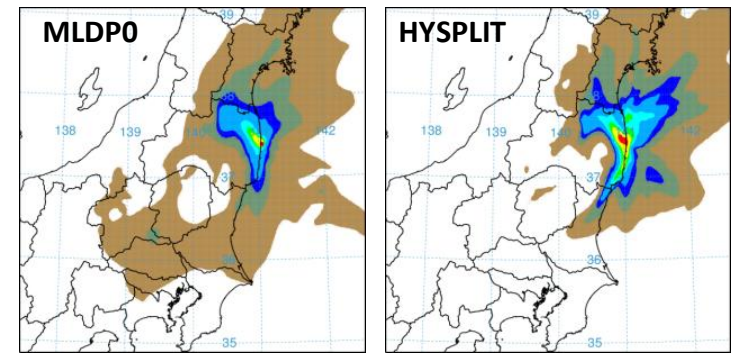

(b) Terada et al. (2012) source term
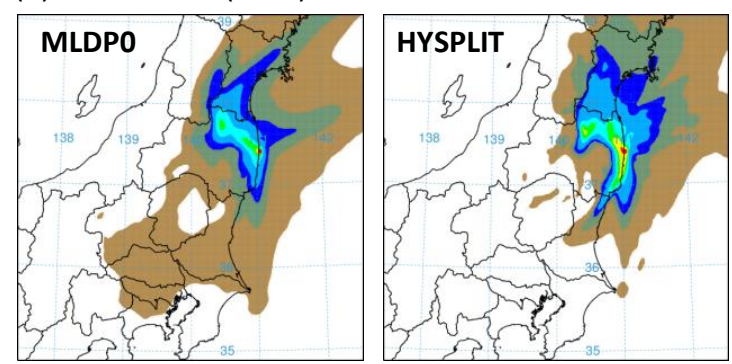
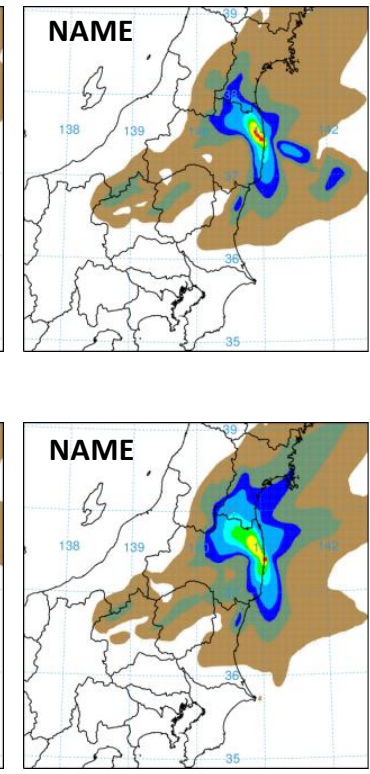

$>3000 \mathrm{kBq} \mathrm{m}^{-2}$ $>1000 \mathrm{kBq} \mathrm{m}^{-2}$ $>600 \mathrm{kBq} \mathrm{m}^{-2}$ $>300 \mathrm{kBq} \mathrm{m}^{-2}$ $>100 \mathrm{kBq} \mathrm{m}^{-2}$ $>60 \mathrm{kBq} \mathrm{m}^{-2}$ $>30 \mathrm{kBq} \mathrm{m}^{-2}$ $>10 \mathrm{kBq} \mathrm{m}^{-2}$

Figure 18. Spatial distributions of surface depositions of ${ }^{137} \mathrm{Cs}\left(\mathrm{kBqm}^{-2}\right)$ on 1 April 2011 calculated by three WMO models (MLDP0, HYSPLIT, and NAME) using (a) the new source term and (b) Terada et al. (2012).

scale results using HYSPLIT with the new source term are depicted in Fig. 21. A large part of data points for both radionuclides are within a factor of 10 . While uncertainties of the model, such as the ratio of ${ }^{131} \mathrm{I} /{ }^{137} \mathrm{Cs}$ for major releases during the early stages of the accident, the model's deposition parameters, and the comparison with other global modeling results (Stohl et al., 2012; Christoudias and Lelieveld, 2013; Evangeliou et al., 2013), should be further evaluated in the future, we can conclude from these results that the new source term is also appropriate for the global-scale atmospheric dispersion studies of the FNPS1 accident.

\subsection{Comparison in source terms}

Figures 22 and 23 show the source terms estimated in the present study and those from prior studies (Terada et al., 2012; Stohl et al., 2012; Hirao et al., 2013; Saunier et al., 2013; Winiarek et al., 201). In terms of the land contamination, the most important result of this study is that the highest release rates shifted from the afternoon to the evening and nighttime of 15 March (Sect. 3.4). As a result, the period of the major release is estimated and is coincident with the wet venting at Unit 3 and/or DW pressure deficits at both 
(a) New source term

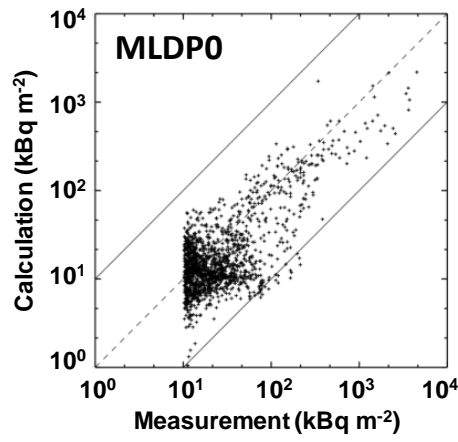

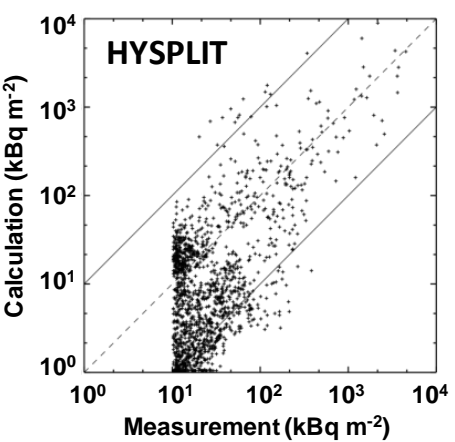

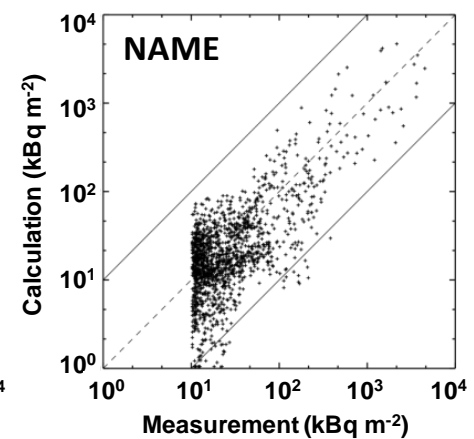

(b) Terada et al. (2012) source term
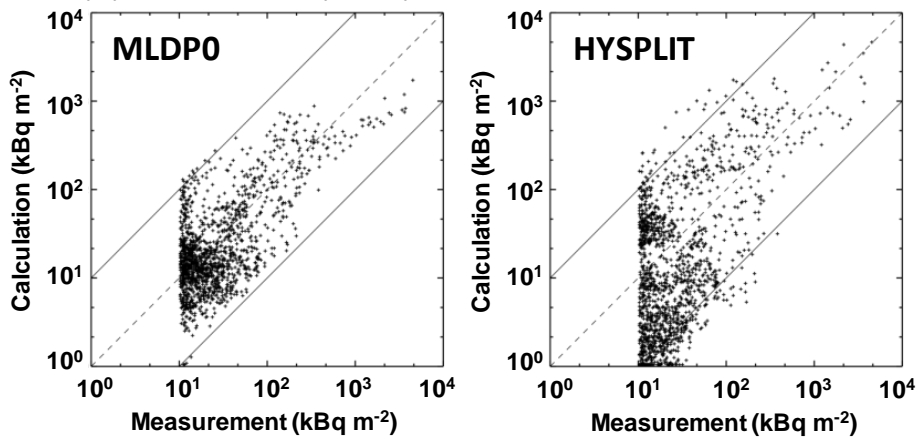

Figure 19. Scatter diagrams of surface deposition $\left(\mathrm{kBq} \mathrm{m}^{-2}\right)$ comparing measurements and calculations using three WMO models (MLDP0, HYSPLIT, and NAME) with the source term of (a) this study and (b) Terada et al. (2012) on 1 April 2011. The black dashed lines show the $1: 1$ correspondence.

Units 2 and 3 reported on 15-16 March (Fig. 8), though it is not clear from our estimation if the release was major or not. These results is the complete opposite of all the previous studies based on the inverse estimation methods using regional (Hirao et al., 2013; Saunier et al., 2013), global (Stohl et al., 2012), and daily fallout and surface deposition data sets (Winiarek et al., 2014).

There are several reasons for the improved estimation of this major release. First, the results of local-scale simulations with much higher spatial resolution $(1 \mathrm{~km})$ were compared with the automated monitoring data of air dose rate close to FNPS1 (Fig. 3b) that were not available for any of the past studies. These were particularly effective in finding this release and determining the timing and release rates. Second, we modified the wet scavenging scheme to increase wet deposition, particularly for conditions with low cloud water content (Fig. A2b). This caused an increase of the modeled ground-shine at Fukushima and litate and also decreased the release rate in the afternoon of 15 March because the previous model's underprediction no longer needed to be compensated by an increased emission rate. Third, the time segment of the release periods from 15 to 16 March was set to every hour to every several hours to resolve drastic temporal changes in the release rate. Our results show that the combination of local-scale monitoring and detailed numerical anal- ysis using atmospheric dispersion models with sophisticated deposition schemes are the most important factors required to estimate the release rates associated with the time-varying events in the reactors (e.g., hydrogen explosion, venting, and pressure drop).

For the periods when the plume flowed over land from the night of 14 March to the morning of 15 March, and from 20 to 21 March, the release rates of the new source term were on the same order of those estimated by previous regional simulation studies (Hirao et al., 2013; Saunier et al., 2013) as well as Terada et al. (2012) (Figs. 22 and 23). In other periods, Saunier et al. (2013) frequently showed higher release rates with uncertainties when the plume flowed toward the ocean. Winiarek et al. (2014) acknowledged that they also overestimated the release rate on 20, 22-23, 25, 27, and 30 March (Fig. 22b).

Interestingly, when the plume flowed toward the Pacific Ocean, our new source term for ${ }^{137} \mathrm{Cs}$ often agreed well with that of Stohl et al. (2012), despite using the different estimation method (Fig. 22). The former used ${ }^{134}{ }^{14}$ s sea surface concentration data, while the latter was mainly based on daily mean air concentrations of ${ }^{137} \mathrm{Cs}$ sampled throughout the world. This indicates that the estimated values in this study were also indirectly confirmed as being reasonable. 


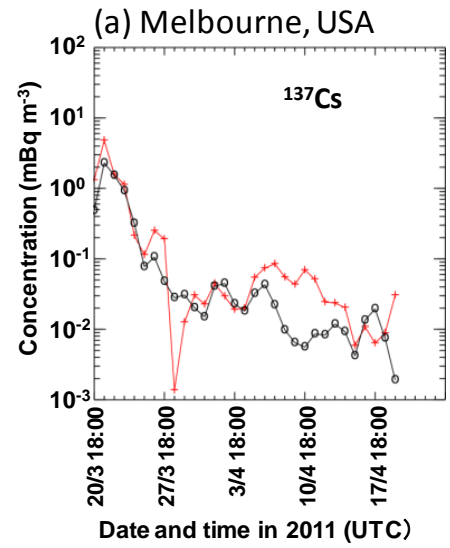

(d) Sand Point, USA

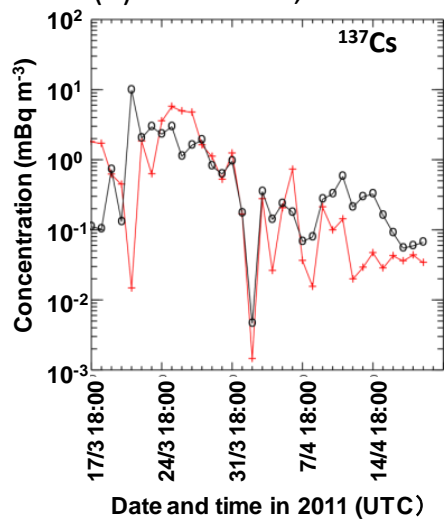

(b) Oahu, USA

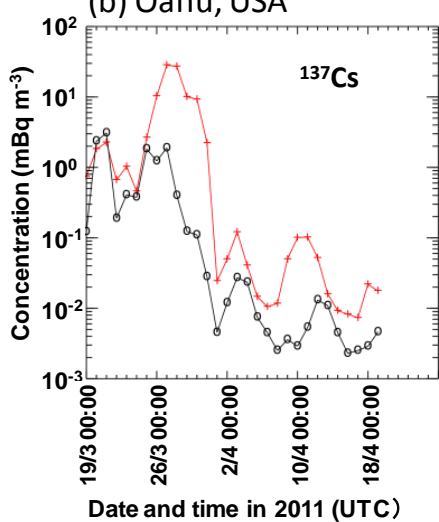

(e) Dublin, Ireland

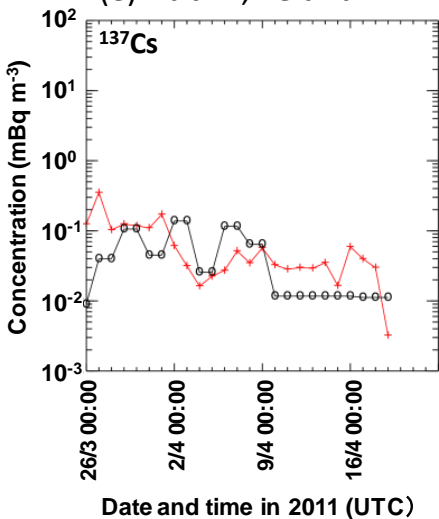

(c) Sacramento, USA

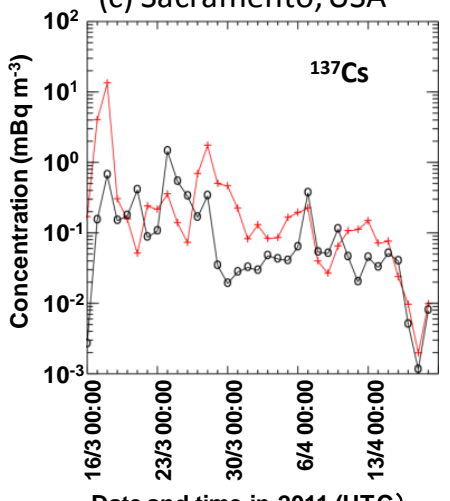

Date and time in 2011 (UTC)

(f) St. Johns, Canada

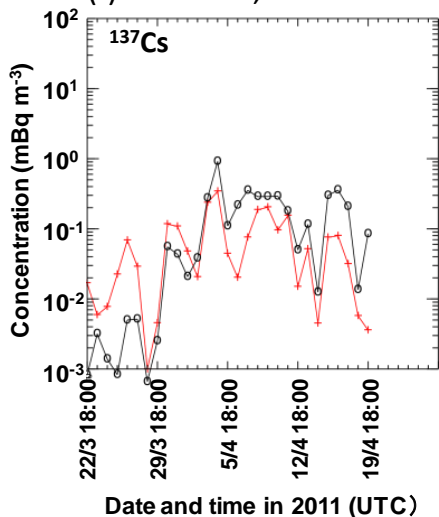

Figure 20. Temporal changes in observed (lines with open circles) and modeled (lines with crosses) air concentrations ( $\mathrm{mBq}^{-3}$ ) $\mathrm{using}$ HYSPLIT with the new source term for air concentration of ${ }^{137} \mathrm{Cs}$ at selected CTBTO, US EPA, and European stations from 13 to 31 March 2011.

(a) Gaseous ${ }^{131}$ I

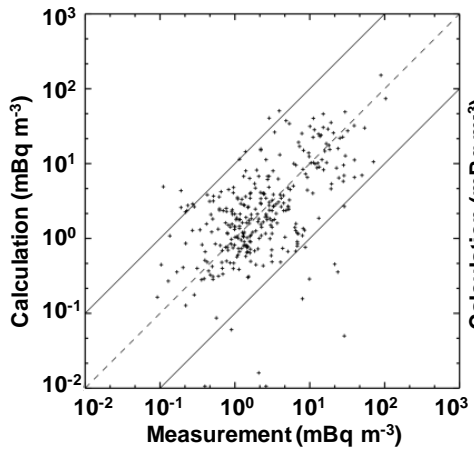

(b) Particulate ${ }^{131}$ I

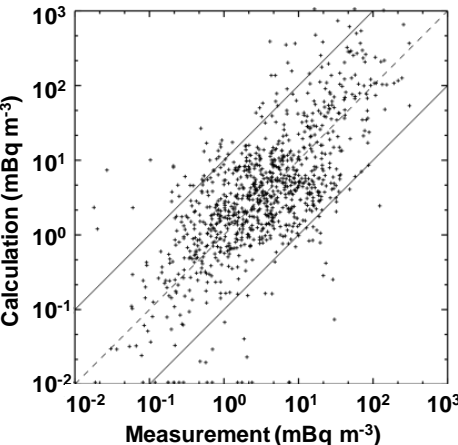

(c) ${ }^{137} \mathrm{Cs}$

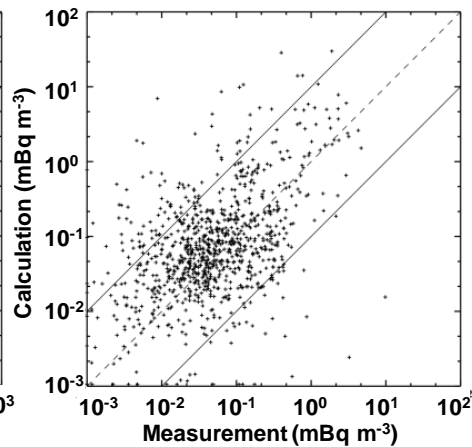

Figure 21. Scatter diagrams of air concentrations $\left(\mathrm{mBq} \mathrm{m}^{-3}\right)$ comparing measurements and calculations using HYSPLIT with the new source term for (a) gaseous and (b) particulate ${ }^{131} \mathrm{I}$, and (c) ${ }^{137} \mathrm{Cs}$ in the CTBTO, US-EPA, and European monitoring stations for the period of 15 March through 20 April. The black dashed lines show the $1: 1$ correspondence.

Table 8 shows the total release amounts of ${ }^{131} \mathrm{I}$ and ${ }^{137} \mathrm{Cs}$ to the atmosphere from FNPS1. For both radionuclides, the total amounts estimated by coupling the atmospheric and oceanic simulations are clearly larger (approximately 151 and $14.5 \mathrm{PBq}$ for ${ }^{131} \mathrm{I}$ and ${ }^{137} \mathrm{Cs}$, respectively) than those of
Terada et al. (2012). From the comparison between the two calculations in this study using the source terms estimated from land data only and from both land and sea data (Table 8), it appears these increases were mainly due to an increase of the release rate when the plume flowed over the 

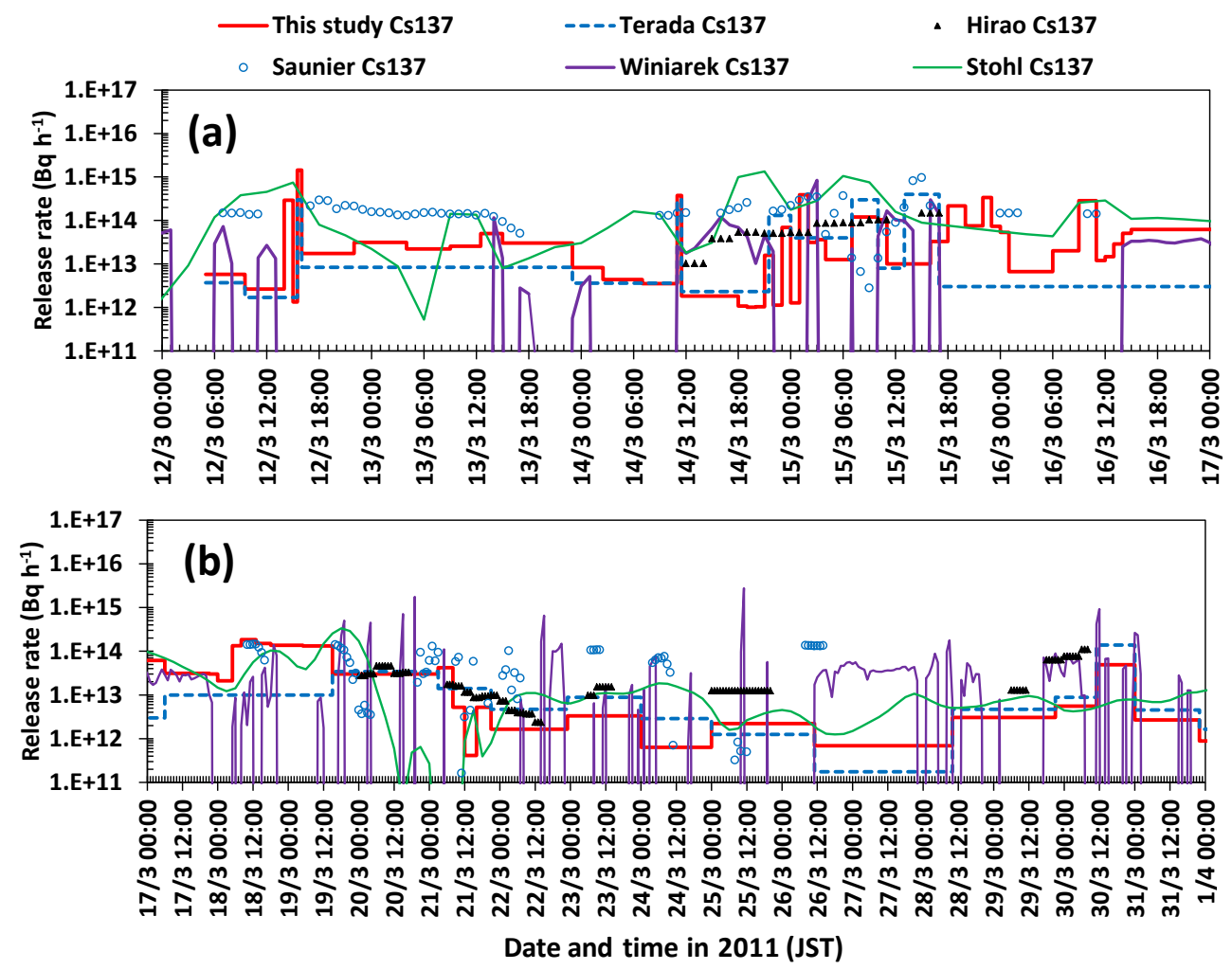

Figure 22. Comparisons of the time varying release rates for ${ }^{137} \mathrm{Cs}$ from 12 March to 1 April 2011 between this study and past studies (Terada et al., 2012; Stohl et al., 2012; Hirao et al., 2013; Saunier et al., 2013; Winiarek et al., 2014). Note that the values of Winiarek et al. (2014) and Stohl et al. (2012) are derived from hourly estimation results using the daily fallout, airborne survey data, and aggregated for all release layers from 0 to $1000 \mathrm{~m}$, respectively. It is also noted that the release rates of Saunier et al. (2013), when the plume directly flowed to the Pacific Ocean, could not be reconstructed correctly.

Table 8. Total release amount of total ${ }^{131}$ I and ${ }^{137} \mathrm{Cs}$ to the atmosphere from 12 March-1 May 2011 using source terms estimated from land data only (referred as "New-land") and from both land and sea data in this study (referred as "New-landsea") and those of past studies. Note that the values of Winiarek et al. (2014) and Stohl et al. (2012) are derived from hourly estimation results using the daily fallout, airborne survey data, and aggregated for all release layers from 0-1000 m, respectively. It is also noted that the release rates of Saunier et al. (2013), when the plume directly flowed to the Pacific Ocean, could not be reconstructed correctly.

\begin{tabular}{llcc}
\hline Name of source term & Integration period & Total ${ }^{131} \mathrm{I}(\mathrm{PBq})$ & ${ }^{137} \mathrm{Cs}(\mathrm{PBq})$ \\
\hline New-land & 12 March-1 May 2011 & 110.7 & 9.8 \\
New-landsea & 12 March-1 May 2011 & 151.0 & 14.5 \\
Terada et al. (2012) & 12 March-1 May 2011 & 123.9 & 8.8 \\
Kobayashi et al. (2013) & 12 March-1 May 2011 & 200.0 & 13.0 \\
Saunier et al. (2013) & 12 March-27 March 2011 & 105.9 & 15.5 \\
Winiarek et al. (2014) & 11 March-1 April 2011 & - & 19.3 \\
Stohl et al. (2012) & 10 March-20 April 2011 & - & 35.9 \\
\hline
\end{tabular}

ocean resulting from the optimization of release rates using additional data over land and the ocean. However, the estimated release amount of ${ }^{137} \mathrm{Cs}$ to the atmosphere was still lower than those of several prior studies (Stohl et al., 2012; Saunier et al., 2013; Winiarek et al., 2014).

\section{Conclusions}

The detailed source terms of total ${ }^{131} \mathrm{I}$ and ${ }^{137} \mathrm{Cs}$ were estimated using a reverse estimation method which coupled environmental monitoring data with the simulation of an atmospheric dispersion model (WSPEEDI-II) and an oceanic dispersion model (SEA-GEARN-FDM). To improve the ac- 

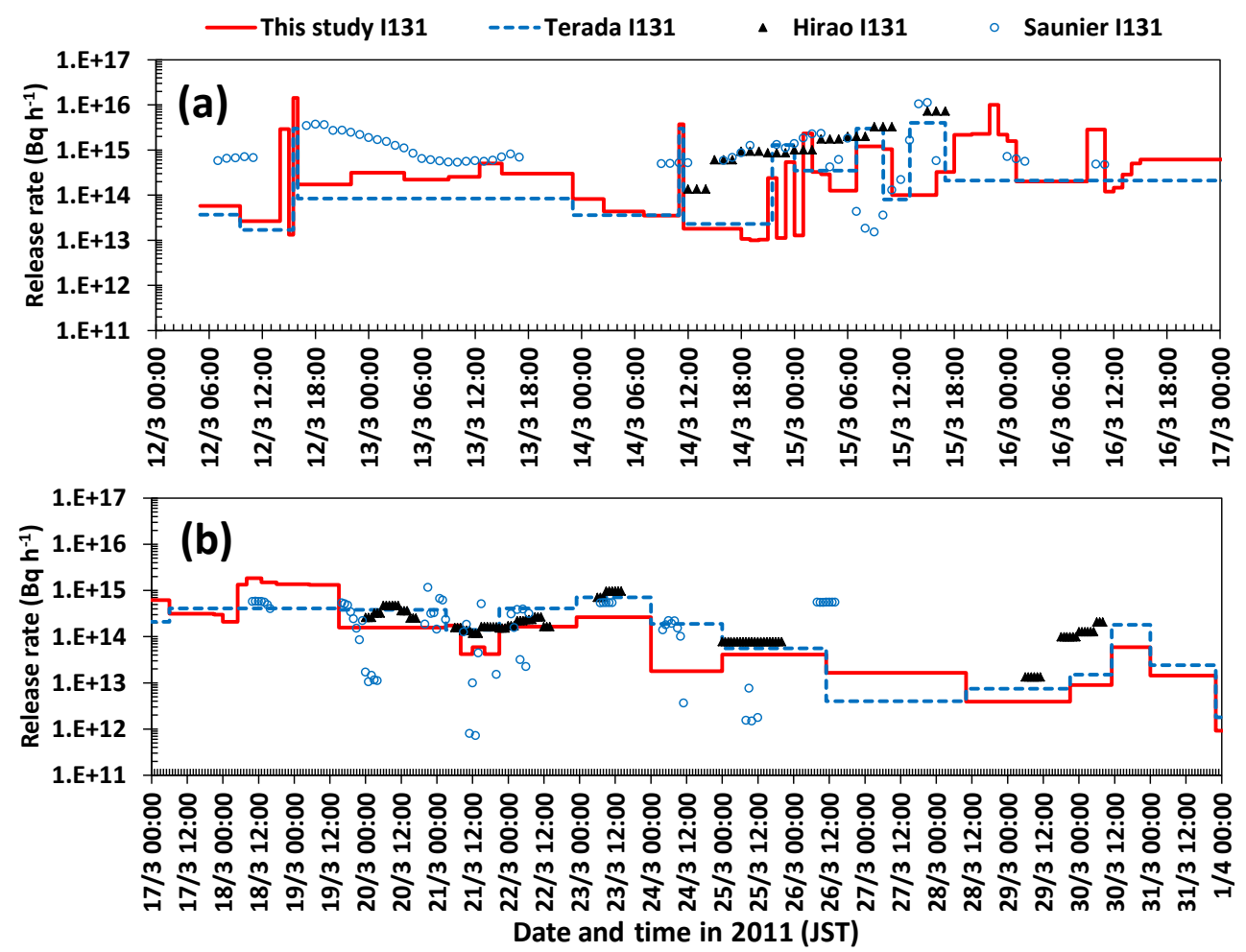

Figure 23. Comparisons of the time varying release rates for total ${ }^{131}$ I from 12 March to 1 April 2011 between this study and past studies (Terada et al., 2012; Hirao et al., 2013; Saunier et al., 2013). It is noted that the release rates of Saunier et al. (2013), when the plume directly flowed to the Pacific Ocean, could not be reconstructed correctly.

curacy of the estimate, we enhanced the deposition scheme of WSPEEDI-II to calculate dry and wet deposition of gaseous and particulate substances, and used additional air dose rate data from automated monitoring posts, and dust sampling and airborne survey data, which were not available in the previous work (Terada et al., 2012).

The major differences in the estimated source term in this work from our previous work are as follows: (1) afternoon of 12 March: the release amount from the wet venting of Unit 1 between 14:00 and 15:00 was newly estimated from the air dose rates at the automated monitoring post near FNPS1. The release amount was approximately half of that from the hydrogen explosion of Unit 1 at 15:36, which was also reestimated using the data at the automated monitoring post. (2) Night of 14 March to early morning of 15 March: the major release from Unit 2 could be separated into three time segments starting from 21:00, 23:00, and 01:00, although the previous study estimated one release rate for this entire period. The results suggest a relationship between the operations of the safety relief valve (SRV) of Unit 2 and discharges to the atmosphere. (3) Morning of 15 March to noon of 16 March: the major releases were estimated during three periods from 07:00 to 11:00, from 18:00 on 15 March to 01:00 on 16 March, and from 09:00 to 11:00 on 16 March, using the air dose rate from automated monitoring posts near the plant.
The release rates during the first two periods were similar to those estimated by our previous work, while the third major release was estimated for the first time in this study. However, the second major release started $4 \mathrm{~h}$ later and continued for $3 \mathrm{~h}$ longer than determined in the previous work. Furthermore, it was revealed that this release was iodine-rich compared with other releases, which was supported by the spatial patterns of the airborne survey of ${ }^{131} \mathrm{I}$ and ${ }^{137} \mathrm{Cs}$ depositions and the dust sampling data at JAEA-Tokai. The plumes of the first and second releases created the highest dose rate zone to the northwest and west of FNPS1 by wet deposition with complicated interactions between rainfall, plume movements, and temporal variety in the release rates.

The total amounts of released ${ }^{131} \mathrm{I}$ and ${ }^{137} \mathrm{Cs}$ estimated in this work were 151 and $14.5 \mathrm{PBq}$, respectively, which were clearly larger than those of the previous work for both radionuclides. The major reason for this increase was that when the plume flowed toward the Pacific Ocean we directly computed a significantly larger release amount, while previously it was simply estimated by a temporal interpolation between release rates computed from land-based measurements.

The new source term estimated in this study was first validated by comparing calculation results of the modified WSPEEDI-II with the data of cumulative surface deposition of ${ }^{137} \mathrm{Cs}$ and ${ }^{131} \mathrm{I}$ and air dose rates over local and regional 
scales. The spatial patterns of cumulative surface deposition were reproduced well. The simulation accuracies including both ${ }^{137} \mathrm{Cs}$ and ${ }^{131} \mathrm{I}$ were within a factor of 5 for $76-89 \%$ of data points for cumulative surface deposition and air dose rates. Furthermore, the new source term was also tested with three atmospheric dispersion models (MLDP0, HYSPLIT, and NAME) for regional and global simulations. All models using the new source term and the same meteorological input data generally reproduced the time series of air concentrations at JAEA-Tokai and surface deposition of ${ }^{137} \mathrm{Cs}$ over eastern Japan. The global calculations using HYSPLIT showed a good agreement with the time of first arrival of the plume by comparing the model results with daily mean air concentration data at various monitoring sites over North America, Hawaii, Alaska, Ireland, and Canada.

These validation results indicated the applicability of the new source term for atmospheric dispersion studies of the FNPS1 accident. However, our estimation results still have uncertainties due to the following assumptions and model capabilities:

1. When the monitoring data observed close to the FNPS1 were used for our source term estimation, the height (or volume size) and the time interval of releases determined from the limited information of the reactors should cause the errors.
2. The composition ratios of radionuclides determined from the observational data are highly scattered (Fig. 4c). The ratio of gaseous and particulate iodine was determined from the data from only one point (JAEA-Tokai). Furthermore, the ratio of $\mathrm{I}_{2}$ and $\mathrm{CH}_{3} \mathrm{I}$ in gaseous iodine is given by literature due to lack of data. The former has large uncertainties when our source term was estimated based on the ground-shine, while the latter can cause the errors in estimated results affected by wet deposition (Fig. S5b).

3. There are also uncertainties caused by the estimation method. For the reverse estimation method, the careful comparison between observations and calculations is particularly needed to reduce the errors.

It is difficult to shrink the above uncertainties unless new information from, for example, severe accident analysis and observation data becomes available. Further analyses of modeled meteorological fields such as precipitation and the impact of dry, wet, and fog-water deposition processes (partially done in the Supplement) are also required in future studies. 
Appendix A: Modifications of the deposition scheme in WSPEEDI-II

The processes in the following subsections are incorporated into WSPEEDI-II to improve the accuracy of the source term estimation and the atmospheric dispersion simulation.

\section{A1 Dry deposition of gases}

Dry deposition flux of gases and particles is normally represented by the deposition velocity, $V_{\mathrm{d}}\left(\mathrm{m} \mathrm{s}^{-1}\right)$, and the concentration, $c\left(\mathrm{~Bq} \mathrm{~m}^{-3}\right)$, according to the inferential technique (Hicks et al., 1987),

$F=c V_{\mathrm{d}}$,

where the downward flux is positive for $F$. As described in Sect. 1, WSPEEDI-II used the typical constant values for $V_{\mathrm{d}}$ over short vegetation, the same as many of the other dispersion models (Table 1). However, $V_{\mathrm{d}}$ of gases and particles depends on many factors such as meteorological variables (wind speed and atmospheric stability), physicochemical forms of substances, and land surface characteristics (Katata et al., 2011b). To improve the accuracy of dry deposition, the more sophisticated resistance model of Zhang et al. (2003) for gaseous radioactive iodine $\left(\mathrm{I}_{2}\right.$ and $\left.\mathrm{CH}_{3} \mathrm{I}\right)$ is incorporated into WSPEEDI-II so that the model can consider the influences of these factors in its dry deposition calculations.

The original model of Zhang et al. (2003) calculates deposition velocity of gases $\left(V_{\mathrm{dg}}\right)$ based on the big-leaf resistance modeling approach for various chemical species. Deposition velocity is parameterized based on an analogy to electrical flow through a series of transfer resistances. The model of Zhang et al. (2003) considers transfer resistances of the aerodynamic, quasi-laminar sublayer, and overall canopy resistance. The canopy resistance is separated into two parallel paths; one is the stomatal resistance with its associated mesophyll resistance, and the other is non-stomatal resistance. The non-stomatal resistance is further decomposed into resistance to soil uptake, which includes the in-canopy aerodynamic resistance and the subsequent soil resistance, as well as resistance to cuticle uptake.

According to the scheme, the non-stomatal resistance for gas species $i, r_{\mathrm{ns} i}$, is parameterized by combining those for $\mathrm{O}_{3}$ and $\mathrm{SO}_{2}$ with the scaling factors of $\alpha_{i}$ and $\beta_{i}$ :

$r_{\mathrm{ns} i}^{-1}=\alpha_{i} / r_{\mathrm{nsSO}_{2}}^{-1}+\beta_{i} / r_{\mathrm{nsO}_{3}}^{-1}$,

where $\alpha_{i}$ and $\beta_{i}$ represent the solubility and half-redox reactivity for species $i$, respectively. We rely on the equation to calculate dry deposition of gaseous ${ }^{131} \mathrm{I}$ by determining appropriate values for $\alpha_{i}$ and $\beta_{i}$ for the non-stomatal resistance in the following way. The behavior of ${ }^{131} \mathrm{I}$ in the atmosphere is complicated because it is either bound to particles (aerosols) or in gaseous form. Unfortunately, there is no available data of chemical analysis of gaseous ${ }^{131} \mathrm{I}$ during the FNPS1 accident and therefore, we focus on two species of elemental $\left(\mathrm{I}_{2}\right)$ and organic forms $\left(\mathrm{CH}_{3} \mathrm{I}\right)$ which have been known to be dominant in the past nuclear accidents (Baklanov and Sørensen, 2001). The former gas is more reactive than the latter probably due to larger reactivity and solubility. The observational results summarized in Sehmel (1980) also suggest that deposition velocity for $\mathrm{I}_{2}\left(V_{\mathrm{dg}}=0.02-7.2 \mathrm{~cm} \mathrm{~s}^{-1}\right)$ in the same range of $\mathrm{SO}_{2}$ $\left(V_{\mathrm{dg}}=0.04-7.5 \mathrm{~cm} \mathrm{~s}^{-1}\right)$ was more than 10 times that for $\mathrm{CH}_{3} \mathrm{I}\left(V_{\mathrm{dg}}=0.0001-0.01 \mathrm{~cm} \mathrm{~s}^{-1}\right)$. By considering this fact, we set the values of $\left(\alpha_{i}, \beta_{i}\right)=(1,0)$ and $(0.01,0)$ for $\mathrm{I}_{2}$ and $\mathrm{CH}_{3} \mathrm{I}$, respectively. The ratio of gaseous $\mathrm{CH}_{3} \mathrm{I}$ to ${ }^{131} \mathrm{I}$ gas was assumed to be constant of 0.6 throughout the simulation period (US NRC, 2012) due to lack of field data.

\section{A2 Dry deposition of particles}

With regard to the calculation of the dry deposition for particles, the modified parameterization of Zhang et al. (2001) is implemented for $V_{\mathrm{d}}$ for particle ( $\left.V_{\mathrm{dp}}\right)$ in Eq. (A1) as in Kajino et al. (2012). The original parameterization calculates deposition velocity of particles as a reciprocal of total transfer resistance in a series of aerodynamic and surface resistances for each particle size bin. From this, the following modifications are made based on more recent studies (Katata et al., 2008, 2011b; Petroff and Zhang, 2010): (1) on the basis of the fact that forests can collect a large amount of submicron particles (Gallagher et al., 1997; Matsuda et al., 2010) caused by high turbulence over the canopy (e.g., Petroff et al., 2009), hygroscopic growth of particles under humid conditions (Katata et al., 2013), and other collection mechanisms, the empirical constant $\varepsilon_{0}$, which is inversely proportional to the surface resistance (Zhang et al., 2001), was set to 5 and 1 for the forest and short vegetation categories, respectively. (2) For the collection efficiency of leaves due to inertial impaction, we used the modified function of Peters and Eiden (1992). (3) Collection efficiencies for vegetative surfaces due to interception and Brownian diffusion were modeled based on Kirsch and Fuchs (1968) and Fuchs (1964), respectively. (4) For the land-use categories of desert, tundra, ice cap, glacier, inland water, and ocean, we adopted the surface resistance for non-vegetated surfaces proposed by Petroff and Zhang (2010).

After these modifications, the dry deposition velocity calculated by the modified model better agreed with the observational data than did the original model of Zhang et al. (2001). For example, the size-segregated $V_{\mathrm{d}}$ for forest is $0.1-1 \mathrm{~cm} \mathrm{~s}^{-1}$ in the range from 0.1 to $1 \mu \mathrm{m}$ diameter and corresponded to the observations. For ground and water surfaces, a good agreement was found between the modified model calculations and the observations from the literature, as shown in Petroff and Zhang (2010) (not shown in the figure). For calculation of $V_{\mathrm{dp}}$, a single lognormal size distribution is assumed for all radioactive particles. The mean mass- 
(a) Daytime

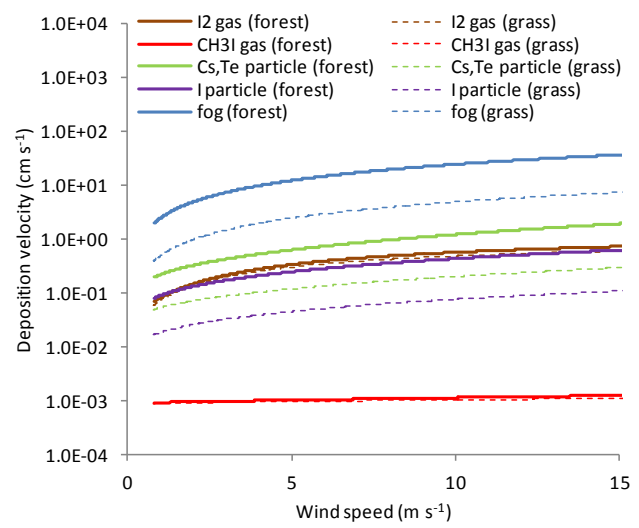

(b) Nighttime

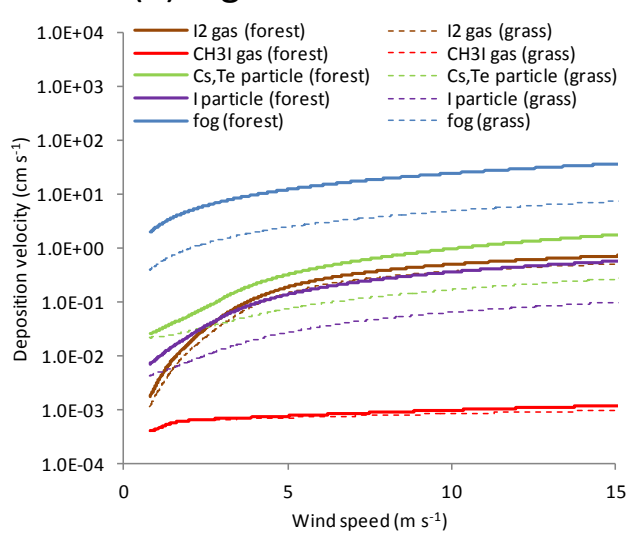

Figure A1. Changes in the modeled deposition velocity $\left(V_{\mathrm{d}}\right)$ of gaseous and particulate radioactive substances and of fog water versus the horizontal wind speed over forest (solid lines) and grassland (dashed lines) surfaces (a) during the daytime and (b) nighttime for typical clear conditions. Input meteorological data are mainly from the surface weather stations in Fukushima Prefecture from 12 to 15 March, 2011 and show the following: 16 and $-1.5^{\circ} \mathrm{C}$ for air temperature, 21 and $-5^{\circ} \mathrm{C}$ for ground surface temperature, 800 and $0 \mathrm{~W} \mathrm{~m}^{-1}$ for solar radiation, 30 and $70 \%$ for relative humidity during the daytime and nighttime, respectively.

equivalent particle diameters are set to 0.5 and $1.5 \mu \mathrm{m}$ for ${ }^{131}$ I and other radionuclides, respectively, based on the observational results at JAEA-Tokai from 17 March to 1 April (Miyamoto et al., 2014) with a geometric standard deviation of $1.6 \mu \mathrm{m}$ (Kaneyasu et al., 2012).

Figure A1 illustrates the dry deposition velocity of ${ }^{131} \mathrm{I}$, gaseous $\mathrm{I}_{2}$ and $\mathrm{CH}_{3} \mathrm{I}$, and particulate iodine and ${ }^{137} \mathrm{Cs}$ (expecting the chemical form of CsI) for grassland and forest against horizontal wind speed for a typical sunny period during the accident. Generally, the deposition velocity of particles is larger in forest than in short vegetation as explained above, while deposition velocities of gases over two vegetation types do not have a large difference because stomata resistance is dominant rather than aerodynamic resistance. Atmospheric stability significantly decreases the nighttime $V_{\mathrm{d}}$ under low wind speed conditions $<5 \mathrm{~m} \mathrm{~s}^{-1}$ (Fig. A1b). Consequently, the modeled dry deposition velocity of $\mathrm{I}_{2}, \mathrm{CH}_{3} \mathrm{I}$, particulate iodine, and other particles can vary in the range of $0.001-0.5 \mathrm{~cm} \mathrm{~s}^{-1}, 0.0004-0.001 \mathrm{~cm} \mathrm{~s}^{-1}, 0.005-0.1 \mathrm{~cm} \mathrm{~s}^{-1}$, and $0.02-0.3 \mathrm{~cm} \mathrm{~s}^{-1}$ over short vegetation. Deposition velocity of ${ }^{131} \mathrm{I}$ depends on chemical composition, and has values from 0.003 to $0.2 \mathrm{~cm} \mathrm{~s}^{-1}$ when for example $\mathrm{I}_{2}: \mathrm{CH}_{3} \mathrm{I}$ : particulate iodine $=2: 3: 5$ based on the measurement of gaseous and particulate iodine concentrations at JAEA-Tokai on 15 March 2011. It should be noted that the original WSPEEDIII used constant values of $V_{\mathrm{d}}$ of 0.3 and $0.1 \mathrm{~cm} \mathrm{~s}^{-1}$ for ${ }^{131} \mathrm{I}$ and ${ }^{137} \mathrm{Cs}$, respectively, which are similar to daytime values calculated by the modified scheme.

During the FNPS1 accident, a few studies have reported the $V_{\mathrm{d}}$ for ${ }^{131} \mathrm{I}$ and ${ }^{137} \mathrm{Cs}$ calculated by the data of deposition flux and air concentration measured by bulk samplers and combined samplers of the dust filter and charcoal cartridge, respectively. Amano et al. (2012) showed that daily mean values of $V_{\mathrm{d}}$ were from 0.1 to $0.2 \mathrm{~cm} \mathrm{~s}^{-1}$ and 0.2 to $0.3 \mathrm{~cm} \mathrm{~s}^{-1}$ for ${ }^{131} \mathrm{I}$ and ${ }^{137} \mathrm{Cs}$, respectively, at Chiba Prefecture from 14 to 17 March. Takeyasu and Sumiya (2014) used the daily fallout data sampled at JAEA-Tokai in Ibaraki Prefecture, and estimated the similar values of $V_{\mathrm{d}}$ of both radionuclides as $0.26 \mathrm{~cm} \mathrm{~s}^{-1}$ and $0.43 \mathrm{~cm} \mathrm{~s}^{-1}$ in $15-16 \mathrm{March}$, respectively. Those results indicate that the modified dry deposition scheme is reasonable.

The in-cloud scavenging is activated in a model grid cell, where the cloud water mixing ratio is higher than $10^{-6}$ $\left(\mathrm{kg} \mathrm{kg}^{-1}\right)$ and the surface precipitation intensity is larger than zero.

\section{A3 In-cloud scavenging}

Wet deposition has been also treated in WSPEEDI-II by a simple exponential function between scavenging coefficient $(\Lambda)$ and precipitation intensity $\left(P_{\mathrm{r}}\right)$ without the separation of chemical forms as in some other dispersion models (Table 1). We modified the scheme to be more mechanistic based on the in-cloud scavenging parameterization of Giorgi and Chameides (1986) for highly hygroscopic aerosols and soluble gases. Furthermore, the effects of gas solubility, aerosol hygroscopicity, and mixed-phase cloud microphysics processes are also considered to the scheme. The new equation for the scavenging coefficient due to nucleation (in-cloud) scavenging for non-convective clouds $\Lambda_{\text {in }}$, which considers the chemical forms of radionuclides, height dependency, aerosol activation, and ice phase, is expressed as follows: 
(a) CCN activation fraction

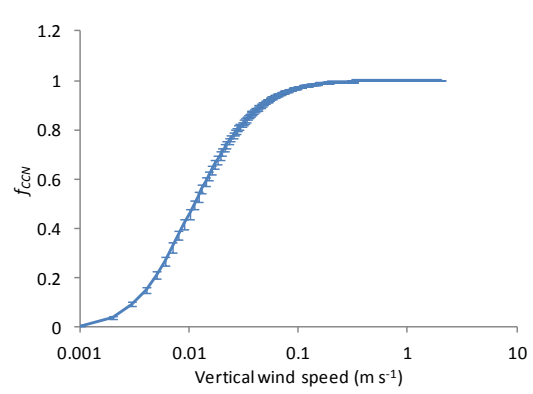

(b) In-cloud scavenging coefficient

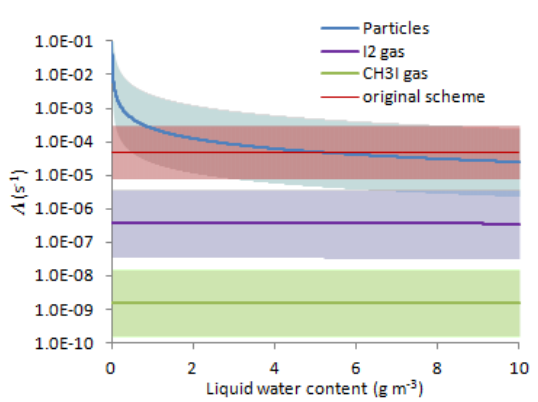

(c) Fraction of aerosols scavenged by settling hydrometeors

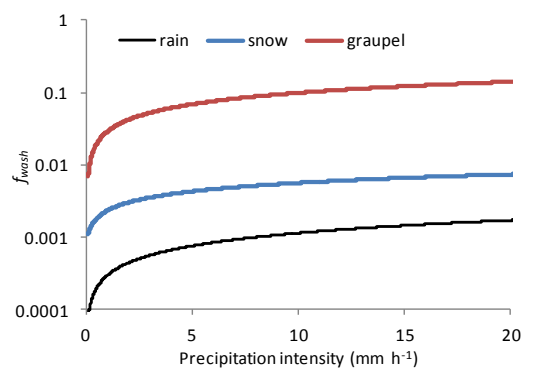

Figure A2. (a) Changes in the CCN activation fraction, $f_{\mathrm{ccn}}$, versus the vertical wind speed, (b) in the modeled in-cloud scavenging coefficient, $\Lambda$, of gaseous and particulate radioactive substances versus the vertical mean liquid water content, $\bar{W}_{\mathrm{L}}$ in Eq. (A7), and (c) in the modeled fraction of aerosols scavenged by settling hydrometeors ( $\left.f_{\text {wash }}\right)$ for rain, snow, and graupel versus the precipitation rate. Input meteorological data are mainly from the surface weather stations in Ibaraki and Fukushima Prefectures from 12 to 15 March, 2011 and show the following: $5^{\circ} \mathrm{C}$ for air temperature and $950 \mathrm{hPa}$ for air pressure in (a) and (c), and $15^{\circ} \mathrm{C}$ for air temperature, $1 \mathrm{~km}$ for cloud thickness, $1 \mathrm{~mm} \mathrm{~h}^{-1}$ for precipitation rate with $f_{\mathrm{ccn}}, f_{\mathrm{ice}}$, and $f_{\mathrm{qc}}=1$ in (b). The vertical bars in (a) show the deviation in $f_{\mathrm{ccn}}$ when air temperature and pressure were changed from 0 to $15^{\circ} \mathrm{C}$ and 900 to $1000 \mathrm{hPa}$, respectively. The shaded areas in (b) represent the range of $\Lambda$ when precipitation rate changes from 0.1 to $10 \mathrm{~mm} \mathrm{~h}^{-1}$.

$$
\begin{aligned}
& \Lambda(z)=\frac{F}{\Delta t}[1-\exp (-b \Delta t)] f_{\mathrm{ccn}}(z) f_{\mathrm{ice}}(z) f_{q_{\mathrm{c}}}(z), \\
& F=\frac{F_{0}}{1+b_{0} \tau} \\
& b=\frac{b_{0}+\tau^{-1}}{F_{0}}
\end{aligned}
$$

where $z$ is the height, $f_{\mathrm{qt}}$ is the fraction of total (solid + liquid) water mixing ratio $\left(q_{\mathrm{t}}\right)$ at each height to $q_{\mathrm{t}}$ accumulated throughout the cloud layer, $\tau_{\text {in }}$ is the lifetime of clouds (not indicating lifetime of a cloud or a cloud system but time for evolution of cloud droplets to settling hydrometeors and precipitation to ground surface), and $F_{0}$ and $b_{0}$ are the parameters given as 0.8 and $F_{0} \times 10^{-4}$, respectively (Giorgi and Chameides, 1986). $F_{\text {in }}\left[1-\exp \left(-b_{\text {in }} \Delta t\right)\right]$ indicates a fraction of hydrometeors in the atmosphere reaching the ground surface within a time step $\Delta t$, whereas $f_{\text {ccn }}(z) f_{\text {ice }}(z) f_{\mathrm{qt}}(z)$ indicates a fraction of aerosols transferring to the hydrometeors in the time step. $f_{\text {ccn }}$ and $f_{\text {ice }}$ in Eq. (A3) are the fraction of the $\mathrm{CCN}$-activated aerosols forming the cloud droplets and the ratio of evolution rate of mixed-phase cloud process relative to warm cloud processes, respectively, which are described later. It should be noted that $f_{\text {ccn }}=1$ for gaseous iodine.

The scavenged time for gases and aerosols in the accumulation mode, $\tau_{\text {in }}$, represents the amount of time required to remove aerosols or gases dissolved in all of the water from the cloud layer at the specified water equivalent precipitation rate, $P_{\mathrm{r}}$ (Byun and Schere, 2006), and is given as follows:
$\tau_{\mathrm{bl}}=\frac{\bar{W}_{\mathrm{S}}}{\rho_{\mathrm{w}} P_{\mathrm{r}}}\left(1+\gamma_{\mathrm{bl}}\right)$,

$\gamma_{\mathrm{bl}}=\left\{\begin{array}{ll}0 & (\text { particles }) \\ \frac{\rho_{\mathrm{W}}}{H_{i}^{*} \bar{W}_{\mathrm{r} T} \mathrm{RT}} & (\text { gases })\end{array}\right.$,

where $\bar{W}_{\mathrm{T}}$ is the vertically averaged total (i.e., solid + liquid) water content, $\rho_{\mathrm{W}}$ is the density of liquid water, $\bar{W}_{\mathrm{L}}$ is the vertically averaged liquid water content (cloud + rain), $R$ is the universal gas constant, $T$ is the in-cloud air temperature, and $H_{i}^{*}$ is the effective Henry's constant for gas species $i$. For gases, only dissolution to liquid hydrometeors is considered, deposition to solid hydrometeors is not considered. $H_{i}^{*}$ is calculated for gaseous ${ }^{131} \mathrm{I}$ using input data of $\mathrm{I}^{-}$concentration in rainwater of $3 \times 10^{-9} \mathrm{~mol} \mathrm{~L}^{-1}$ (Gilfedder et al., 2008) and a typical value of rainwater $\mathrm{pH}=5$ observed in eastern Japan (Ministry of the Environment of Japan, 2010), resulting in $H_{i}^{*}$ of approximately 55 and 0.23 for $\mathrm{I}_{2}$ and $\mathrm{CH}_{3} \mathrm{I}$, respectively.

\section{A4 Cloud condensation nuclei $(\mathrm{CCN})$ activation}

For calculating $f_{\mathrm{ccn}}$, the $\mathrm{CCN}$ activation and subsequent cloud microphysical processes were parameterized using Abdul-Razzak and Ghan (2000) and Lin et al. (1983). When the Abdul-Razzak and Ghan (2000) parameterization predicts that $\mathrm{CCN}$ activation occurs in a grid cell, the portions of the mass (calculated based on the predicted critical diameters and prescribed lognormal size distribution parameters of radioactive aerosols) were transferred to the grid-scale cloud droplets $\left(f_{\mathrm{ccn}}\right)$. In the above $\mathrm{CCN}$ activation scheme, the following size distribution parameters are 
adopted. Number equivalent geometric mean dry diameter was set to $100 \mathrm{~nm}$ with geometric standard deviation of 1.6 (Adachi et al., 2013). The aerosol hygroscopicity $\kappa=0.4$ was assumed based on an internal mixture of sulfate and organics (Petters and Kreidensweis, 2007), which is consistent with the activity (mass) equivalent wet particle diameter obtained by Kaneyasu et al. (2012) under the typical meteorological conditions for the season in Japan. Figure A2a shows the sensitivity of $\mathrm{CCN}$ activation fraction, $f_{\mathrm{ccn}}$, to vertical wind velocity. As shown in the figure, the value of $f_{\mathrm{ccn}}$ rapidly increases with an increase of vertical wind speed, and ambient aerosols become almost completely activated with vertical wind speed of $>0.1 \mathrm{~m} \mathrm{~s}^{-1}$.

\section{A5 Mixed-phase cloud microphysical processes}

Lin et al. (1983) developed a grid-scale explicit cloud microphysics model in which interactions between cloud droplets and other hydrometeors, such as rain, snow, and graupel droplets, are formulated. The autoconversion rate (cloud $\rightarrow$ rain) and the accretion rate of cloud droplets by rain, snow, and graupel (cloud $\rightarrow$ rain, cloud $\rightarrow$ snow, cloud $\rightarrow$ graupel), predicted by Lin et al. (1983), were used to calculate the transfer of the aerosol moments and mass in the cloud droplets to the other hydrometeors. To include the difference in the scavenging coefficient between liquid (rain) and ice phases (snow, ice crystal, and graupel), $f_{\text {ice }}$ in Eq. (A3) is modeled based on the accretion rates for both phases using the cloud microphysics model of Lin et al. (1983) as follows. First, the accretion rate from cloud to the mixture of rain, snow, and graupel is calculated at each atmospheric layer. Then, the accretion rate of cloud droplets by rain by assuming all snow and graupel water are rainwater. Finally, $f_{\text {ice }}$ is determined by dividing the former accretion ratio for mixed with rain, snow, and graupel by the latter for rain, which is considered to represent the evolution rates for ice-phase hydrometeors. During the FNPS1 accident, this modeling approach using $f_{\text {ice }}$ increased the snowfall $\Lambda_{\text {in }}$ to up to 1.4 times that of the rainfall $\Lambda_{\text {in }}$ in the model domain (Fig. S7c and e) due to the effects of riming under the supercooling environment and smaller number concentration and density of ice crystals. This is consistent to the experimental (Wolf and Dana, 1969; Graedel and Franey, 1975; Sparmacher et al., 1993; Kyrö et al., 2009; Paramonov et al., 2011) and modeling works of snow scavenging of aerosols with $1 \mu \mathrm{m}$ in mass-equivalent diameter (Stier et al., 2005; Croft et al., 2009; Zhang et al., 2013). However, some modeling studies reported a lower scavenging rate of snow crystals (Maryon and Ryall, 1996; Hongisto, 1998). This difference may be caused by a large variety in the collection efficiencies of cloud droplets by snow crystals (Sauter and Wang, 1989; Mircea and Stefan, 1998) depending on the complex physical background such as the size and shape of ice crystals and the ambient humidity (Miller and Wang, 1991; Feng, 2009; Wang et al., 2010).
Subgrid-scale scavenging is not considered in the study because the horizontal grid resolution is fine enough for regional-scale analysis $(<3 \mathrm{~km})$ and, in addition, the subgridscale convection should not be strong during the cold season.

\section{A6 Below-cloud scavenging}

The below-cloud scavenging of aerosols by raindrops and ice crystals (aerosol-hydrometeor coagulation) is very small when compared with the nucleation scavenging rate for low and moderate rainfall rates of $0.1-10 \mathrm{~mm} \mathrm{~h}^{-1}$ (Andronache, 2003; Henzing et al., 2006; Zhang et al., 2013); Oshima et al. (2013) reported that even neglecting below-cloud scavenging resulted in better performance in a regional-scale aerosol transport simulation. However, even though the scavenging coefficient is small, below-cloud scavenging may be dominant over in-cloud scavenging at locations where few aerosols exists above the cloud base, such as areas close to the emission source.

Similarly to the in-cloud scavenging, the below-cloud scavenging of aerosols and gases are formulated as follows:

$\Lambda_{\mathrm{bl}}(z)=\frac{\left[1-\exp \left(-\Delta t / \tau_{\mathrm{bl}}\right)\right]}{\Delta t} f_{\mathrm{wash}}(z) f_{\mathrm{qs}}(z)$,

where $f_{\text {wash }}(z)$ is a fraction of aerosols scavenged by settling hydrometeors in the atmosphere within a time step $\Delta t$ described as $1-\exp (-\lambda \Delta t)$ where $\lambda$ is a sum of below-cloud scavenging coefficients of aerosols by rain, snow, and graupel particles. The values of Slinn et al. (1983) with enhancement due to thermophoresis, diffusiophoresis, and electrostatic forces (Andronache, 2004, 2006) are used for the scavenging coefficient of aerosols by rain droplets, while the values of Murakami et al. (1985) are used for that by snow and graupel particles. $f_{\mathrm{qs}}$ is the fraction of settling hydrometeors (rain, snow, and graupel) mixing ratio $\left(q_{\mathrm{s}}\right)$ at each height to $q_{\text {s }}$ accumulated throughout the cloud layer. Number equivalent geometric mean diameter of aerosols is set as $500 \mathrm{~nm}$ here considering hygroscopic growth under rainfall conditions. The term $\left[1-\exp \left(-\Delta t / \tau_{\mathrm{bl}}\right)\right]$ indicates a fraction of the relevant hydrometeors in the atmosphere reaching the ground surface within a time step $\Delta t$, whereas $f_{\text {wash }}(z) f_{\mathrm{qs}}(z)$ indicates a fraction of aerosols transferring to the hydrometeors within the time step. $\tau_{\mathrm{bl}}$ is defined as

$$
\begin{aligned}
& \tau_{\mathrm{bl}}=\frac{\bar{W}_{\mathrm{S}}}{\rho_{w} P_{r}}\left(1+\gamma_{\mathrm{bl}}\right), \\
& \gamma_{\mathrm{bl}}=\left\{\begin{array}{cc}
0 & \text { (particles) } \\
\frac{\rho_{w}}{H_{i}^{*} \bar{W}_{\mathrm{r}} R T} & \text { (gases) }
\end{array}\right.
\end{aligned}
$$

where $\bar{W}_{\mathrm{S}}$ is the vertically averaged settling hydrometeors water content and $\gamma_{\mathrm{bl}}$ is similar to that of Eq. (A7) but with $\bar{W}_{\mathrm{r}}$, the vertically averaged rainwater content. It should be noted that $f_{\text {wash }}=1$ for gaseous iodine. The below-cloud scavenging is activated in a model grid cell when the settling 
hydrometeor mixing ratio is higher than $10^{-9}\left(\mathrm{~kg} \mathrm{~kg}^{-1}\right)$ and the surface precipitation intensity is larger than zero.

\section{A7 Modeled scavenging coefficient}

The modeled scavenging coefficient $\left(\Lambda_{\text {in }}\right)$ by the modified wet deposition scheme for particle and gas is depicted in Fig. A2b. It is shown that $\Lambda$ for particles decreases with an increase of total water content $\left(\bar{W}_{\mathrm{T}}\right)$ with constant precipitation rate $\left(P_{\mathrm{r}}\right)$ according to Eqs. (A3-A5) because $\Lambda$ is a function of a reciprocal of $\tau$ represented as Eqs. (A6) and (A9). This means that less scavenged water is present in the atmosphere when $\bar{W}_{\mathrm{T}}$ is small. For $\mathrm{I}_{2}$ and $\mathrm{CH}_{3} \mathrm{I}$ gases, $\gamma$ becomes large compared with that of a particle (Eqs. A7 and A10) because it takes a longer time for the cloud droplets to dissolve less-soluble gases. This increases the removal time for clouds (Eqs. A6 and A9), resulting in a lower scavenging coefficient. Figure A2c shows the precipitation intensity dependence of $f_{\text {wash }}$ for aerosols in Eq. (A8). As seen in Fig. A2c, $f_{\text {wash }}$ increases as the precipitation increases but the values are up to $0.1,1$, and $10 \%$ for rain, snow, and graupel, respectively, even at very high precipitation intensity $\left(10 \mathrm{~mm} \mathrm{~h}^{-1}\right)$. In the presence of same amounts of radionuclides, hydrometeors in the air, and precipitation intensity, $\Lambda_{\text {bl }}$ is almost equivalent to $\Lambda_{\text {in }}$ as shown in Fig. A2b multiplied by $f_{\text {wash }}$. Therefore, the contribution of $\Lambda_{\text {bl }}$ to total scavenging coefficient $\Lambda\left(\Lambda_{\text {in }}+\Lambda_{\text {bl }}\right)$ for rain, snow, and graupel are approximately $0.01-0.1,0.1-1$, and $1-10 \%$, respectively. In the current simulation, since most of the precipitation was due to rain and snow in the contaminated areas, $\Lambda_{\mathrm{bl}}$ was smaller. The contribution of below-cloud scavenging to the total wet deposition over the whole regional and local domains was up to $1 \%$. The original WSPEEDI-II has $\Lambda=10^{-5}-10^{-4} \mathrm{~s}^{-1}$, empirically determined from field measurement data of $\Lambda$ by Brenk and Vogt (1981). This value is consistent with the calculation result of the modified scheme of Eq. (A3) when the cloud liquid water content is high. For low cloud water content $\left(<1 \mathrm{~g} \mathrm{~m}^{-3}\right), \Lambda$ becomes large, up to $10^{-1} \mathrm{~s}^{-1}$ in the new scheme. In the FNPS1 accident, for example, calculated values of $\Lambda$ in the areas of Nakadori and Tochigi and Gunma Prefectures in the WSPEEDI simulation ranged from $10^{-4}$ to $10^{-3} \mathrm{~s}^{-1}$ when the plume passed through there in the afternoon of 15 March (Fig. S6). This result is reasonable when compared with many observational studies for light and moderate rain events in various areas including Japan (Jylhä, 1991; Okita et al., 1996; Minoura and Iwasaka, 1997; Laakso et al., 2003; Andronache, 2004; Zhang et al., 2013). A few studies also reported very high values of $\Lambda>10^{-3} \mathrm{~s}^{-1}$ for cosmogenic radionuclides (Davis, 1972) and of $\Lambda=0.2 \mathrm{~s}^{-1}$ for cloud droplets in 5-60 $\mu \mathrm{m}$ diameter range (Levine and Schwartz, 1982).

The $\Lambda$ for radioactive particles is 2 orders of higher magnitude than that of $I_{2}$ gas due to the effect of gas solubility modeled in Eqs. (A7) and (A10). In the same manner, the $\Lambda$ for $\mathrm{CH}_{3} \mathrm{I}$ gas has very small values in the range of $10^{-10_{-}}$
$10^{-8} \mathrm{~s}^{-1}$ due to its very low Henry's constant (Fig. A2b). Such a tendency as lower $\Lambda$ for gas than that for particle is supported by the observational studies (Brenk and Vogt, 1981).

\section{A8 Fog-water deposition}

Fog-water deposition is the phenomenon that radionuclides in liquid water droplets of fog or low clouds are transported downward by turbulence above the ground, and eventually these droplets are intercepted by the plant canopies (Lovett, 1984). Although the potential effect of this process has been suggested in prior work (Baklanov and Sørensen, 2001), modeling of fog-water deposition is not done in any of the existing dispersion models (Table 1). This study introduces a simple and accurate Fog Deposition EStimation (FogDES) scheme for meteorological models (Katata et al., 2011a; Katata, 2014). In general, fog-water deposition can be also calculated using Eq. (A1) with the concentration of radionuclides in cloud liquid water in the lowest atmospheric layer. To simplify, radionuclides are assumed to be completely absorbed by fog water. Only the parameter of $V_{\mathrm{d}}$ is required to calculate the fog-water deposition flux. In the FogDES scheme, $V_{\mathrm{d}}$ for fog water $\left(V_{\mathrm{df}}\right)$ can be parameterized as a linear function of the horizontal wind speed and vegetation parameters:

$V_{\mathrm{df}}=R_{\mathrm{LUC}} A_{\mathrm{c}} U$

$A_{\mathrm{c}}=\left\{\begin{array}{l}0.0164(\mathrm{LAI} / h)^{-0.5} \\ 0.0095 \mathrm{LAI}^{3} \\ -0.05 \mathrm{LAI}^{2}+0.0916 \mathrm{LAI}+0.0082\end{array}\right.$

where LAI is the leaf area index, $h$ is the canopy height, $R_{\mathrm{LUC}}$ is the ratio of $V_{\mathrm{df}}$ for each land-use category (LUC) of MM5 to that for coniferous forest (i.e., $R_{\mathrm{LUC}}=1$ for coniferous forest). $A_{\mathrm{c}}$ value was set to be constant as 0.0248 determined at dense mountainous forest in Germany (Katata et al., 2008) due to lack of accurate data of vegetation parameters (LAI and $h$ ) in the study area. By considering relatively small $V_{\mathrm{df}}$ for short vegetation compared with tall vegetation (e.g., Gallagher et al., 1988), the value of $1,0.2$, and 0.1 were applied to $R_{\mathrm{LUC}}$ for forest, short vegetation (such as crop- and grassland), and smooth surfaces (such as water bodies and bare soil).

The deposition velocity due to fog water is plotted against wind speed in Fig. A1. The calculations are in the range of observation data ranging from 2 to $8 \mathrm{~cm} \mathrm{~s}^{-1}$ and 1 to $100 \mathrm{~cm} \mathrm{~s}^{-1}$ over short vegetation (e.g., Gallagher et al., 1988; Thalmann et al., 2002) and dense closed forest (e.g., Dasch, 1988; Klemm and Wrzesinsky, 2007; Eugster et al., 2006) as reviewed in Katata (2014). Importantly, the figure also shows relatively large impacts of fog-water deposition to total deposition compared with dry deposition because the fog droplets are larger than submicron aerosols and have a higher impaction efficiency on plant leaves. 


\section{The Supplement related to this article is available online at doi:10.5194/acp-15-1029-2015-supplement.}

Acknowledgements. The authors express their gratitude to Shinichiro Kado, Kyoto University in Japan, Fumiya Tanabe, Sociotechnical Systems Safety Research Institute in Japan, and Yu Maruyama, Japan Atomic Energy Agency (JAEA) in Japan, for their helpful comments and suggestions. Kevin Foster, Lawrence Livermore National Laboratory, Livermore (LLNL) of the USA, provided the digital data of air dose rate from US-DOE airborne monitoring. The source terms of Hirao et al. (2013) and Winiarek et al. (2014) were provided by Shigekazu Hirao, Nagoya University in Japan and Victor Winiarek, Centre d'Enseignement et de Recherche en Environnement Atmosphérique (CEREA) in France, respectively. This study was partly supported by a Grant-in-Aid for Scientific Research, no. 21120512, provided by the Japan Society for the Promotion of Science (JSPS).

Edited by: A. Stohl,

\section{References}

Abdul-Razzak, H., and Ghan, S. J.: A parameterization of aerosol activation, 2. Multiple aerosol types, J. Geophys. Res., 105, 6837-6844, doi:10.1029/1999JD901161, 2000.

Achim, P., Monfort, M., Le Petit, G., Gross, P., Douysset, G., Taffary, T., Blanchard, X., and Moulin, C.: Analysis of radionuclide releases from the Fukushima Dai-ichi Nuclear Power Plant Accident Part II, Pure Appl. Geophys., 171, 645-667, doi:10.1007/s00024-012-0578-1, 2014.

Adachi, K., Kajino, M., Zaizen, Y., and Igarashi, Y.: Emission of spherical cesium-bearing particles from an early stage of the Fukushima nuclear accident, Sci. Rep., 3, 2554, doi:10.1038/srep02554, 2013.

Amano, H., Akiyama, M., Chunlei, B., Kawamura, T., Kishimoto, T., Kuroda, T., Muroi, T., Odaira, T., Ohta, Y., Takeda, K., Watanabe, Y., and Morimoto, T.: Radiation measurements in the Chiba Metropolitan Area and radiological aspects of fallout from the Fukushima Dai-ichi Nuclear Power Plants accident, J. Environ. Radioactiv., 111, 42-52, doi:10.1016/j.jenvrad.2011.10.019, 2012.

Andronache, C.: Estimated variability of below-cloud aerosol removal by rainfall for observed aerosol size distributions, Atmos. Chem. Phys., 3, 131-143, doi:10.5194/acp-3-131-2003, 2003.

Andronache, C.: Estimates of sulfate aerosol wet scavenging coefficient for locations in the Eastern United States, Atmos. Environ., 38, 795-804, doi:10.1016/j.atmosenv.2003.10.035, 2004.

Aoyama, M., Tsumune, D., and Hamajima, Y.: Distribution of ${ }^{137} \mathrm{Cs}$ and ${ }^{134} \mathrm{Cs}$ in the North Pacific Ocean: impacts of the TEPCO Fukushima-Daiichi NPP accident, J. Radioanal. Nucl. Ch., 296, 535-539, doi:10.1007/s10967-012-2033-2, 2012.

Baklanov, A. and Sørensen, J. H.: Parameterisation of radionuclide deposition in atmospheric long-range transport modelling, Phys. Chem. Earth, 26, 787-799, doi:10.1016/S1464-1909(01)000879, 2001.
Brenk, H. D. and Vogt, K. J., The calculation of wet deposition from radioactive plumes, Nucl. Safety, 22, 362-371, 1981.

Byun, D. and Schere, K. L.: Review of the governing equations, computational algorithms, and other components of the models3 Community Multiscale Air Quality (CMAQ) modeling system, Appl. Mech. Rev., 59, 1-6, 2006.

Chino, M., Nakayama, H., Nagai, H., Terada, H., Katata, G., and Yamazawa, H.: Preliminary estimation of release amounts of ${ }^{131} \mathrm{I}$ and ${ }^{137} \mathrm{Cs}$ accidentally discharged from the Fukushima Daiichi nuclear power plant into atmosphere, J. Nucl. Sci. Technol., 48, 1129-1134, doi:10.1080/18811248, 2011.

Christoudias, T. and Lelieveld, J.: Modelling the global atmospheric transport and deposition of radionuclides from the Fukushima Dai-ichi nuclear accident, Atmos. Chem. Phys., 13, 1425-1438, doi:10.5194/acp-13-1425-2013, 2013.

Comprehensive Nuclear-Test-Ban Treaty Organization, Preparatory Commission (CTBTO): Fukushima-related Measurements by CTBTO, available at: http://www.ctbto.org/press-centre/ highlights/2011/fukushima-related-measurements-by-the-ctbto (last access: 12 November 2014), 2011.

Croft, B., Lohmann, U., Martin, R. V., Stier, P., Wurzler, S., Feichter, J., Posselt, R., and Ferrachat, S.: Aerosol size-dependent below-cloud scavenging by rain and snow in the ECHAM5HAM, Atmos. Chem. Phys., 9, 4653-4675, doi:10.5194/acp-94653-2009, 2009.

D’Amours, R., Malo, A., Servranckx, R., Bensimon, D., Trudel, S., and Gauthier, J.-P.: Application of the atmospheric Lagrangian particle dispersion model MLDP0 to the 2008 eruptions of Okmok and Kasatochi volcanoes, J. Geophys. Res., 115, D00L11, doi:10.1029/2009JD013602, 2010.

Dasch, M. J.: Hydrological and chemical inputs to fir trees from rain and clouds during a 1-month study at Clingmans Peak, NC, Atmos. Environ., 22, 2255-2262, 1988.

Davis, W. E.: A model for in-cloud scavenging of cosmogenic radionuclides, J. Geophys. Res., 77, 2159-2165, doi:10.1029/JC077i012p02159, 1972.

Draxler, R. R.: The use of global and mesoscale meteorological model data to predict the transport and dispersion of tracer plumes over Washington, DC, Weather Forecast., 21, 383-394, 2006.

Draxler, R. R. and Rolph, G. D.: Evaluation of the transfer coefficient matrix (TCM) approach to model the atmospheric radionuclide air concentrations from Fukushima, J. Geophys. Res., 117, D05107, doi:10.1029/2011JD017205, 2012.

Draxler, R., Arnold, D., Chino, M., Galmarini, S., Hort, M. Jones, A., Leadbetter, S., Malo, A., Maurer, C., Rolph, G., Saito, K., Servranckx, R., Shimbori, T., Solazzo, E., and Wotawa, G.: World Meteorological Organization's model simulations of the radionuclide dispersion and deposition from the Fukushima Daiichi Nuclear Power Plant accident, J. Environ. Radioactiv., 172-184, doi:10.1016/j.jenvrad.2013.09.014,139, 2015

Dvorzhak, A., Puras, C., and Montero, M.: Spanish experience on modeling of environmental radioactive contamination due to Fukushima Daiichi NPP Accident using JRODOS, Environ. Sci. Technol., 46, 11887-11895, doi:10.1021/es301687t, 2012.

Eugster, W., Burkard, R., Holwerda, F., Scatena, F. N., and Bruijnzeel, L. A.: Characteristics of fog and fogwater fluxes in 
a Puerto Rican elfin cloud forest, Agr. Forest Meteorol., 139, 288-306, doi:10.1016/j.agrformet.2006.07.008, 2006.

Evangeliou, N., Balkanski, Y., Cozic, A., and Moller, A. P.: Global transport and deposition of Cs-137 following the Fukushima Nuclear Power Plant Accident in Japan: emphasis on Europe and Asia using high-resolution model versions and radiological impact assessment of the human population and the environment using interactive tools, Environ. Sci. Technol., 47, 5803-5812, doi:10.1021/es400372u, 2013.

Feng, J.: A size-resolved model for below-cloud scavenging of aerosols by snowfall, J. Geophys. Res., 114, D08203, doi:10.1029/2008JD011012, 2009.

Fuchs, N. A.: The Mechanics of Aerosols, Pergamon Press, Oxford, 1964.

Fukushima Prefecture: Results of environmental radioactivity monitoring around $20 \mathrm{~km}-50 \mathrm{~km}$ zone, available at: http://www.pref. fukushima.jp/j/20-50km0315-0331.pdf (last access: 12 November 2014), 2011a (in Japanese).

Fukushima Prefecture: Results of environmental radioactivity monitoring in Fukushima Prefecture, available at: http://www.pref. fukushima.jp/j/7houbu0311-0331.pdf (last access: 25 Novemner 2014), 2011b (in Japanese).

Fukushima Prefecture: Results of air dose rate measurement on March 2011 (data retrieved from monitoring posts in Fukushima Prefecture), available at: http://www.atom-moc.pref.fukushima. jp/monitoring/monitoring201103/201103_mpdata.html (last access: 12 November 2014), 2012 (in Japanese).

Furuno, A., Terada, H., Chino, M., and Yamazawa, H.: Experimental verification for real-time environmental emergency response system: WSPEEDI by European tracer experiment, Atmos. Environ., 38, 6989-6998, doi:10.1016/j.atmosenv.2004.02.074, 2004.

Furuta, S., Sumiya, S., Watanabe, H., Nakano, M., Imaizumi, K., Takeyasu, M., Nakada, A., Fujita, H., Mizutani, T., Morisawa, M., Kokubun, Y., Kono, T., Nagaoka, M., Yokoyama, H., Hokama, T., Isozaki, T., Nemoto, M., Hiyama, Y., Onuma, T., Kato, C., and Kurachi, T.: Results of the environmental radiation monitoring following the accident at the Fukushima Daiichi Nuclear Power Plant; Interim report (Ambient radiation dose rate, radioactivity concentration in the air and radioactivity concentration in the fallout), JAEA-Review 2011-035, Japan Atomic Energy Agency, Ibaraki, Japan, 2011 (in Japanese with English abstract).

Gallagher, M. W., Choularton, T. W., Morse, A. P., and Fowler, D.: Measurements of the size dependence of cloud droplet deposition at a hill site, Q. J. Roy. Meteor. Soc., 114, 1291-1303, 1988.

Gallagher, M. W., Beswick, K. M., Choularton, T. W., Duyzer, J., Westrate, H., and Hummelshøj, P.: Measurements of aerosol fluxes to speulder forest using a micrometeorological technique, Atmos. Environ., 31, 359-373, doi:10.1016/S13522310(96)00057-X, 1997.

Gilfedder, B. S., Lai, S. C., Petri, M., Biester, H., and Hoffmann, T.: Iodine speciation in rain, snow and aerosols, Atmos. Chem. Phys., 8, 6069-6084, doi:10.5194/acp-8-6069-2008, 2008.

Giorgi, F. and Chameides, W. L.: Rainout lifetimes of highly soluble aerosols and gases inferred from simulations with a general circulation model, J. Geophys. Res., 91, 14367-14376, 1986.

Graedel, T. E. and Franey, J. P.: Field measurements of submicron aerosol washout by snow, Geophys. Res. Lett., 2, 325-328, doi:10.1029/GL002i008p00325, 1975.
Grell, G. A., Dudhia, J., and Stauffer, D. R.: A Description of the Fifth-generation Penn State/NCAR Mesoscale Model (MM5), NCAR Tech. Note NCAR/TN-3921STR, Boulder, CO, 122 pp., 1994.

Haba, H., Kaneya, J., Mukai, H., Kambara, T., and Kase, M.: Oneyear monitoring of airborne radionuclides in Wako, Japan, after the Fukushima Dai-ichi nuclear power plant accident in 2011, Geochem. J., 46, 271-278, 2012.

HCRM (Health Canada's Radiation Monitoring): Health Canada's Radiation Monitoring (HCRM) Data and the Nuclear Emergency in Japan, the CTBTO data for Canadian stations, http://www. hc-sc.gc.ca/hc-ps/ed-ud/respond/nuclea/data-donnees-eng.php (last access: 25 November 2014), 2011.

Henzing, J. S., Olivié, D. J. L., and van Velthoven, P. F. J.: A parameterization of size resolved below cloud scavenging of aerosols by rain, Atmos. Chem. Phys., 6, 3363-3375, doi:10.5194/acp-63363-2006, 2006.

Hertel, O., Christensen, J., Runge, E. H., Asman, W. A. H., Berkowicz, R., Hovmand, M. F., and Hov, Ø.: Development and testing of a new variable scale air pollution model - ACDEP, Atmos. Environ., 29, 1267-1290, doi:10.1016/1352-2310(95)00067-9, 1995.

Hicks, B. B., Baldocchi, D. D., Meyers, T. P., Hosker, R. P., and Matt, D. R.: A preliminary multiple resistance routine for deriving dry deposition velocities from measured quantities, Water Air Soil Poll., 36, 311-330, doi:10.1007/BF00229675, 1987.

Hirao, S., Yamazawa, H.; Nagae, T.: Estimation of release rate of iodine-131 and cesium-137 from the Fukushima Daiichi nuclear power plant, J. Nucl. Sci. Technol., 50, 139-147, doi:10.1080/00223131.2013.757454, 2013.

Honda, M. C., Aono, T., Aoyama, M., Hamajima, Y., Kawakami, H., Kitamura, M., Masumoto, Y., Miyazawa, Y., Takigawa, M., and Saino, T.: Dispersion of artificial caesium134 and -137 in the western North Pacific one month after the Fukushima accident, Geochem. J., 46, E1-E9, 2012.

Hongisto, M.: HILATAR, a Regional Scale Grid Model for the Transport of Sulphur and Nitrogen Compounds, Description of the Model and Simulation Results for the Year 1993, Finnish Meteorological Institute, Helsinki, No. 21, 1998.

Ibaraki Prefecture: Radiation Dose Measurements in Ibaraki Prefecture, available at: http://www.pref.ibaraki.jp/20110311eq/ radiation.html (last access: 12 November 2014), 2011 (in Japanese).

Jacobson, M. Z.: Fundamentals of Atmospheric Modeling, Cambridge University Press, Cambridge, 828 pp., 2005.

Jones, A. R., Thomson, D. J., Hort, M. C., and Devenish, B.: The UK Met Office's next-generation atmospheric dispersion model, NAME III, in: Air Pollution and its Applications XVII, edited by: Borrego, C. and Norman, A. L., Proceedings of the 27th NATO/CCMS International Technical Meeting on Air Pollution Modelling and its Application, Springer, 580-589, 2007.

Jylhä, K.: Empirical scavenging coefficients of radioactive substances released from chernobyl, Atmos. Environ., 25, 263-270, doi:10.1016/0960-1686(91)90297-K, 1991.

Kajino, M., Inomata, Y., Sato, K., Ueda, H., Han, Z., An, J., Katata, G., Deushi, M., Maki, T., Oshima, N., Kurokawa, J., Ohara, T., Takami, A., and Hatakeyama, S.: Development of the RAQM2 aerosol chemical transport model and predictions of the Northeast Asian aerosol mass, size, chemistry, and mixing 
type, Atmos. Chem. Phys., 12, 11833-11856, doi:10.5194/acp12-11833-2012, 2012.

Kaneyasu, N., Ohashi, H., Suzuki, F., Okuda, T., and Ikemori, F.: Sulfate aerosol as a potential transport medium of radiocesium from the Fukushima nuclear accident, Environ. Sci. Technol., 46, 5720-5726, doi:10.1021/es204667h, 2012.

Katata, G.: Fogwater deposition modeling for terrestrial ecosystems: A review of developments and measurements, J. Geophys. Res., 119, 8137-8159, doi:10.1002/2014JD021669, 2014.

Katata, G., Nagai, H., Wrzesinsky, T., Klemm, O., Eugster, W., and Burkard, R.: Development of a land surface model including cloud water deposition on vegetation, J. Appl. Meteorol.Climatol., 47, 2129-2146, 2008.

Katata, G., Kajino, M., Hiraki, T., Aikawa, M., Kobayashi, T., and Nagai, H.: A method for simple and accurate estimation of fog deposition in a mountain forest using a meteorological model, J. Geophys. Res., 116, D20102, doi:10.1029/2010JD015552, 2011a.

Katata, G., Nagai, H., Zhang, L., Held, A., Serça, D., and Klemm, O.: Development of an atmosphere-soil-vegetation model for investigation of radioactive materials transport in the terrestrial biosphere, Prog. Nucl. Sci. Technol., 2, 530-537, $2011 b$.

Katata, G., Terada, H., Nagai, H., and Chino, M.: Numerical reconstruction of high dose rate zones due to the Fukushima Daiichi Nuclear Power Plant accident, J. Environ. Radioact., 111, 2-12, doi:10.1016/j.jenvrad.2011.09.011, 2012a.

Katata, G., Ota, M., Terada, H., Chino, M., and Nagai, H.: Atmospheric discharge and dispersion of radionuclides during the Fukushima Dai-ichi Nuclear Power Plant accident, Part I: Source term estimation and local-scale atmospheric dispersion in early phase of the accident, J. Environ. Radioactiv., 109, 103-113, doi:10.1016/j.jenvrad.2012.02.006, 2012b.

Katata, G., Kajino, M., Matsuda, K., Takahashi, A., and Nakaya, K.: A numerical study of the effects of aerosol hygroscopic properties to dry deposition on a broad-leaved forest, Atmos. Environ., 97, 501-510, doi:10.1016/j.atmosenv.2013.11.028, 2014.

Kawamura, H., Kobayashi, T., Furuno, A., Usui, N., Kamachi, M.: Numerical simulation on the long-term variation of radioactive cesium concentration in the North Pacific due to the Fukushima disaster, J. Environ. Radioact., 136, 64-75, doi:10.1016/j.jenvrad.2014.05.005, 2014.

KEK (High Energy Accelerator Research Organization): Radiation monitoring at KEK, available at: http://legacy.kek.jp/quake/ radmonitor/index-e.html (last access: 12 November 2014), 2011.

Kerkweg, A., Buchholz, J., Ganzeveld, L., Pozzer, A., Tost, H., and Jöckel, P.: Technical Note: An implementation of the dry removal processes DRY DEPosition and SEDImentation in the Modular Earth Submodel System (MESSy), Atmos. Chem. Phys., 6, 4617-4632, doi:10.5194/acp-6-4617-2006, 2006.

Kirsch, A. A. and Fuchs, N. A.: Studies on fibrous aerosol filters. III. Diffusional deposition of aerosols in fibrous filters, Ann. Occup. Hyg., 11, 299-304, 1968.

Klemm, O. and Wrzesinsky, T.: Fog deposition fluxes of water and ions to a mountainous site in Central Europe, Tellus B, 59, 705714, doi:10.1111/j.1600-0889.2007, 2007.

Kobayashi, T., Otosaka, S., Togawa, O., and Hayashi, K.: Development of a non-conservative radionuclides dispersion model in the ocean and its application to surface cesium-137 dis- persion in the Irish Sea, J. Nucl. Sci. Technol., 44, 238-247, doi"10.1080/18811248.2007.9711278, 2007.

Kobayashi, T., Nagai, H., Chino, M., and Kawamura, H.: Source term estimation of atmospheric release due to the Fukushima Dai-ichi Nuclear Power Plant accident by atmospheric and oceanic dispersion simulations, J. Nucl. Sci. Technol., 50, 255264, doi:10.1080/00223131.2013.772449, 2013.

Korsakissok, I., Mathieu, A., and Didier, D.: Atmospheric dispersion and ground deposition induced by the Fukushima Nuclear Power Plant accident: a local-scale simulation and sensitivity study, Atmos. Environ., 70, 267-279, doi:10.1016/j.atmosenv.2013.01.002, 2013.

Kyrö, E. M., Grönholm, T., Vuollekoski, H., Virkkula, A., Kulmala, M., and Laakso, L.: Snow scavenging of ultrafine particles: field measurements and parameterization, Boreal Environ. Res., 14, 527-538, 2009.

Laakso, L., Grönholm, T., Rannik, U., Kosmale, M., Fiedler, V., Vehkamäki, H., and Kulmala, M.: Ultrafine particle scavenging coefficients calculated from 6 years field measurements, Atmos. Environ., 37, 3605-3613, doi:10.1016/S1352-2310(03)00326-1, 2003.

Leadbetter, S., Hort, M., Jones, A., Webster, H., and Draxler, R.: Sensitivity of the modeled deposition of Caesium-137 from the Fukushima Dai-ichi nuclear power plant to the wet deposition parameterization in NAME, 200-211, doi:10.1016/j.atmosenv.2014.03.018, 139, 2015.

Levine, S. Z. and Schwartz, S. E.: In-cloud and below-cloud scavenging of Nitric acid vapor, Atmos. Environ., 16, 1725-1734, doi:10.1016/0004-6981(82)90266-9, 1982.

Lin, Y.-L., Richard, D. F., and Harold, D. O.: Bulk parameterization of the snow field in a cloud model, J. Clim. Appl. Meteorol., 22, 1065-1092, 1983.

Lovett, G. M.: Rates and mechanisms of cloud water deposition to a subalpine balsam fir forest, Atmos. Environ., 18, 361-371, doi:10.1016/0004-6981(84)90110-0, 1984.

Maryon, R. H. and Ryall, D. B.: Developments to the UK Nuclear Accident Response Model (NAME), Department of Environment, UK Met. Office, DoE Report \# DOE/RAS/96.011, London, UK, 1996.

Masson, O., Baeza, A., Bieringer, J., Brudecki, K., Bucci, S., Cappai, M., Carvalho, F. P., Connan, O., Cosma, C., Dalheimer, A., Didier, D., Depuydt, G., De Geer, L. E., De Vismes, A., Gini, L., Groppi, F., Gudnason, K., Gurriaran, R., Hainz, D., Halldorsson, O., Hammond, D., Hanley, O., Holey, K., Zs Homoki,., Ioannidou, A., Isajenko, K., Jankovic, M., Katzlberger, C., Kettunen, M., Kierepko, R., Kontro, R., Kwakman, P. J. M., Lecomte, M., Leon Vintro, L., Leppänen, A.-P., Lind, B., Lujaniene, G., Mc Ginnity, P., Mc Mahon, C., Mala, H., Manenti, S., Manolopoulou, M., Mattila, A., Mauring, A., Mietelski, J. W., Moller, B., Nielsen, S. P., Nikolic, J., Overwater, R. M. W., Palsson, S. E., Papastefanou, C., Penev, I., Pham, M. K., Povinec, P. P., Ramebäck, H., Reis, M. C., Ringer, W., Rodriguez, A., Rulik, P., Saey, P. R. J., Samsonov, V., Schlosser, C., Sgorbati, G., Silobritiene, B. V., Söderström, C., Sogni, R., Solier, L., Sonck, M., Steinhauser, G., Steinkopff, T., Steinmann, P., Stoulos, S., Sykora, I., Todorovic, D., Tooloutalaie, N., Tositti, L., Tschiersch, J., Ugron, A., Vagena, E., Vargas, A., Wershofen, H., and Zhukova, O.: Tracking of airborne radionuclides from the damaged Fukushima Dai-Ichi nuclear re- 
actors by European Networks, Environ. Sci. Technol., 45, 76707677, doi:10.1021/es2017158, 2011.

Mathieu, A., Korsakissok, I., Quélo, D., Groëll, J., Tombette, M., Didier, D., Quentric, E., Saunier, O., Benoit, J.-P., and Isnard, O.: Atmospheric dispersion and deposition of radionuclides from the Fukushima Daiichi nuclear power plant accident, Elements, 8, 195-200, doi:10.1175/1520-0450(1998)037, 2012.

Masuda, S., Awaji, T., Sugiura, N., Toyoda, T., Ishikawa, Y., and Horiuchi, K.: Interannual variability of temperature inversions in the subarctic North Pacific, Geophys. Res. Lett., 33, L24610, doi:10.1029/2006GL027865, 2006.

Matsuda, K., Fujimura, Y., Hayashi, K., Takahashi, A., and Nakaya, K.: Deposition velocity of $\mathrm{PM}_{2.5}$ sulfate in the summer above a deciduous forest in central Japan, Atmos. Environ., 44, 4582-4587, doi:10.1016/j.atmosenv.2010.08.015, 2010.

METI (Ministry of Economy, Trade and Industry), available at: http://www.meti.go.jp/press/2011/06/20110603019/ 20110603019.html (last access: 12 November 2014), 2011 (in Japanese).

Miller, C. T., Poirier Mcneill, M. M., and Mayer, A. S.: Dissolution of trapped nonaqueous phase liquids: mass transfer characteristics, Water Resour. Res., 26, 2783-2796, doi:10.1029/WR026i011p02783, 1990.

Miller, N. L. and Wang, P. K.: Theoretical determination of the efficiency of aerosol particle collection by falling columnar ice crystals, J. Atmos. Sci., 46, 1656-1663, doi:10.1175/1520-0469, 1989.

Ministry of the Environment of Japan: Comprehensive summary report on acid deposition monitoring survey Phase 4, available at: http://db.cger.nies.go.jp/dataset/acidrain/ja/04/ index.html (last access: 12 November 2014), 2010 (in Japanese).

Minoura, H. and Iwasaka, Y.: Ion concentration changes observed in drizzling rains, Atmos. Res., 45, 165-182, doi:10.1016/S01698095(97)00041-0, 2006.

Mircea, M. and Stefan, S.: A theoretical study of the microphysical parameterization of the scavenging coefficient as a function of precipitation type and rate, Atmos. Environ., 32, 2931-2938, doi:10.1016/S1352-2310(98)00018-1, 1998.

Miyamoto, Y., Yasuda, K., and Magara, M.: Size distribution of radioactive particles collected at Tokai, Japan 6 days after the nuclear accident, J. Environ. Radioactiv., 132, 1-7, doi:10.1016/j.jenvrad.2014.01.010, 2014.

Morino, Y., Ohara, T., and Nishizawa, M.: Atmospheric behavior, deposition, and budget of radioactive materials from the Fukushima Daiichi nuclear power plant in March 2011, Geophys. Res. Lett., 38, L00G11, doi:10.1029/2011GL048689, 2011.

Morino, Y., Ohara, T., Watanabe, M., Hayashi, S., and Nishizawa, M.: Episode analysis of deposition of radiocesium from the Fukushima Daiichi nuclear power plant accident, Environ. Sci. Technol., 47, 2314-2322, doi:10.1021/es304620x, 2013.

Morrison, H., Curry, J. A., and Khvorostyanov, V. I.: A new doublemoment microphysics parameterization for application in cloud and climate models, Part I: Description, J. Atmos. Sci., 62, 16651677, 2005.

NOAA (National Oceanic and Atmospheric Administration): National Oceanic and Atmospheric Administration, Air Resources Laboratory, Fukushima Daiichi Nuclear Power Plant Trans- fer Coefficient Matrix, available at: http://ready.arl.noaa.gov/ READY_fdnpp.php (last access: 12 November 2014), 2012.

NOAA: World Meteorological Organization (WMO) Atmospheric Dispersion Model Simulations of Fukushima Daiichi Accident, US National Oceanic and Atmospheric Administration, available at: http://ready.arl.noaa.gov/READY_fdnppwmo.php (last access: 12 November 2014), 2014.

Nishihara, K., Iwamoto, H., and Suyama, K.: Estimation of fuel compositions in Fukushima-Daiichi nuclear power plant, JAEAData/Code 2012-018, Japan Atomic Energy Agency, 2012 (in Japanese with English abstract).

NRA (Nuclear Regulation Authority), Readings of Seawater and Dust Monitoring in Sea Area by MEXT (March 2011), http: //radioactivity.nsr.go.jp/en/list/259/list-201103.html, 2011 (last access: 12 November 2014)

NRA: Airborne Monitoring Results in each prefecture, available at: http://radioactivity.nsr.go.jp/en/list/203/list-1.html (last accress: 12 November 2014), 2012a.

NRA: Readings of dust sampling (All Results for May 2011), available at: http://radioactivity.nsr.go.jp/en/contents/4000/3156/ 24/dustsampling_AllResultsforMay 2011.pdf (last access: 12 November 2014), 2012b.

Ohfuchi, W., Nakamura, H., Yoshioka, M. K., Enomoto, T., Takaya, K., Peng, X., Yamane, S., Nishimura, T., Kurihara, Y., and Ninomiya, K.: $10-\mathrm{km}$ mesh meso-scale resolving simulations of the global atmosphere on the Earth Simulator: preliminary outcomes of AFES (AGCM for the Earth Simulator), J. Earth Simulator, 1, 8-34, doi:10.1029/2004GL019895, 2004.

Ohkura, T., Oishi, T., Taki, M., Shibanuma, Y., Kikuchi, M., Akino, H., Kikuta, Y., Kawasaki, M., Saegusa, J., Tsutsumi, M., Ogose, H., Tamura, S., and Sawahata, T.: Emergency Monitoring of Environmental Radiation and Atmospheric Radionuclides at Nuclear Science Research Institute, JAEA Following the Accident of Fukushima Daiichi Nuclear Power Plant, JAEAData/Code 2012-01, Japan Atomic Energy Agency, Ibaraki, Japan, 2012 (in Japanese with English abstract).

Okita, T., Hara, H., and Fukuzaki, N.: Measurements of atmospheric $\mathrm{SO}_{2}$ and $\mathrm{SO}_{4}^{2-}$, and determination of the wet scavenging coefficient of sulfate aerosols for the winter monsoon season over the sea of Japan, Atmos. Environ., 30, 3733-3739, 1996.

Oshima, N., Koike, M., Kondo, Y., Nakamura, H., Moteki, N., Matsui, H., Takegawa, N., and Kita, K.: Vertical transport mechanisms of black carbon over East Asia in spring during the AFORCE aircraft campaign, J. Geophys. Res., 118, 13175-13198, doi:10.1002/2013JD020262, 2013.

Paramonov, M., Grönholm, T., and Virkkula, A.: Below-cloud scavenging of aerosol particles by snow at an urban site in Finland, Boreal Environ. Res., 16, 304-320, 2011.

Peters, K. and Eiden, R.: Modelling the dry deposition velocity of aerosol particles to a spruce forest, Atmos. Environ., 26A, 25552564, doi:10.1016/0960-1686(92)90108-W, 1992.

Petroff, A. and Zhang, L.: Development and validation of a size-resolved particle dry deposition scheme for application in aerosol transport models, Geosci. Model Dev., 3, 753-769, doi:10.5194/gmd-3-753-2010, 2010.

Petroff, A., Zhang, L., Pryor, S. C., and Belot, Y.: An extended dry deposition model for aerosols onto broadleaf canopies, J. Aerosol Sci., 40, 218-240, doi:10.1016/j.jaerosci.2008, 2009. 
Petters, M. D. and Kreidenweis, S. M.: A single parameter representation of hygroscopic growth and cloud condensation nucleus activity, Atmos. Chem. Phys., 7, 1961-1971, doi:10.5194/acp-71961-2007, 2007.

Prime Minister of Japan and His Cabinet: Report of Japanese Government to the IAEA Ministerial Conference on Nuclear Safety - The Accident at TEPCO's Fukushima Nuclear Power Stations, available at: http://japan.kantei.go.jp/kan/topics/201106/ iaea_houkokusho_e.html (last access: 12 November 2014), 2011.

RADNET: United States Environmental Protection Agency's Radiation monitoring Network (RADNET) Sampling Data for the Japanese Nuclear Emergency, available at: http://www.epa. gov/japan2011/rert/radnet-sampling-data.html (last access: 12 November 2014), 2011.

Reisner, J., Rasmussen, R. M., and Bruintjes, R. T.: Explicit forecasting of supercooled liquid water in winter storms using the MM5 mesoscale model, Q. J. Roy. Meteor. Soc., 124, 10711107, doi:10.1002/qj.49712454804, 1998.

Sanada, N. and Torii, T.: Aerial radiation monitoring around the Fukushima Dai-ichi Nuclear Power Plant using an unmanned helicopter, J. Environ. Radioact., 139, 294-299, doi:10.1016/j.jenvrad.2014.06.027, 2015.

Saunier, O., Mathieu, A., Didier, D., Tombette, M., Quélo, D., Winiarek, V., and Bocquet, M.: An inverse modeling method to assess the source term of the Fukushima Nuclear Power Plant accident using gamma dose rate observations, Atmos. Chem. Phys., 13, 11403-11421, doi:10.5194/acp-13-11403-2013, 2013.

Sauter, D. P. and Wang, P. K.: An experimental study of the scavenging of aerosol particles by natural snow crystals, J. Atmos. Sci., 46, 1650-1655, doi:10.1175/15200469(1989)0462.0.CO;2, 1989.

Sehmel, G. A.: Particle and gas dry deposition: a review, Atmos. Environ., 14, 983-1011, doi:10.1016/0004-6981(80)90031-1, 1980.

Smagorinsky, J.: General circulation experiments with the primitive equations, Mon. Weather Rev., 91, 99-164, 1963.

Sparmacher, H., Fulber, K., and Bonka, H.: Below-cloud scavenging of aerosol particles: particle-bound radionuclides - experimental, Atmos. Environ., 27, 605-618, doi:10.1016/09601686(93)90218-N, 1993.

Srinivas, C. V., Venkatesan, R., Baskaran, R., Rajagopal, V., and Venkatraman, B.: Regional scale atmospheric dispersion simulation of accidental releases of radionuclides from Fukushima Dai-ichi reactor, Atmos. Environ., 61, 66-84, doi:10.1016/j.atmosenv.2012.06.082, 2012.

Stier, P., Feichter, J., Kinne, S., Kloster, S., Vignati, E., Wilson, J., Ganzeveld, L., Tegen, I., Werner, M., Balkanski, Y., Schulz, M., Boucher, O., Minikin, A., and Petzold, A.: The aerosol-climate model ECHAM5-HAM, Atmos. Chem. Phys., 5, 1125-1156, doi:10.5194/acp-5-1125-2005, 2005.

Stohl, A., Seibert, P., Wotawa, G., Arnold, D., Burkhart, J. F., Eckhardt, S., Tapia, C., Vargas, A., and Yasunari, T. J.: Xenon133 and caesium-137 releases into the atmosphere from the Fukushima Dai-ichi nuclear power plant: determination of the source term, atmospheric dispersion, and deposition, Atmos. Chem. Phys., 12, 2313-2343, doi:10.5194/acp-12-2313-2012, 2012.

Sugiura, N., Awaji, T., Masuda, S., Mochizuki, T., Toyoda, T., Miyama, T., Igarashi, H., and Ishikawa, Y.: Development of a four-dimensional variational coupled data assimilation system for enhanced analysis and prediction of seasonal to interannual climate variations, J. Geophys. Res., 113, C10017, doi:10.1029/2008JC004741, 2008.

Sugiyama, G., Nasstrom, J., Pobanz, B., Foster, K., Simpson, M., Vogt, P., Aluzzi, F., and Homann, S.: Atmospheric sispersion modeling: challenges of the Fukushima Daiichi response, Health Phys., 102, 493-508, doi:10.1097/HP.0b013e31824c7bc9, 2012.

Takemura, T., Nakamura, H., Takigawa, M., Kondo, H., Satomura, T., Miyasaka, T., and Nakajima, T.: A numerical simulation of global transport of atmospheric particles emitted from the Fukushima Daiichi nuclear power plant, Sola, 7, 101-104, 2011.

Takeyasu, M. and Sumiya, S.: Estimation of dry deposition velocities of radionuclides released by the accident at the Fukushima Dai-ichi Nuclear Power Plant, Prog. Nucl. Sci. Technol., 4, 64 67, 2014.

Tanabe, F.: A scenario of large amount of radioactive materials discharge to the air from the Unit 2 reactor in the Fukushima Daiichi NPP accident, J. Nucl. Sci. Technol., 49, 360-365, 2012.

Ten Hoeve, J. E. and Jacobson, M. Z.: Worldwide health effects of the Fukushima Daiichi nuclear accident, Energ. Environ. Sci., 5, 8743-8757, doi:10.1039/C2EE22019A, 2012.

TEPCO (Tokyo Electric Power Company): Press Releases, available at: http://www.tepco.co.jp/en/press/corp-com/release/ index-e.html (last access: 12 November 2014), 2011a.

TEPCO: Radiation dose measured in the Fukushima Daiichi Nuclear Power Station 2011 Archives, available at: http://www. tepco.co.jp/en/nu/fukushima-np/f1/indexold-e.html (last access: 12 November 2014), 2011 b.

TEPCO: Radiation dose measured in the Fukushima Daiichi Nuclear Power Station 2011 Archives, available at: http://www. tepco.co.jp/en/nu/fukushima-np/f2/index-e.html (last access: 12 November 2014), 2011c.

TEPCO: Release of the Fukushima Nuclear Accidents Investigation Report, available at: http://www.tepco.co.jp/en/ press/corp-com/release/2012/1205638_1870.html (last access: 12 November 2014), 2012.

Terada, H. and Chino, M.: Improvement of Worldwide Version of System for Prediction of Environmental Emergency Dose Information (WSPEEDI), (II) Evaluation of numerical models by ${ }^{137} \mathrm{Cs}$ deposition due to the Chernobyl nuclear accident, J. Nucl. Sci. Technol., 42, 651-660, doi:10.1080/18811248.2004.9715527, 2005.

Terada, H. and Chino, M.: Development of an atmospheric dispersion model for accidental discharge of radionuclides with the function of simultaneous prediction for multiple domains and its evaluation by application to the Chernobyl nuclear accident, J. Nucl. Sci. Technol., 45, 920-931, doi:10.1080/18811248.2008.9711493, 2008.

Terada, H., Furuno, A., and Chino, M.: Improvement of Worldwide Version of System for Prediction of Environmental Emergency Dose Information (WSPEEDI), (I) New combination of models, atmospheric dynamic model MM5 and particle random walk model GEARN-new, J. Nucl. Sci. Technol., 41, 632-640, doi:10.1080/18811248.2004.9715527, 2004.

Terada, H., Katata, G., Chino, M., and Nagai, H.: Atmospheric discharge and dispersion of radionuclides during the Fukushima Dai-ichi Nuclear Power Plant accident, Part II: Verification of the source term and analysis of regional-scale at- 
mospheric dispersion, J. Environ. Radioactiv., 112, 141-154, doi:10.1016/j.jenvrad.2012.05.023, 2012.

Thalmann, E., Burkard, R., Wrzesinsky, T., Eugster, W., and Klemm, O.: Ion fluxes from fog and rain to an agricultural and a forest ecosystem in Europe, Atmos. Res., 64, 147-158, doi:10.1016/S0169-8095(02)00087-X, 2002.

Tochigi Prefecture: Results of Environmental Radioactivity (Air Dose Rate), available at: http://www.pref.tochigi.lg.jp/kinkyu/ documents/20110312-18.pdf (last access: 12 November 2014), 2011 (in Japanese).

Tohoku Electric Power, available at: http://www.tohoku-epco.co.jp/ news/atom/topics/1183332_1984.html (last access: 12 November 2014), 2011 (in Japanese).

Tokyo Metropolitan Government: Measurement of nuclear fission products of dust particles in the air in Tokyo, available at: http://www.sangyo-rodo.metro.tokyo.jp/whats-new/ measurement-kako.html (last access: 12 November 2014), 2011 (in Japanese).

Torii, T., Sugita, T., Okada, C. E., Reed, M. S., and Blumenthal, D. J.: Enhanced analysis methods to derive the spatial distribution of I-131 deposition on the ground by airborne surveys at an early stage after the Fukushima Daiichi nuclear power plant accident, Health Phys., 105, 192-200, doi:10.1097/HP.0b013e318294444e, 2013.

Tost, H., Jöckel, P., Kerkweg, A., Sander, R., and Lelieveld, J.: Technical note: A new comprehensive SCAVenging submodel for global atmospheric chemistry modelling, Atmos. Chem. Phys., 6, 565-574, doi:10.5194/acp-6-565-2006, 2006.

Tsuruta, H., Takigawa, M., and Nakajima, M., Summary of atmospheric measurements and transport pathways of radioactive materials released by the Fukushima Daiichi Nuclear Power Plant accident, edited by: Kurihara, O., Akahane, K., Fukuda, S., Miyahara, N., and Yonai, S., Proceedings on the 1st NIRS Symposium on Reconstruction of Early Internal Dose in the TEPCO Fukushima Daiichi Nuclear Power Station Accident, Nat. Inst. Radio. Sci., 101-111, 2012.

Uematsu, M., Merrill, J. T., Patterson, T. L., Duce, R. A., and Prospero, J. M.: Aerosol residence times and iodine gas/particle conversion over the North Pacific as determined from Chernobyl radioactivity, Geochem. J., 22, 157-163, doi:10.2343/geochemj.22.157, 1988.

UNSCEAR (United Nations Scientific Committee on the Effects of Atomic Radiation): UNSCEAR 2013 Report: Sources, Effects and Risks of Ionizing Radiation, Vol. I, available at: http://www.unscear.org/docs/reports/2013/13-85418_ Report_2013_Annex_A.pdf (last access: 12 November 2014), 2014.

US DOE (Department of Energy): Response to 2011 Fukushima Incident - Data and Documentation, available at: http://energy.gov/downloads/us-doennsa-response-2011 (last access: 12 November 2014), 2011.
US NDC (United States National Data Center): United States National Data Center, International Monitoring System Data for the CTBTO network, available at: http://www.usandc.gov/ radionuclide.html (last access: 12 November 2014), 2011.

US NRC (Nuclear Regulatory Commission): RASCAL 4: Description of Models and Methods, NUREG-1940, Richland, WA, 2012.

Wang, X., Zhang, L., and Moran, M. D.: Uncertainty assessment of current size-resolved parameterizations for below-cloud particle scavenging by rain, Atmos. Chem. Phys., 10, 5685-5705, doi:10.5194/acp-10-5685-2010, 2010.

Wesely, M. L.: Parameterization of surface resistances to gaseous dry deposition in regional-scale numerical models, Atmos. Environ., 23, 1293-1304, doi:10.1016/0004-6981(89)90153-4, 1989.

Wesely, M. L. and Hicks, B. B.: Some factors that affect the deposition rates of sulfur dioxide and similar gases on vegetation, J. Air Pollut. Control Assoc., 27, 1110-1116, doi:10.1080/00022470.1977.10470534, 1977.

Winiarek, V., Bocquet, M., Duhanyan, N., Roustan, Y., Saunier, O., and Mathieu, A.: Estimation of the caesium-137 source term from the Fukushima Daiichi nuclear power plant using a consistent joint assimilation of air concentration and deposition observations, Atmos. Environ., 82, 268-279, doi:10.1016/j.atmosenv.2013.10.017, 2014.

WMO (World Meteorological Organization): Evaluation of Meteorological Analyses for the Radionuclide Dispersion and Deposition from the Fukushima Daiichi Nuclear Power Plant Accident, 1120, 64 pp., available at: https://www.wmo.int/e-catalog/detail_ en.php?PUB_ID=669\&SORT $=$ N\&q= (last access: 12 November 2014), 2014.

Wolf, M. A. and Dana, M. T.: Experimental studies on precipitation scavenging, USAEC Report BNWL-105, Battelle Pacific Northwest Laboratory, Richland, Wash., 18-25, 1969.

Yasunari, T. J., Stohl, A., Hayano, R. S., Burkhart, J. F., Eckhardt, S., and Yasunari, T.: Cesium-137 deposition and contamination of Japanese soils due to the Fukushima nuclear accident, Proc. Natl. Acad. Sci. USA, 108, 19530-19580, doi:10.1073/pnas.1112058108, 2011.

Zhang, L., Gong, S., Padro, J., and Barrie, L.: A size-segregated particle dry deposition scheme for an atmospheric aerosol module, Atmos. Environ., 35, 549-560, doi:10.1016/S13522310(00)00326-5, 2001.

Zhang, L., Brook, J. R., and Vet, R.: A revised parameterization for gaseous dry deposition in air-quality models, Atmos. Chem. Phys., 3, 2067-2082, doi:10.5194/acp-3-2067-2003, 2003.

Zhang, L., Wang, X., Moran, M. D., and Feng, J.: Review and uncertainty assessment of size-resolved scavenging coefficient formulations for below-cloud snow scavenging of atmospheric aerosols, Atmos. Chem. Phys., 13, 10005-10025, doi:10.5194/acp-13-10005-2013, 2013. 